\title{
Factors influencing reproduction in the Jamaican field cricket Gryllus assimilis: fighting, signalling, and condition
}

\author{
by \\ Vanessa L.M. Rook \\ Masters of Science, Carleton University, 2010
}

A thesis submitted to the Faculty of Graduate Studies and Research in partial fulfillment of the requirements for the degree of

Masters of Science

in

Biology

Carleton University

Ottawa, ON, Canada

(C) Vanessa L.M. Rook 2010 


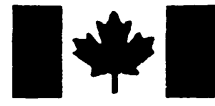

\author{
Library and Archives \\ Canada \\ Published Heritage
Branch
}

395 Wellington Street

Ottawa ON K1A ON4

Canada
Bibliothèque et

Archives Canada

Direction du

Patrimoine de l'édition

395 , rue Wellington

Ottawa ON K1A ON4

Canada
Your file Votre référence
ISBN: 978-0-494-71596-3
Our file Notre référence
ISBN: $978-0-494-71596-3$
NOTICE:

The author has granted a nonexclusive license allowing Library and Archives Canada to reproduce, publish, archive, preserve, conserve, communicate to the public by telecommunication or on the Internet, loan, distribute and sell theses worldwide, for commercial or noncommercial purposes, in microform, paper, electronic and/or any other formats.

The author retains copyright ownership and moral rights in this thesis. Neither the thesis nor substantial extracts from it may be printed or otherwise reproduced without the author's permission.
AVIS:

L'auteur a accordé une licence non exclusive permettant à la Bibliothèque et Archives Canada de reproduire, publier, archiver, sauvegarder, conserver, transmettre au public par télécommunication ou par l'Internet, prêter, distribuer et vendre des thèses partout dans le monde, à des fins commerciales ou autres, sur support microforme, papier, électronique et/ou autres formats.

L'auteur conserve la propriété du droit d'auteur et des droits moraux qui protège cette thèse. Ni la thèse ni des extraits substantiels de celle-ci ne doivent être imprimés ou autrement reproduits sans son autorisation.
In compliance with the Canadian Privacy Act some supporting forms may have been removed from this thesis.

While these forms may be included in the document page count, their removal does not represent any loss of content from the thesis.
Conformément à la loi canadienne sur la protection de la vie privée, quelques formulaires secondaires ont été enlevés de cette thèse.

Bien que ces formulaires aient inclus dans la pagination, il n'y aura aucun contenu manquant. 


\begin{abstract}
The indicator hypothesis of sexual selection predicts that sexually selected traits should be honest indicators of body condition. How each trait influences mating success has been explored singly, but, they have rarely been studied in concert. I explored the relationship between aggression, signalling, and condition and determined how they interacted to influence courtship and reproduction in the Jamaican field cricket, Gryllus assimilis. I quantified aggression and signalling in 162 males. Winners did not differ from losers in overall condition. Further, while signalling was influenced by body size and age, it was not influenced by condition. Likewise, courtship behaviour was not influenced by aggressiveness, signalling ability, or condition. Male courtship and subsequent female egg laying was, however, influenced by female mass. Overall, my findings provide no support for the prediction that sexually selected traits are honest indicators of condition, suggesting that sexually selected traits may not have evolved via indicator mechanisms.
\end{abstract}




\section{Acknowledgements}

The work in this thesis would not have been possible without the help of the numerous graduates, honour's and summer students that generously gave their time over the past two years. Many thanks to Lauren P. Fitzsimmons for teaching me the protocol and ways of the lab, as well as providing me with guidance and suggestions that helped this thesis tremendously, to Emily M. Whattam for providing me with her expertise on cricket signalling behaviour and NEARS protocol, to Amisha Agrawal, Andrew Rouble and Heather Bocz, for a summer spent analyzing hundreds of hours of male aggression videos, collecting and entering data, and cricket care, to Jeff Dawson for generously teaching and allowing the use of his microscopes for pronotum photography, to Gary Bourque for photo analysis and data entry, and to Laksanavadee Visanuvimol and to the rest of the Bertram lab for making the past two years a great experience. Special thanks to my family and friends, for their support and encouragement throughout this process, and to my committee members, Jean-Guy Godin and Howard D. Rundle, for their time, guidance and expertise. Most importantly, thanks to my supervisor, Susan M. Bertram, for all the time, effort, support, and advice she invested into making sure I was always improving and producing the best work I could. Her patience, encouragement and motivation over the last two years has been greatly appreciated and never forgotten. 


\section{Table of Contents}

General Introduction ........................................................................................

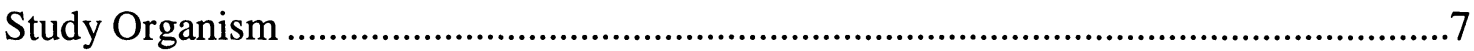

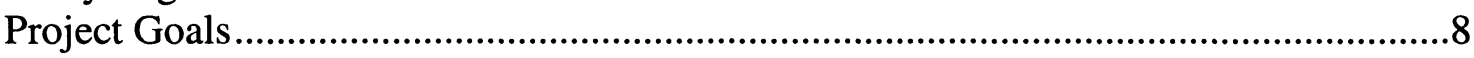

Chapter 1 - Male-Male Competition ………….........................................11

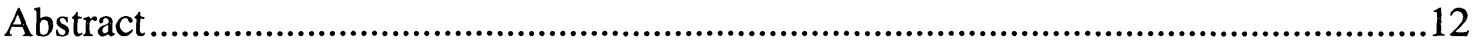

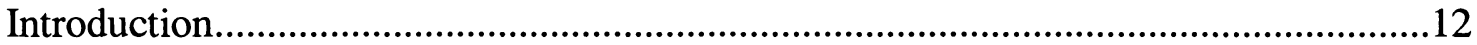

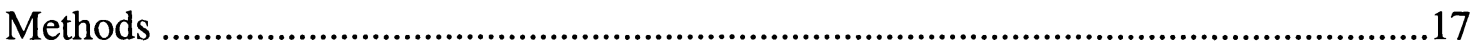

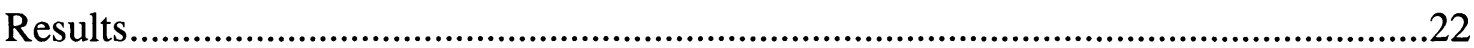

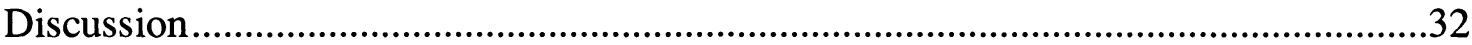

Chapter 2 - Attraction Displays: Age, Size and Condition...........40

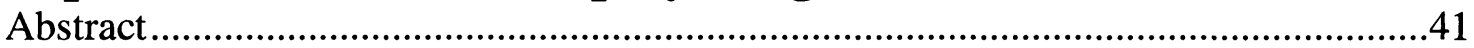

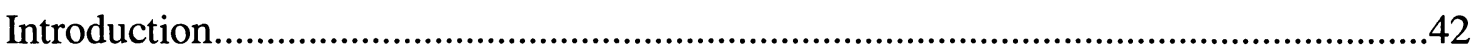

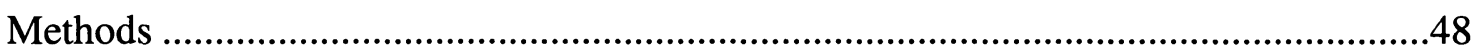

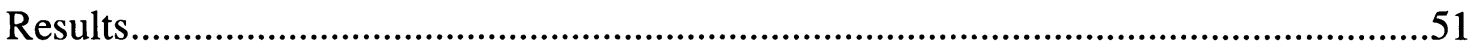

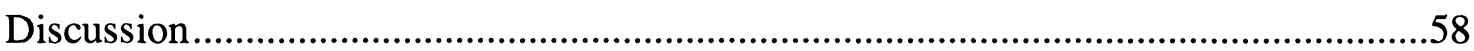

Chapter 3 - The Interplay Between Aggression, Signalling, Condition and Mating success ...................................................................64

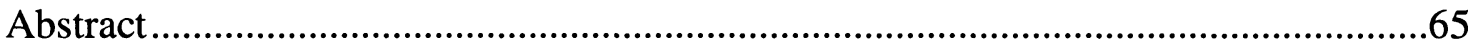

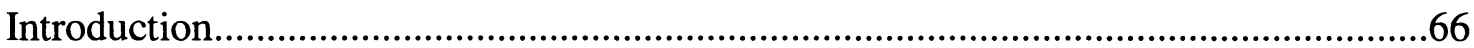

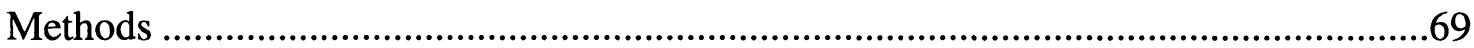

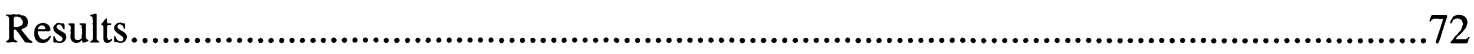

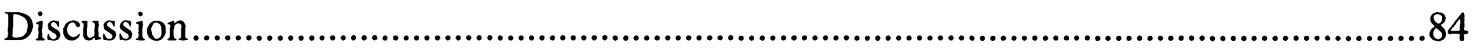

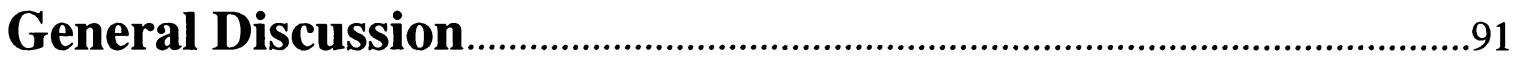

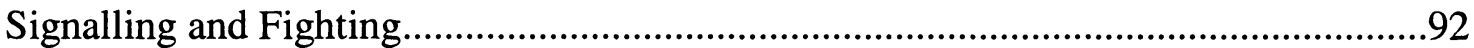

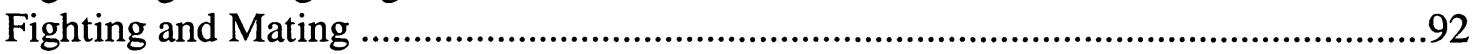

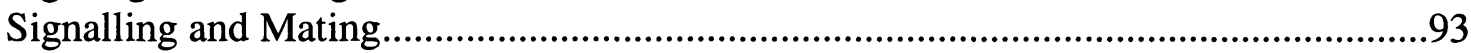

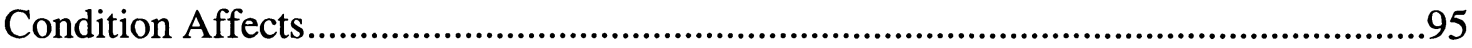

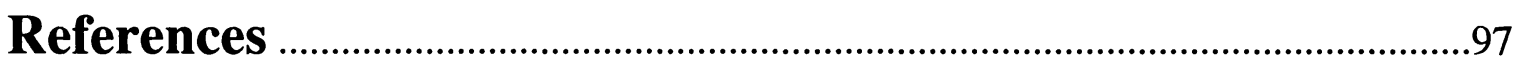




\section{List of Figures}

Figure 1.1 Ethogram of the agggressive behaviours observed in male G. assimilis fights. The transitions from starting fight behaviours (antennation) to end fight behaviours (withdraw) are shown with double sided arrows. Both winners and losers perform all of the aggressive behaviours

Figure 1.2 Distrobution of maximum aggression scores of $G$. Assimilis males in the 54 aggressive fighting contests. Aggressive scores range from 1 to 6 (see Chapter 1 methods for description of aggressive behaviours)

Figure 1.3 Correlation of fight intensity score (see Chapter 1 methods for calculation)by maximum aggression for the 54 fighting contests (Spearman $\rho=$ $0.2341, P=0.0138$ ).

Figure 1.4 The difference between first Principle Components for winners and losers for $A$ ) the number of times an aggressive behaviour was observed (frequency) and $B$ ) the mean duration of aggressive behaviours. Each line represents the relationship between the winner and loser for that pair

Figure $1.5 \quad$ A) The mean number of times (frequency) and B) mean duration in which winners (blue) and losers (red) were engaged in aggressive activities during the fighting contest. Losers are seen in red and winners in blue. Activities asterisked are significant.

Figure 2.1 Acoustic signalling parameters of the long-distance mate attraction signals of $\mathrm{G}$. assimilis (Created by $\mathrm{E}$. Whattam).

Figure 2.2 The influence of age (number of days past final moult) on the a) signalling quality (PC1), and b) signalling quantity (PC3) of male $\mathrm{G}$. assimilis.

Figure 2.3 Influence of a) mass $(\mathrm{mg})$ and b) size (pronotum area $\left(\mathrm{mm}^{2}\right)$ on PC3 (Quantity) for control group G. assimilis males from age 8 to 21 days of adulthood.......57

Figure 3.1 Influence of female mass $(\mathrm{mg})$ onto the number of eggs laid by the female.

Figure 3.2 Influence of the difference in male and female mass onto A) PC1 courtship and B) the number of eggs laid by the female.

Figure I.I Influence of age on A) chirp duration and B) amplitude of male G. assimilis aged 8 to 21 days.

Figure I.II Influence of A) mean weight ( $\mathrm{mg}$ ) and B) average size (pronotum area $\mathrm{mm} 2$ ) on dominant frequency $(\mathrm{kHz})$ for $\mathrm{G}$. assimilis males aged 8 to 21 days 


\section{List of Tables}

Table 1.1 Aggressive behaviours of G. assimilis and their intensity score value. Adapted from Hofmann and Schildberger (2001)

Table 1.2 The eigenvectors from a multivariate Principle Componet Analysis performed on the number of times the behaviour is performed and the mean duration performing the behaviour for antennate, chase, body jerk, aggressive song and unilateral mandible spread performed during the fighting trial

Table 1.3 Matched pair's analyses on the number of times aggressive behaviours were performed and the mean duration of behaviours during the 54 analyzed fighting trials. Data is subdivided into the behaviour of the winner and loser. Duration data are in seconds

Table 1.4 Matched pair's analysis on the pre-and post-condition, wet mass and dry mass of the 54 fighting contests analyzed. Data is subdivided into the behaviour of the winners and losers

Table 1.5 Regressions of the mean duration of the fighting behaviours onto body condition and body mass for G. assimilis males. Only males with all size measurements who also performed the beahviours were included in each regression.....30

Table 1.6 Regressions of the number of times each of the fighting behaviours were performed onto condition and mass for $\mathrm{G}$. assimilis males. Only males with all size measurements who also performed the behaviours were included in each regression.

Table 2.1 The natural variation for all signalling parameters for $\mathrm{G}$. assimilis males during days 8 to 21 of adulthood.

Table 2.2 Correlations and probabilities between long distance mate attraction signalling parameters

Table 2.3 The eigenvectors from a multivariate Principle Component Analysis of signalling parameters

Table 2.4 The effects of individual and age on the Principle Components of signalling in male G. assimilis. Signalling was quantified from 8 to 21 days of adult age.

Table 2.5 Influence of body condition, mass, and size on the Principle Components of signalling in male $G$. assimilis. Male signalling behaviour was quantified from days 8 to 21 of adulthood, and then averaged to produce a mean value for each call parameter for each male. 
Table 3.1 The relationship between acoustic mate attraction displays and the probability of winning or losing a fight in G. assimilis (Logistic regression).

Table 3.2 Do winners and losers differ in their acoustic long distance mate attraction signals? Paired t-tests suggest they do not.

Table 3.3 Influence of signalling parameters, signalling quality and quantity on the number of aggressive behaviours and the duration of aggressive behaviours in the fighting contests.

Table 3.4 Descriptive statistics of all $\mathrm{G}$. assimilis mating parameters 75

Table 3.5 Correlations and probabilities between courtship behaviour parameter...77

Table 3.6 The eigenvectors from a multivariate Principle Component Analysis of the courtship parameters.

Table 3.7 Influence of aggression and signalling behaviours on the courtship behaviours of males and the number of eggs laid by females.

Table 3.8 Paired $t$-test on the courtship behaviours. Data is subdivided into the behaviour of the winner and loser.

Table 3.9 Influence of body condition, mass, and size on courtship behaviour and number of eggs laid by females mated with $\mathrm{G}$. assimilis males.

Table I.I Influence of age onto the signalling parameters and first Principle Component Analysis of male G. assimilis aged 8 to 21

Table I.II Influence of body condition, mass, and size onto signalling parameters of $\mathrm{G}$. assimilis males aged 8 to 21 of adulthood (parameters averaged across days)....111

Table II.I Correlations between rates of aggression parameters.

Table II.II Eigenvectors from a multivariate Principle Component Analysis on the rates of aggressive behaviours..

Table II.III Univariate correlations and probabilities of courtship parameters by aggressive parameters.

Table II.IV Univariate correlations and probabilities of courtship parameters by signalling parameters

Table II.V Univariate correlations and probabilities of courtship parameters by condition parameters 


\section{List of Appendices}

Appendix 1 Univariate data on signalling ability.

106

Appendix 2 Principle Component Analysis of rate of aggressive behaviour and univariate data on courtship....................................................................................... 111 
General Introduction 
Charles Darwin first developed the idea of sexual selection in 1871 to account for the differences in secondary sexual characteristics that could not be fully explained by natural selection (Carranza, 2010). Darwin suggested that natural selection and sexual selection were quantitatively different from one another. He proposed that natural selection was the differential reproductive success that resulted from variation among individuals in terms of their survival and reproduction (Darwin, 1871), whereas sexual selection was the differential reproductive success due to variation among individuals in terms of their ability to mate (obtaining mates, Darwin, 1871; sperm competition, Parker, 1970). Darwin further proposed that sexual selection could be subdivided into two distinct processes: (1) intrasexual selection (competition for mates) and (2) intersexual selection (mate choice) (Maynard Smith, 1991).

Intrasexual selection refers to one sex (typically males) competing aggressively with other members of the same sex for access to the opposite sex (typically females) (Maynard Smith, 1991). Secondary sexual traits that evolve via intrasexual selection are thought to be tightly dependent on body size and condition because both can strongly affect the outcome of fights (Wescott, 1992). Individuals with access to more available resources should have more energy to invest in aggressive encounters compared to individuals with access to fewer resources (Brown et al., 2006). Likewise, larger individuals are usually stronger and thus more able to out-compete smaller individuals in aggressive encounters (Schuett, 1996; Brown et al., 2006). Intersexual selection refers to one sex (typically males) competing with each other for the other sex's (typically females) attention. Competition between males to be selected by females is typically based on male signalling ability (e.g. 
morphological, acoustic, olfactory, tactile, and/or behavioural; Maynard Smith, 1991). Female preference for male secondary sexual signals can result in their evolution. Male sexual signals may reflect the male's ability to provide direct benefits to the female or her offspring. Direct benefits can include high-quality territories, access to food, parental care, and/or protection from predators (Andersson \& Simmons, 2006; Maynard Smith, 1991). If a female can use the male's signals to distinguish between good providers and poor providers, then being choosy should allow her and/or her offspring to directly benefit from her choice.

Why should females be choosy if they get no direct benefits from the male? Hypotheses that explain the evolution of mate choice without direct benefits include: (1) Pre-existing sensory bias, where female preference for ornamentation can initially evolve under natural selection for reasons such as foraging or predator avoidance. Males that evolve traits that exploit this female bias then become favoured (Ryan et al., 1990); (2) Fisherian sexy sons, where female preference for a specific male trait is genetically connected to this trait. Females choosing attractive males will produce attractive sons and daughters who also have a preference for the attractive male trait. The intensity of both trait and preference will increase until the trait is no longer favoured by natural selection (Fisher, 1930); (3) Indicator mechanisms ('good genes' or 'handicap mechanisms') suggest that females are more likely to mate with males that produce attractive signals, as male signals reflect their broad genetic quality (Maynard Smith, 1976; 1991). Males with very attractive displays (which could become disadvantageous or maladaptive if expressed too highly) indicate their higher overall fitness to females more than males with less attractive 
displays (Maynard Smith, 1976; 1991). This may allow females to receive better genes that may be passed onto their offspring.

One of the problems with the indicator mechanism is the paradox of the lek (Rowe \& Houle, 1996). How can the indicator mechanism explain sexually selected traits when strong directional selection constantly removes the genetic variation from the population? Rowe and Houle (1996) proposed a solution after considering life history traits and condition. They suggested that life history should be considered as a process of accumulating resources that can be allocated to the production or maintenance of traits that enhance fitness. Given this, condition should be considered as a pool of resources. When resources are allocated to a trait, they are depleted from the pool and thus can't be allocated towards other fitness enhancing traits. Because sexually selected traits are costly to express, they should continually drain the resources being allocated, and as such should continually drain condition. When individuals are in good condition, they should have a large resource pool and be better able to allocate resources to their many competing demands. Therefore, individuals in better condition are assumed to signal their quality through greater sexual trait size or more vigorous displays, compared to individuals that are in poor condition and unable to exaggerate because of the viability costs associated with such extravagance are too high (Cotton, 2004). Condition dependence is thus expected to arise in sexually selected traits that have evolved via the indicator mechanism (Rowe \& Houle, 1996).

Condition measures have been used as a general estimate of individual nutritional state, resources, energy reserves and health in a variety of biological contexts and have been viewed as a trait closely related to viability (Cotton, 2004). 
When considering the condition dependence of sexual traits, ornaments should have a greater dependence compared to other traits and this dependence should increase as the ornament becomes more exaggerated (Cotton, 2004). Further, many ornaments and traits appear to have some degree of allometric scaling with body size (Cotton, 2004). This suggests that the ornament may signal both body size and certain components of condition, as exaggerated ornaments may be representations of body size and/or reflect condition factors which may be partially independent of body size. The manipulation of environmental quality, such as food availability and parasitization, can allow for high and low condition levels to be assigned to individuals to assess the changes in condition dependence of sexual traits and whether any changes in ornament size occur (Cotton, 2004). Conversely, when environment is not manipulated, natural variation in condition can also allow high and low condition levels to be assigned to individuals, thereby assessing whether sexually selected traits are condition dependent.

Together, the ideas presented above suggest that there may be a link between sexually selected traits, condition and body size. The traits used in aggressive competitions and the traits used in mate attraction displays should, therefore, be positively correlated with body size and/or condition, provided the indicator hypothesis explains the occurrence of mate choice without direct benefits. Males that are large and/or in good condition should, therefore, win more aggressive competitions and be better at mate attraction signalling than males that are small or in poor condition. Further, males that are large and/or in good condition should be preferred by females, mate more often, and produce more offspring than smaller and/or in poor condition males. 
Female preferences for certain male traits (for example male signalling traits) can become heritable if strong benefits for the male trait occur (Hedrick, 1988; Gray \& Cade, 1998). However, these preferences may create a substantial cost if the female becomes too choosy in her search at finding a good mate. These costs include decreases in foraging, predator avoidance, grooming, allocation of resources to egg production, and an increase in energy expenditure (Gibson and Bachman, 1992; Byers et al., 2005; Vitousek et al., 2007). For example, Byers et al., 2005 estimated that female choice (over two-weeks) of the pronghorn antelope (Antilocapra americana) increased the energetic expenditure of one day's energy budget by $\sim 50 \%$. Further, in the marine iguana (Amblyrhynchus cristatus), female mate choice represents a relatively high cost to females, as females spent $\sim 78 \%$ of one day's energy budget searching for high quality mates when tested over a 30 day period (Vitousek et al., 2007). These findings suggest that assessing high quality males is more costly than assessing low quality males as females must spend more time searching, decreasing their ability to engage in other important survival behaviours (Vitousek et al., 2007).

To date, most studies of sexual selection have focused only on whether aggressive displays or mate attraction signals are tied to condition. Little research has examined the interplay between aggression and mate signalling. If large males and/or males in better condition win more aggressive interactions, do they also produce better or more acoustic mate attraction signals (as would be predicted if both aggression and signalling are tightly tied to condition)? Or, do individuals that lose aggressive interactions make the best of a bad situation by putting more energy into mate attraction (suggesting signalling is not condition dependent)? Here, I test these 
ideas to determine if both aggression and mate signalling are indicators of condition. I also examine how male aggression and signalling influences subsequent courtship behaviour, mating behaviour and offspring production.

\section{Study Organism}

I used the Jamaican field cricket, Gryllus assimilis, as my model organism. Field crickets are ideal organisms to study questions pertaining to the interplay between condition, aggression, mate attraction, and reproduction because males fight with each other for access to territories (Jang et al., 2008), and then use these territories to produce acoustic mate signals to attract females (Nelson and Nolen, 1997). Females distinguish between potential mates based on several aspects of the acoustic signals, and are readily willing to mate and lay eggs in a laboratory setting (Nelson and Nolen, 1997).

Male-male aggressive contests are composed of behaviours such as antennal fencing, unilateral mandible spreading, bilateral mandible spreading, mandible engagement and grappling, as well as post conflict displays such as aggressive songs and body jerks (these behaviours are described in detail in Chapter 1; Tachon et al., 1999; Hofmann and Schildberger, 2001). If male aggressive behaviours are honest indicators of one's size and/or condition than theoretically, larger males or males in better condition should be more aggressive and/or more able to win fights because they have a higher pool of resources to allocate to these behaviours.

Once males have obtained their signalling territories, they produce long-range acoustic signals to attract females into their territory. Males switch to short-distance courtship signals to entice females to mate (Bertram, 2002). These acoustic signals 
should, like aggressive beahviours, be honest signals of one's size and/or condition because they are energetically expensive to produce (Gray, 1997). Females may, therefore, be more likely to mate with a male who is aggressive, wins aggressive contests, produces loud acoustic mate attraction signals, signals often, and/or produces a higher quality (sexier) signal (Bertram, 2002).

Gryllus assimilis are suitable study organisms because females show a distinct preference for male signals (Bertram, 2002). Most female field crickets appear to prefer to mate with males that produce mate attraction songs that are long in duration (long chirp duration and high number of pulses per chirp), produced at a high chirp rate, a low frequency, loudly (high amplitude) and that are also produced most often (high time spent signalling) (Wagner \& Hoback, 1999; Scheuber et al., 2003). These signalling parameters tend to be energetically expensive to produce (up to 10-16 times that of resting in the species Anurogryllus arboreus, Prestwich and Walker, 1981; Neoconocephalus robustus, Stevens and Josephson, 1977) and may provide females with information about the male's size, condition and/or genetic quality (Wagner \& Hoback, 1999).

\section{General Objectives}

Aggressiveness in animals has been studied extensively, usually with an emphasis on understanding what factors influence the occurrence of fighting and the tactics that individuals use to win contests (Hofmann \& Schildberger, 2001). However, little work has been published on aggression in G. assimilis. Chapter 1 of my MSc thesis provides the first in-depth description of fighting in male G. assimilis. I also quantify whether male size and/or condition influences aggression and the 
ability to win contests. Further, I compare the aggression of $G$. assimilis to other field crickets to ascertain how aggression compares across species.

Acoustic mate attraction behaviour has also been studied extensively in crickets, usually with an emphasis on understanding what factors influence the variation in these displays and how this variation influences mating success (Hack, 1997; Bertram, 2000; Holzer et al, 2003; Bertram and Warren, 2005). However, little work has been published on acoustic mate attraction behaviour in G. assimilis. For Chapter 2 of my thesis, I explore the factors that influence variation in male $G$. assimilis acoustic mate attraction signals. Because female field crickets are typically attracted to long, loud signals that are produced often (Wagner \& Hoback, 1999; Scheuber et al., 2003), I quantify whether these acoustic parameters correlate with body size and/or condition. I also quantify whether male age influences acoustic mate attraction signalling. Lastly, I explore the relationships between the acoustic signalling parameters to ascertain whether males that produced the most attractive signals also signal louder and more often (other possible indicators of male condition).

With Chapter 3 I provide the first ever integration of how size, condition, aggression and acoustic mate signalling behaviour interact to influence mating success and subsequent reproduction in G. assimilis. Together, these chapters should allow me to determine whether competitive ability and/or mate signalling are indicators of body size and/or condition and how they influence courtship and reproductive success in $G$. assimilis.

To address the goals laid out in chapters 1-3, I conducted one large experiment. I quantified acoustic mate attraction displays from age 7-14 days (details 
in Chapter 2). I then size-matched $2 / 3$ of the males and allowed them to fight until I could identify a clear winner and loser (details in Chapter 1 ; the other $1 / 3$ were controls and did not fight). I then quantified acoustic mate attraction displays again from age 14-21 days (details in Chapter 2) to assess if any changes to signalling occurred after the fighting trial. At 21 days I allowed males to mate with a virgin female and quantified their courtship and reproductive behaviours. I then counted the number of eggs each female laid over a two-week period (details in Chapter 3). 
Chapter 1: Male-Male Competition 


\section{Abstract}

Aggressive contests between males typically escalate until there is a clear winner and loser, sometimes causing injury to one of the opponents. Contests can occur to ensure access to food, territories, and/or mates and should only be considered adaptive if the benefits of winning the contest outweigh the costs of aggressive interactions (energetic expenses, risk of injury, loss of territory etc.). Theoretically, males that are larger and/or in better condition should have more energy to sustain these aggressive encounters, allowing them to win more fights and gain more resources than small males in poor condition. To determine whether male condition influences aggression and the ability to win contests, I staged 62 dyad contests with 124 mass-matched male Jamaican field crickets, Gryllus assimlis and quantified their fighting behaviours, aggressiveness, and the winner/loser of each fight. My research provides the first detailed description of fighting and aggression in G. assimilis. Gryllus assimilis was as aggressive as G. fultoni and G. vernalis. However, G. assimilis produced post-conflict displays similar to G. pennsylvanicus and G. rubens. Winners performed all aggressive acts more often, and for a longer duration than losers. Winners, however, were no more likely to be in better condition than losers. This finding may have been simply due to the fact that males were size matched prior to the contest to increase the likelihood of aggressive interactions

\section{Introduction}

Aggressive competition amongst males over access to mates is a common factor influencing reproductive success in many species (Elwood et al., 1998; Kravitz $\&$ Huber, 2003). Contests usually escalate until there is a definite winner and loser, 
sometimes causing harm to the losing opponent (Tachon et al., 1999). Aggressive contests are, therefore, only considered adaptive if the benefits of winning the contest (access to food, territory, or mates) outweigh the costs of aggressive interactions (energetic expenses, risk of injury, loss of territory; Tachon et al., 1999).

Given that fighting is costly, males in good condition should, theoretically, have more energy to sustain aggressive encounters, allowing them to win more fights than males in poor condition (Brown et al., 2006). Likewise, larger individuals should be stronger and thus more able to outcompete and defend themselves against smaller individuals in aggressive encounters (Schuett, 1996; Brown et al., 2006). As a result, larger and/or better condition males should win more aggressive contests, gaining more access to valuable resources, than males that are small and/or in poor condition (Shackleton et al., 2005). This idea has been supported in diverse taxa (birds, Hagelin, 2002; lizards, Lopez ct al., 2002; spiders, Kotiaho et al., 1997), and suggests that size and condition play an important role in the outcome of aggressive contests in many species (Shackleton et al., 2005). Moretz (2003), for example, studied the aggressive contests of male swordtail fish, Xiphophorus cortezi. Within each contest, the larger of the two males usually won the encounter. This resulted in a positive relationship between size and fighting ability (Moretz, 2003). In the Australian frog, Uperoleia rugosa, Robertson (1986) saw similar results where the heavier males typically won the fighting contest and smaller males typically retreated from opponents more often. Males of similar size were more likely to engage in fighting contests than males with larger mass differences (Robertson, 1986). Olsson (1992) also found that during the mating season male sand lizards, Latcerta agilis typically escalate into physical combat with males that enter their territory. Larger males won $86 \%$ of the fights. 
Further, males that were similar in size engaged in more frequent physical combat than males with larger size differences (Olsson, 1992). Competitive displays may therefore be honest indicators of male size and/or condition because both can strongly affect the outcome of the fight (Savage et al., 2004).

Darwin proposed that the costs incurred during the expression of male aggressive displays might be compensated for by the advantages gained through subsequent reproductive success (Darwin, 1871). Females may consider fighting ability and/or territory ownership to be important cues for mate choice (Savage et al., 2004). In many species, females often prefer to mate with males that win fights compared to males that lose (reptiles: Lopez et al., 2002; fish: Berglund \& Rosenqvist, 2000; birds: Double \& Cockburn, 2003). Schuett (1997) demonstrated this when he studied male copperhead snakes, Agkistrodon contortrix. Two males of different sizes were placed into an arena and allowed to fight while a female observed. Larger males always won the contest and were always first to locate, court and guard females (Schuett, 1997). In Telmatherina fish species, Gray and McKinnon (2006) noted that male-male competition frequently occurred between a male that was paired to a female and a non-paired male that approached. The winner of the contest then became the new paired male and was more likely to mate than the loser (Gray \& McKinnon, 2006). By mating with a male that is successful in his fights, a female may be able to ensure she mates with a male who is of superior size and/or condition. Given this, male size, condition and fighting ability may directly influence subsequent reproductive success.

Females may benefit from mating with males who are good fighters by gaining protection and/or having access to superior resources (e.g. territory, food; 
Cordero \& Eberhand, 2003). If males offer nothing to the females other than sperm, females could gain a genetic benefit for their offspring, provided that (1) fighting ability is correlated to male size or condition and, (2) fighting ability, size, and/or condition are heritable. This genetic benefit could then be passed on to the female's sons, so that he too will be likely to win fights and gain access to limited resources like his father (Shackleton et al., 2005). Given the potential impacts fighting ability and aggressive interactions may have on subsequent mate choice and fitness, it is important to understand the factors influencing aggression.

Here I investigated fighting ability and aggressive interactions in the Jamaican field cricket, Gryllus assimilis. Male field crickets frequently engage in aggressive contests to gain access to food, establish dominance in social interactions, and/or to gain access to a mate attraction territory (Alexander 1961; Mersterton-Gibbons \& Sherratt, 2006). Cricket aggressive interactions (fights) are composed of discrete behaviours such as antennal fencing, unilateral mandible spreading, bilateral mandible spreading, mandible engagement and grappling (Table 1.1; Tachon et al., 1999; Hofmann \& Schildberger, 2001). Fights typically escalate in a fixed sequence of mutual behaviours; however, any aggressive behaviour can be performed at any time, along with bouts of rivalry song mixed in (Hofmann \& Schildberger, 2001). These discrete behaviours can be scored to quantify the level of aggression each male exhibits during the aggressive encounter.

Studies on Acheta domesticus (Tachon et al., 1999) and Gryllus bimaculatus (Adamo \& Hoy, 1995) suggest crickets engage in a series of rounds at the beginning of a contest that are devoted to assessment, before any actual combat occurs. Males use these rounds to assess their opponent's fighting ability, strength, motivation, and 
intentions (Hack, 1997; Hofmann \& Schildberger, 2001; Brown et al., 2006), along with body size, performance quality, endurance, and speed (Hack, 1997). Once these factors have been assessed, the crickets either engage in a fight or walk away from each other (Hofmann \& Schildberger, 2001).

Jang et al (2008) studied aggression in four field cricket species ( $G$. fultoni, $G$. vernalis, G. pennsylvanicus, and G. rubens). These four cricket species differed extensively in their aggressive behaviours. Gryllus pennsylvanicus and G. rubens were highly aggressive, whereas $G$. fultoni and $G$. vernalis were much less aggressive. Jang et al (2008) proposed that the interspecics differences in aggressiveness could be explained by competition for signalling sites (territories). Species that compete for limited signalling sites (ie. signalling burrows) were much more aggressive than species that call from sites that are readily availability (ie. under leaves). They also found that male size only correlated with aggressiveness in one of the cricket species examined, G. pennsylvanicus (Jang et al., 2008).

In contrast to Jang et al's (2008) findings, Hack (1997) revealed that winners of $A$. domesticus aggressive contests are generally heavier than their opponents. Further, when the winners were much larger in size, the fights were resolved at a much lower intensity, compared to when the individuals were of equal size (Hack, 1997). Brown et al. (2006) also revealed that A. domesticus winners were in significantly better condition (heavier for their size) than losers. Jang et al. (2008) did not quantify cricket condition, so it is unknown whether this relationship with condition transcends across field cricket species.

Here I used mass-matched males to quantify fighting behaviour and determine whether condition influences aggression and the ability to win contests in the 
Jamaican field cricket, G. assimilis. My research provides the first in-depth description of fighting and aggression in G. assimilis. It also explores whether male condition explains any of the variation in fighting behaviours, overall aggression, and fight outcome. I put $G$. assimilis aggression and fighting into context by comparing my findings with that of Jang et al (2008) to reveal how G. assimilis' aggressive interactions compare to other field cricket species.

\section{Methods}

Field Collection and Laboratory Rearing

I captured male and female adult Gryllus assimilis in Austin, Texas, U.S.A. in September 2008. Crickets were reared in a large colony at Carleton University. I used third generation laboratory reared crickets for this experiment. I checked the colony daily to determine when individuals had moulted from juvenile to adulthood. Upon reaching adulthood, each individual (male and female) were housed alone in a clear plastic container (Diameter: $11 \mathrm{~cm}$, height: $7 \mathrm{~cm}$ ). These crickets were all placed in one room, so they were likely able to sense each other using auditory, olfactory, and visual cues. Temperature was controlled at $25 \pm 2^{\circ} \mathrm{C}$; the lighting was set to $12 \mathrm{~h}$ light: $12 \mathrm{~h}$ dark cycle. Crickets were provided with ad libitum food (powdered Harlan Teklad Rodent diet \#8604) and water. Food and water were checked daily and replaced as required. The males were individually housed until day 7 of adulthood to (1) control for the effects of prior social experiences, (2) ensure they were naïve virgins, and (3) allow them to mature to an age at which we typically find them fighting, producing acoustic mate attraction signals, and mating in the field. 
Males were weighed on day 7 of adulthood using a Denver Instruments analytical balance (Pinnacle Series model PI-314). Immediately following weighing, I painted each male's pronotum with a distinct colour (Sally Hansen New Lengths Ceramic nail colours \#33 purple, \#32 blue, \#07 copper and \#10 red) to allow for easy identification during the aggressive contests. From day 7 to 14 males were placed into the New Electronic Acoustic Recording system to record their long distance mate attraction signals (data described and utilized in Chapter 2). On day 14 post-final moult I quantified male fighting behaviours and aggressive interactions.

\section{Aggressive Interactions}

I paired 124 male crickets in 62 contests. Crickets were paired by minimizing mass differences, such that each individual was within $15 \%$ of the mass of his opponent; this was done to maximize the likelihood that the pair would engage in an aggressive interaction, as large size/mass differences between crickets usually result in immediate dominance (Hack, 1997; Brown et al., 2006).

Fighting trials were conducted in a small, sand covered Plexiglas arena (Length: $15 \mathrm{~cm}$, width: $15 \mathrm{~cm}$, height: $21 \mathrm{~cm}$ ) with two compartments separated by a removable divider. The outside of the arena was covered with white paper so that I did not distract the crickets. One cricket was placed on each side of the divided arena and given two minutes to acclimatize. The divider was then removed, allowing the male crickets to come into contact with each other, initiating the contest.

The start of the contest was marked by the first body contact between the males, following Jang et al (2008). The conclusion of the contest was defined as occurring once the loser withdrew or retreated multiple times following aggressive 
behaviours by his opponent. The behavioural categories used to quantify the level of aggressiveness performed by participants in the contest were adapted from the scoring system of Hofmann \& Schildberger (2001). The scale of aggressive behaviours ranged from zero to six: 0) mutual avoidance, 1) pre-established dominance, 2) antennal fencing, 3) unilateral mandible spreading, 4) bilateral mandible spreading, 5) mandible engagement, and 6) grappling or wrestling (Hofmann \& Schildberger 2001; described in Table 1.1). Aggressive songs (with distinct temporal and frequency structures to differentiate them from other types of acoustic songs) and body jerks (back and forth shaking motion) were also recorded when they occurred during or immediately following an aggressive contest.

Table 1.1: Aggressive behaviours of G. assimilis and their intensity score value. Adapted from Hofmann and Schildberger (2001).

\begin{tabular}{|c|c|c|}
\hline Action & Description & Aggression \\
\hline Mutual Avoidance & $\begin{array}{l}\text { No interaction between the opponents occur } \\
\text { or they are immobile for more than } 15 \mathrm{~s}\end{array}$ & 0 \\
\hline $\begin{array}{l}\text { Pre-established } \\
\text { dominance }\end{array}$ & $\begin{array}{l}\text { One opponent has early dominance over the } \\
\text { other }\end{array}$ & 1 \\
\hline Antennal fencing & $\begin{array}{l}\text { Crickets rapidly antennate the others } \\
\text { antennae }\end{array}$ & 2 \\
\hline $\begin{array}{l}\text { Unilateral Mandible } \\
\text { Spreading }\end{array}$ & $\begin{array}{l}\text { One of the opponents hyper-extends its } \\
\text { mandibles }\end{array}$ & 3 \\
\hline $\begin{array}{l}\text { Bilateral Mandible } \\
\text { Spreading }\end{array}$ & Both opponents hyper-extends mandibles & 4 \\
\hline Mandible engagement & Pinches conspecific with mandibles & 5 \\
\hline Grapple/wrestling & $\begin{array}{l}\text { Crickets butt heads and/or interlock } \\
\text { mandibles and push or pull their opponent }\end{array}$ & 6 \\
\hline
\end{tabular}

Fighting trials were conducted between $0900 \mathrm{~h}$ and $1200 \mathrm{~h}$. Trials were approximately $10 \mathrm{~min}$ in duration (less if clear dominance was established; more if crickets were still engaged in a fight at the 10 min mark). If the crickets were engaged 
in a fight at the 10 min mark, the fight was allowed to continue until clear dominance was established and fighting had ceased. Fights were filmed from above using a colour video camera (Canon HG10) in real time mounted on a tripod and recorded directly onto the camera's hard drive. Fights were later examined in slow motion (50\% to $75 \%$ slower than real time speed) to determine the timing, duration, frequency, and intensity of all aggressive behaviours. Once a contest was completed, crickets were returned to their individual containers and their acoustic mate signalling displays recorded (data presented in Chapter 2). The walls of the arena were wiped down with 95\% ethyl alcohol, and the sand was raked. This approach minimized the chance of pheromones, marks or footprints from previous contests affecting future fights. Each male was fought only once.

When analyzing the aggressive contests, the aggressive contest duration began at the start of the first physical contact between opponents and ended at the termination of the contest. Each contest was then subdivided into fight periods and post conflict periods dependent on whether the two individuals were in physical contact with each other or not (following Bertram et al., in press).

The aggressiveness of the fight was scored in two separate ways. First, the maximum level of aggression reached by both the winner and the loser in a fight was quantified (Hofmann \& Schildberger, 2001; Jang et al 2008). I then quantified each fight's intensity by multiplying each behaviour's aggressive score by the total number of seconds it was performed. These scores were then summed across all of the behaviours each individual performed, and the resulting sum was divided by the total time the individual spent in fights (following Bertram et al. submitted). Only 
behaviours scored using the scale of 0-6 were in used to calculate each individual's fighting intensity.

\section{Condition Measures}

Upon conclusion of the experiment on day 28 of adulthood, males were euthanized (frozen) and their body size quantified using a Zeiss Axio Observer inverted dissecting microscope and highly magnified photographs (AxioVisionLE v4.8, Carl Zeiss; magnification: $\sim 8.5 \mathrm{x}$, resolution: $\sim 1.60 \mu \mathrm{m})$. Condition was quantified using the residuals from an allometric regression of body mass (wet mass (mg) taken on Day 7 post final moult; scale: Pinnacle Series model PI-314) on body size. Residual mass was used as it standardizes mean condition within each group to zero (Gray \& Eckhardt, 2001). Size measurements included measures of maximum head width, maximum pronotum width and length, maximum forewing length, and femur length. These measures were incorporated into a principal component analysis. The first principal component was a good measure of overall size, with larger individuals having higher PC1 size scores than smaller individuals.

\section{Statistical Analyses}

All statistical analyses were performed in JMP v8.0.1 (SAS, Cary, North Carolina, USA). Values are given as mean \pm standard error. Fifty-eight of 62 contests had clear winners (94\%). Neither male displayed aggressively in the four conflicts with no obvious winner; these fights were not included in subsequent analyses. I used a paired t-test to determine whether winners were in better condition than losers. Paired t-tests were also used to determine whether winners were more likely to 
perform aggressive displays at higher rates or longer durations than losers. Spearman rank correlation assessed the relationship between maximum aggression score and fight intensity. I used Principle Component Analyses to reduce the number of aggressive behaviours to one for the number of times a behaviour was performed and one for the duration of an aggressive behaviour. I then regressed these principal components against fighting outcome and condition to determine if there were any effects. I used a false discovery rate B-Y adjustment $(\alpha<0.0111)$ to account for the 51 regressions I performed. I used this instead of the Bonferroni adjustment because the Bonferroni adjustment ( $\alpha<0.0010$ for the 51 correlations) has been shown repeatedly to be overly conservative (e.g., Benjamini et al. 2001 Nakagawa, 2004; Narum, 2006).

\section{Results}

Aggressive Interactions

Most males performed aggressive behaviours in a particular order, moving from least aggressive interactions (e.g. antennation and antennal fencing) to most aggressive interactions (e.g. mandible engagement and grappling/wrestling). At any point males could withdraw, either to chase the opponent, perform aggressive song and/or perform a body jerks displays (Figure 1.1). Males interacted with each other (physical contact) an average of $13.8 \pm 0.6$ times and each aggressive interaction lasted an average of $5.6 \pm 0.6 \mathrm{~s}$. The average number of non-contact aggressive displays (such as chase, body jerk, and aggressive song) performed after a fighting period was $13.5 \pm 0.8$ and each non-contact aggressive interaction lasted an average of $4.6 \pm 0.2 \mathrm{~s}$. The aggressive behaviours (contact or non-contact) that occurred most often in 
fighting contests were antennate (100\% of contests), body jerk (97\%), aggressive song $(97 \%)$, chase $(90 \%)$, and bilateral mandible spread $(86 \%)$. The behaviours that were rarely observed in fighting contests were unilateral mandible spread (29\%), mandible engagement (28\%), and grappling (21\%). Individuals rarely exhibited mutual avoidance but when they did they tended to do so for long periods of time. Further, males spent the longest total time performing aggressive songs, body jerk displays and chasing (Table 1.2).

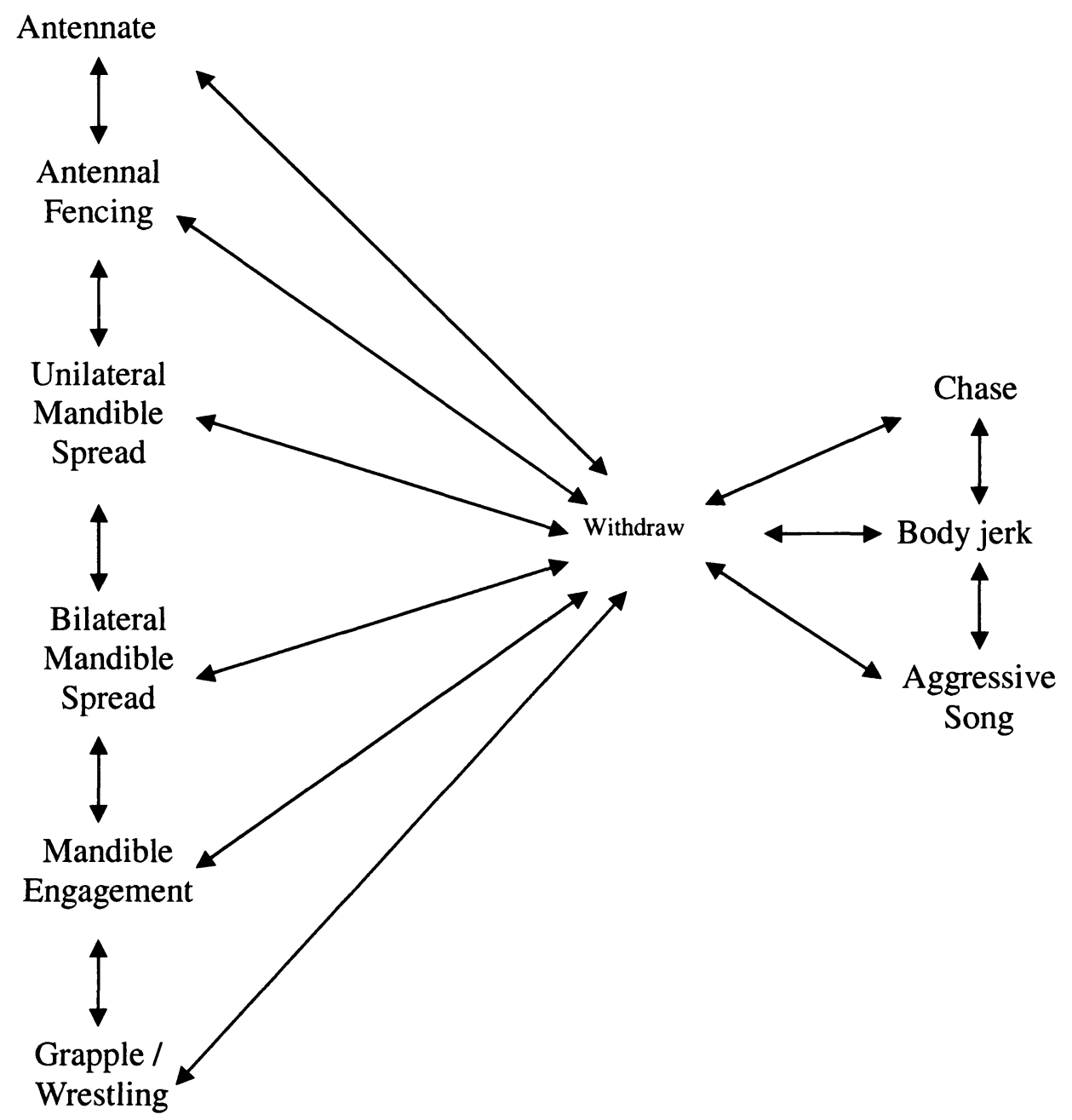

Figure 1.1: Ethogram of the aggressive behaviours observed in male G. assimilis fights. The transitions from starting fight behaviours (antennation) to end fight behaviours (withdraw) are shown with double sided arrows. Both winners and losers performed all of the aggressive behaviours. 


\section{Aggression Scores}

The standard way of quantifying aggression uses maximum aggression score (Bertram et al., 2010), the most aggressive action performed in a fight. For $G$. assimilis, there was considerable variation among fights in how aggressive individuals were.

On average, the maximum aggression score was $4.38 \pm 0.10$ (bilateral mandible spreading) on the scale of zero to six; $50 \%$ of the contests had a maximum aggressive score of four, $20 \%$ had a maximum score of five, $19 \%$ had a maximum score of six, and $12 \%$ had a maximum aggression score of less than or equal to three (Figure 1.2).

Because so many fights had a maximum aggression score of four (bilateral mandible spread), it was difficult to tease apart the variation in these fights. For example, did a pair of fighters spend most of the time flaring their mandibles at each other, or were most of the fights rather low-level aggressive interactions with just a second or two of mandible flares? To address this, I quantified fight intensity using the relationship between the amount of time each behaviour was performed and each behaviours aggression score (controlling for fight duration; see methods for details). Maximum aggression score and fight intensity of the contests were significantly positively correlated (Spearman $\rho=0.2341, \mathrm{P}=0.0138$; Figure 1.3). Because these two measures were positively correlated, I could use either fight intensity or maximum aggression score as a way of quantifying male aggressiveness in the fighting contests. 


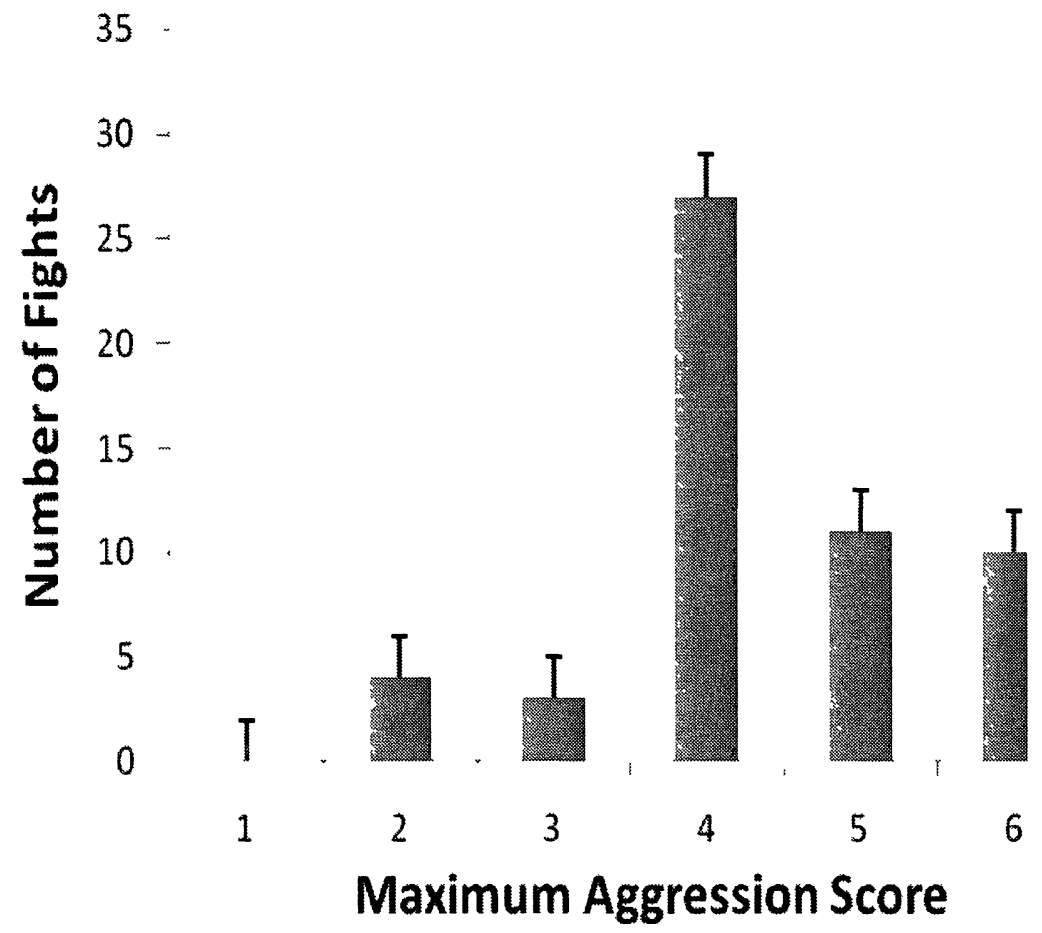

Figure 1.2: Distribution of maximum aggression scores of $G$. assimilis males in the 54 aggressive fighting contests. Maximum aggression scores range from 1 to 6 (see Chapter 1 methods for description of aggressive behaviours).

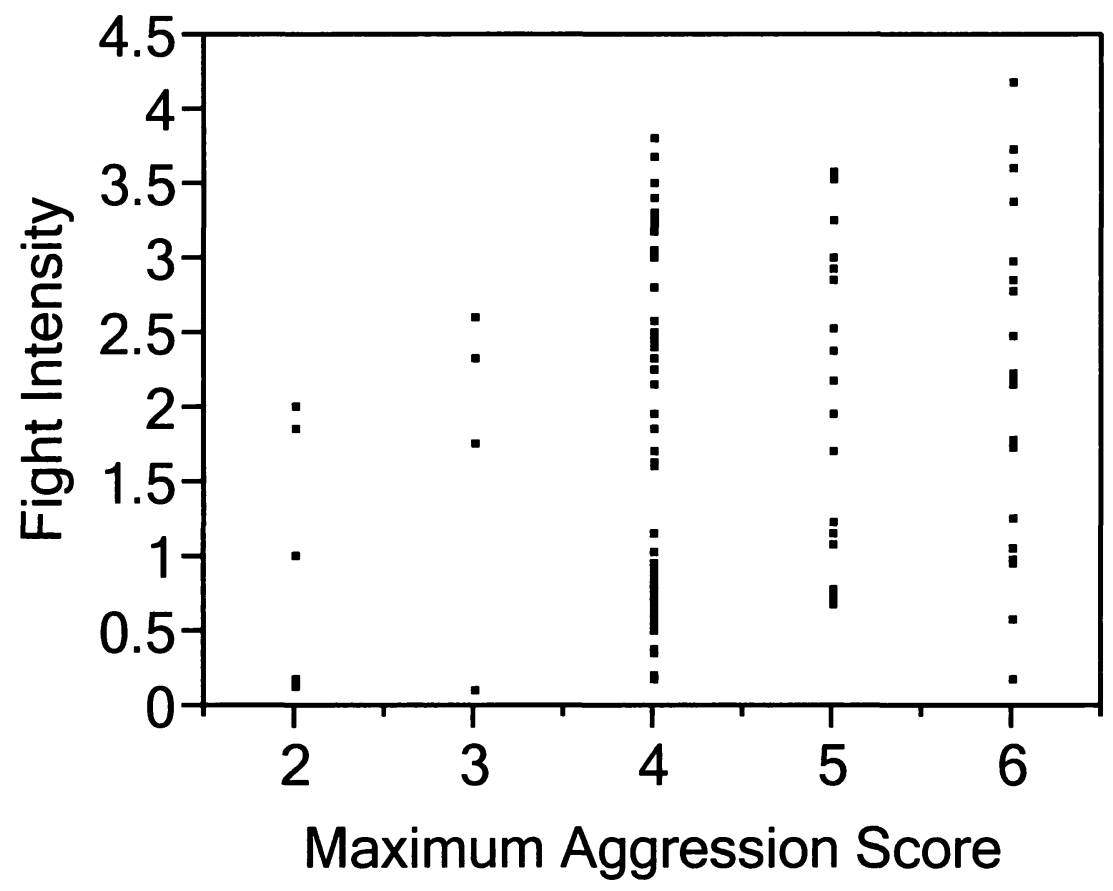

Figure 1.3: Correlation of fight intensity score (see Chapter 1 methods for calculation) and maximum aggression score for the 54 fighting contests (Spearman $\rho$ $=0.2341, \mathrm{P}=0.0138$ ). 
Are Winners More Aggressive Than Losers?

I used a Principle Component Analysis to reduce the number of aggressive variables used to analyze the differences between winners and losers. Antennate, chase, body jerk displays, aggressive songs and unilateral mandible spread were included in the multivariate analysis. Bilateral mandible spread, grapple and mandible engagement were not included as both winner and losers must perform these behaviours together and not all pairs performed them (especially grapple and mandible engagement). The first principle component of the number of times an aggressive behaviour was observed explained $52 \%$ of the variation in these behaviours and loaded onto each behaviour relatively equally (Table 1.2). The first principle component of the mean duration of aggressive behaviours explained $30 \%$ of the variation in these behaviours and loaded onto the behaviours somewhat equally (Table 1.2). Therefore, I used these principle components as overall measures of aggressive behaviour between winners and losers in subsequent analyses.

The first principle component of the number of times an aggressive behaviour was observed was significantly higher for winners than it was for losers (Table 1.3; Figure 1.3). Further, the first principle component of the mean duration performing aggressive behaviours was also significantly higher for winners than losers (Table 1.3; Figure 1.4). When I investigated the relationship between winner and loser behaviour univariately, I found that winners performed all aggressive behaviours more often (number of times) than losers (Table 1.3; Figure 1.5A). Winners also spent significantly more time (mean duration) than losers performing body jerk displays and chases (Table 1.3; Figure 1.5B). 
Table 1.2: The eigenvectors from a multivariate Principle Component Analysis performed on the number of times the behaviour is performed and the mean duration performing the behaviour for antennate, chase, body jerk, aggressive song and unilateral mandible spread performed during the fighting trial.

Factor

Behaviour

Eigenvector

Number of times behaviour is observed

Antennate

0.252

Chase

0.516

Body jerk

0.537

Aggressive song

0.534

Unilateral mandible spread

0.311

Mean duration performing behaviours

Antennate

0.453

Chase

0.304

Body jerk

0.451

Aggressive song

0.518

Unilateral mandible spread

0.480

Table 1.3: Matched pair's analyses of the number of times aggressive behaviours were performed and the mean duration of behaviours during the 54 analyzed trials. Data is subdivided into the behaviour of the winner and loser. Duration data are in seconds.

\begin{tabular}{llrrrr} 
Factor & Behaviour & $\begin{array}{r}\text { Winner } \\
\text { Mean }\end{array}$ & $\begin{array}{r}\text { Loser } \\
\text { Mean }\end{array}$ & t & \multicolumn{1}{c}{$\mathbf{P}$} \\
\hline Number of times & Antennate & 1.904 & 1.500 & 2.98 & $* \mathbf{0 . 0 0 4 3}$ \\
behaviour is & Chase & 3.058 & 0.019 & 11.1 & $*<\mathbf{0 . 0 0 0 1}$ \\
observed & Body jerk & 3.077 & 0.096 & 9.40 & $*<\mathbf{0 . 0 0 0 1}$ \\
& Aggressive song & 6.462 & 0.808 & 9.47 & $*<\mathbf{0 . 0 0 0 1}$ \\
& Unilateral & 0.308 & 0.058 & 2.44 & 0.0180 \\
& mandible spread & & & & \\
Mean duration & PC1 & 1.180 & -1.280 & 11.8 & $*<\mathbf{0 . 0 0 0 1}$ \\
performing & Antennate & 4.334 & 4.264 & 0.11 & 0.9139 \\
behaviours & Chase & 3.299 & 0.019 & 9.18 & $*<\mathbf{0 . 0 0 0 1}$ \\
& Body jerk & 5.217 & 0.308 & 4.02 & $* \mathbf{0 . 0 0 0 2}$ \\
& Aggressive song & 4.188 & 3.375 & 1.39 & 0.1707 \\
& Unilateral & 1.064 & 0.279 & 1.21 & 0.2306 \\
Aggression & mandible spread & & & & \\
& PC1 & 0.505 & -0.494 & 6.27 & $*<\mathbf{0 . 0 0 0 1}$ \\
& Fight Intensity & 2.698 & 0.977 & -14.9 & $*<\mathbf{0 . 0 0 0 1}$
\end{tabular}



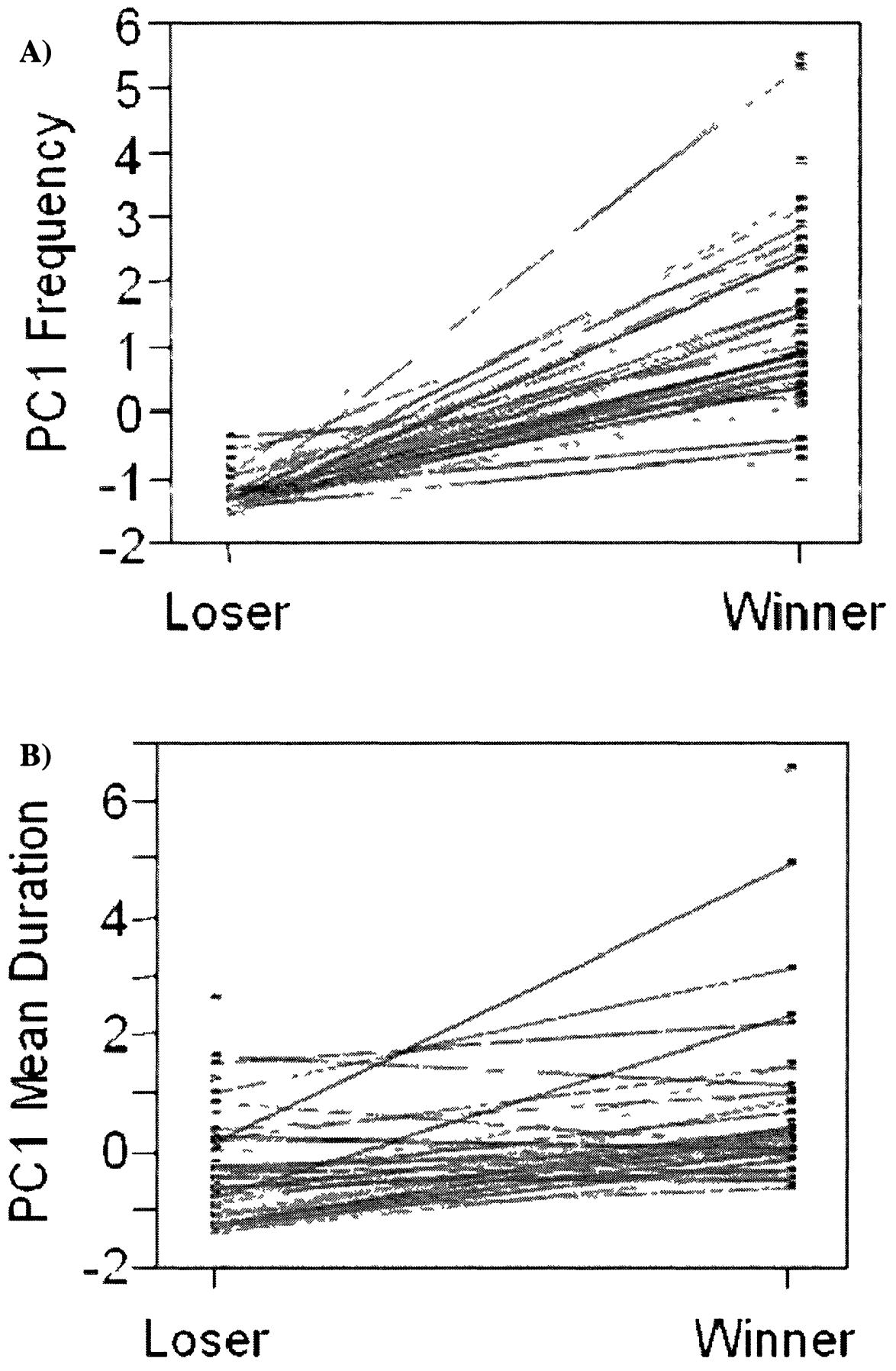

Figure 1.4: The difference between first Principle Components for winners and losers for A) the number of times an aggressive behaviour was observed (frequency) and B) the mean duration of aggressive behaviours. Each line represents the relationship between the winner and loser for that pair. 
A)

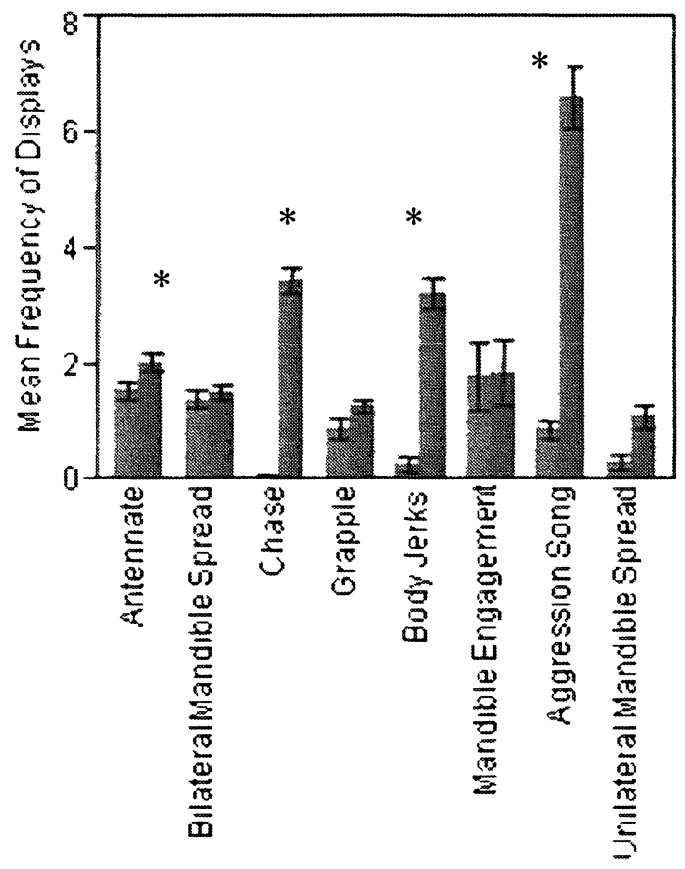

Displays

B)

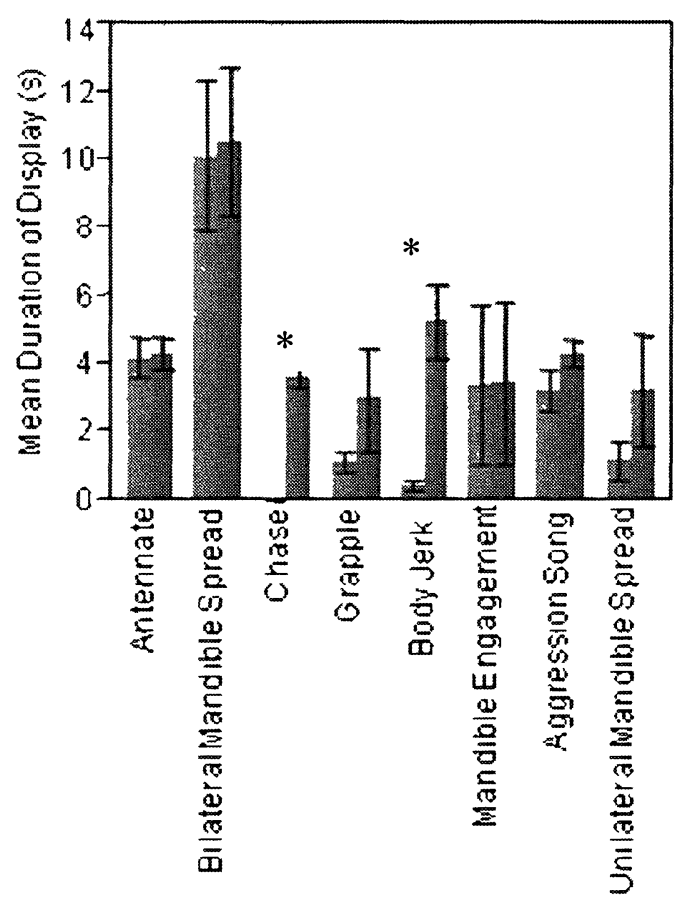

Eusplay

Figure 1.5: A) The mean number of times (frequency) and B) mean duration in which winners (blue) and losers (red) were engaged in aggressive displays during the fighting contest. Activities asterisked are significant. 
Condition

Winners were in no better condition than losers (Table 1.4). When examining whether aggressive behaviours were influenced by condition, mean duration of an aggressive behaviour nor the number of times an aggressive behaviour was observed affected by male condition (Table 1.5, 1.6). Individuals were mass matched to increase the chance that they would fight (Brown et al., 2006). I did not, therefore, expect fight outcome to be dependent on either size differences or mass differences between opponents. I calculated the difference between condition, mass and size of winning and losing males in each contest to determine if there was a relationship between the difference and how aggressive the fight became. Differences in condition, mass and/or size did not explain the variation in maximum fight intensity or maximum aggression level reached in each contest (all $\mathrm{P}>0.05$ ).

Table 1.4: Matched pair's analysis on the pre- and post-condition, wet mass and dry mass of the 54 fighting contests analyzed. Data is subdivided into the behaviour of the winners and losers.

\begin{tabular}{lrrrc} 
Matched Pairs & X Winners & X Losers & \multicolumn{1}{c}{ t } & P \\
\hline Pre-Condition & -2.430 & 0.642 & -0.47 & 0.6422 \\
Post-Condition & -3.105 & 0.874 & -0.82 & 0.4163 \\
Wet Mass (mg) & 474.7 & 469.3 & 1.56 & 0.1259 \\
Dry Mass (mg) & 156.4 & 157.0 & -0.16 & 0.8754
\end{tabular}


Table 1.5: Regressions of the mean duration of the fighting behaviours onto body condition and body mass for $G$. assimilis males. Only males with all size measurements who also performed the behaviours were included in each regression.

\begin{tabular}{llrrrc} 
Parameter & Aggressive Behaviours & \multicolumn{1}{c}{ DF } & $\mathbf{R}^{\mathbf{2}} \mathbf{a d j}$ & \multicolumn{1}{c}{$\mathbf{F}$} & $\mathbf{P}$ \\
\hline Condition & Antennal Fencing & 1,108 & 0.000 & 1.037 & 0.3109 \\
& Unilateral Mandible Spread & 1,15 & 0.035 & 0.462 & 0.5068 \\
& Bilateral Mandible Spread & 1,96 & 0.007 & 0.348 & 0.5565 \\
& Mandible Engagement/Biting & 1,31 & 0.032 & 0.000 & 0.9952 \\
& Grappling/Wrestling & 1,20 & 0.011 & 1.235 & 0.2796 \\
& Body jerk & 1,59 & 0.009 & 0.482 & 0.4905 \\
& Aggressive Song & 1,83 & 0.012 & 0.043 & 0.8365 \\
& Chase & 1,52 & 0.007 & 1.349 & 0.2509 \\
& First Principle Component & 1,102 & 0.007 & 0.269 & 0.6051 \\
\hline Body Mass & Antennal Fencing & 1,108 & 0.009 & 0.008 & 0.9303 \\
& Unilateral Mandible Spread & 1,15 & 0.065 & 0.022 & 0.8847 \\
& Bilateral Mandible Spread & 1,96 & 0.010 & 0.004 & 0.9511 \\
& Mandible Engagement/Biting & 1,31 & 0.021 & 0.340 & 0.5639 \\
& Grappling/Wrestling & 1,20 & 0.163 & 5.097 & 0.0353 \\
& Body jerk & 1,59 & 0.019 & 2.184 & 0.1447 \\
& Aggressive Song & 1,83 & 0.009 & 0.221 & 0.6392 \\
& Chase & 1,52 & 0.016 & 0.196 & 0.6601 \\
& First Principle Component & 1,102 & 0.010 & 0.027 & 0.8698
\end{tabular}


Table 1.6: Regressions of the number of times each of the fighting behaviours were performed onto condition and mass for G. assimilis males. Only males with all size measurements who also performed the behaviours were included in each regression.

\begin{tabular}{llrrrr} 
Parameter & Aggressive Behaviours & DF & $\mathbf{R}^{\mathbf{2}} \mathbf{a d j}$ & $\mathbf{F}$ & \multicolumn{1}{c}{$\mathbf{P}$} \\
\hline Condition & Antennal Fencing & 1,108 & 0.001 & 1.077 & 0.3017 \\
& Unilateral Mandible Spread & 1,15 & 0.019 & 1.301 & 0.2719 \\
& Bilateral Mandible Spread & 1,96 & 0.010 & 0.003 & 0.9596 \\
& Mandible Engagement/Biting & 1,31 & 0.013 & 0.602 & 0.4437 \\
& Grappling/Wrestling & 1,20 & 0.027 & 0.456 & 0.5073 \\
& Body jerk & 1,59 & 0.017 & 0.000 & 0.9943 \\
& Aggressive Song & 1,83 & 0.012 & 0.016 & 0.8988 \\
& Chase & 1,52 & 0.016 & 0.201 & 0.6555 \\
& Max aggressive score & 1,107 & 0.022 & 3.442 & 0.0663 \\
& Fight intensity & 1,107 & 0.008 & 0.100 & 0.7521 \\
& First Principle Component & 1,102 & 0.010 & 0.001 & 0.9699 \\
Winner/Loser of fight & 1,477 & 0.001 & 1.559 & 0.2125 \\
\hline Body Mass & Antennal Fencing & 1,108 & 0.017 & 2.860 & 0.0937 \\
& Unilateral Mandible Spread & 1,15 & 0.060 & 0.095 & 0.7625 \\
& Bilateral Mandible Spread & 1,96 & 0.010 & 0.003 & 0.9541 \\
& Mandible Engagement/Biting & 1,31 & 0.032 & 0.020 & 0.8895 \\
& Grappling/Wrestling & 1,20 & 0.012 & 0.744 & 0.3987 \\
Body jerk & 1,59 & 0.016 & 0.046 & 0.8316 \\
Aggressive Song & 1,83 & 0.012 & 0.001 & 0.9726 \\
Chase & 1,52 & 0.012 & 0.384 & 0.5384 \\
Max aggressive score & 1,107 & 0.162 & 21.85 & $*<\mathbf{0 . 0 0 0 1}$ \\
& Fight intensity & 1,107 & 0.008 & 0.099 & 0.7532 \\
First Principle Component & 1,102 & 0.005 & 0.485 & 0.4877 \\
Winner/Loser of fight & 1,477 & 0.002 & 0.007 & 0.9322
\end{tabular}




\section{Discussion}

Comparing Fights in G. assimilis to Other Species

To be successful in a fighting contest, the winning male must perform more aggressive displays and allocate more energy to fighting than the losing male (Hack, 1998). Therefore, a winner should perform more aggressive behaviours and for a longer time compared to his opponent. Supporting this contention, winning $G$. assimilis performed all aggressive behaviours more often and for longer periods of time than losers.

The behaviours I observed most often in G. assimilis contests were chasing, body jerk displays, and aggressive song. Given that the winners of the fights performed these displays most often and for longer durations, they may be giving an honest signal that they are fit and capable of continuing the contest, which the loser can evaluate to determine whether they want to escalate to fighting again (MestertonGibbons \& Sherratt, 2006).

Gryllus assimilis is a moderately aggressive species as most total aggression scores were in the mid to high range $(4.38 \pm 0.10=$ bilateral mandible spread $)$. When comparing $G$. assimilis to other cricket species, G. assimilis was most similar to $G$. fultoni and G. vernalis in the aggressiveness of the fight, as G. vernalis never grappled and G. fultoni only grappled a few times (Jang et al., 2008). Gryllus assimilis males were much less aggressive than $G$. pennsylvanicus and G. rubens. Gryllus pennsylvanicus and G. rubens grappled in $83 \%$ and $62 \%$ of their contests, respectively (Jang et al., 2008). Further, G. fultoni and G. vernalis reached an average aggressive level equivalent to the level $G$. assimilis reached (level 4 on the aggression scale). These results suggest that these three species, G. assimilis, G. fultoni, and G. 
vernalis may share similar motivation levels. In comparison, G. pennsylvanicus and G. rubens performed very aggressive behaviours in the majority of their contests, often reaching the highest level of aggression.

Jang et al (2008) suggested that interspecies differences in aggressiveness may occur as a result of access to limited resources. Gryllus fultoni and G. vernalis exhibit minimal aggression. These two species have high availability of signalling sites as they use grass or leaves for cover and do not stay in the same place for long periods of time (Jang et al., 2008). Conversely, male G. pennsylvanicus, G. rubens and G. veletis frequently occupy burrows or other crevices that are much more scarce in nature. Jang et al (2008) suggested that males, which use burrows, are more territorial and aggressive than males who use leaves as signalling sites. Males that must defend their territories from conspecifics may be more aggressive because the cost associated with losing the signalling territory may be higher than the costs associated with being injured in the contest (in comparison to males that don't experience intense competition for signalling sites). Gryllus assimilis exhibited low aggression scores similar to G. fultoni, and G. vernalis suggesting that they may not keep long-term burrows and, therefore, may have a lower motivation to escalate contests. Since grass and leaves are readily available, males may rather leave the area or retreat to another leaf instead of risking injury fighting over an area that is not a limited resource (Jang et al., 2008).

In contrast to the above findings, Gryllus assimilis' motivation and willingness to fight until a winner is determined may be more comparable to $G$. pennsylvanicus and G. rubens than to G. fultoni and G. vernalis, as the proportion of fights with clear winners and losers was similar in these three species (and 
significantly lower in G. fultoni and G. vernalis). Gryllus assimilis had a clear winner and loser in almost all of the fighting contests (94\%) and G. pennsylvanicus and $G$. rubens had clear winners/losers in every contest (Jang et al., 2008). Fights, however, involving G. assimilis will usually not escalate to a stage where injury is probable for either of the males (much rarer to see grappling and wrestling in contests).

Body jerks and aggressive songs are non-contact displays that tend to occur after a male has retreated from a fighting interaction (Bertram et al., in press). While I have no evidence for the function of these non-contact aggressive displays, winning G. assimilis performed them more often than losers. Further, these behaviours were usually performed upon the conclusion of aggressive interactions. These observations suggest that body jerks and aggressive songs may function as post-conflict victory displays (Bertram et al. in press). Post-conflict victory displays are usually performed to reinforce the dominance and quality of the winner to both the loser of the contest and to any audience members that may be in hearing/visual range, to dissuade future aggression towards the winner or create a dominance hierarchy (Mesterton-Gibbons \& Sherratt, 2006).

Post-conflict displays in G. assimilis were comparable to G. pennsylvanicus and G. rubens. When G. pennsylvanicus and G. rubens losers retreated, winners displayed aggressive song and body jerk displays in $81 \%$ of trials. Gryllus assimilis was similar, as winners displayed aggressive songs and body jerks in $97 \%$ of the trials. On the other hand, G. fultoni and G. vernalis only produced aggressive songs as dominance displays and they only occurred in $21 \%$ and $34 \%$ of trials, respectively (Jang et al., 2008). Further, losing males of each species retreated or withdrew upon 
aggressive displays by the opponent (antennal contact or body contact), suggesting that they have similar submission behaviours (Jang et al., 2008).

Post-conflict displays may, therefore, be more frequent in G. assimilis, $G$. pennsylvanicus, and G. rubens because of the high proportion of fights with clear winners and losers. Further, increased motivation and willingness to fight may also increase signalling between males or signalling to an audience. This signalling acoustic and visual signalling may advertise that they are still able and willing to fight.

Gryllus assimilis, therefore, seems to be intermediate among the four cricket species that Jang et al (2008) studied for both aggressive displays and post conflict displays: closer to G. fultoni and G. vernalis in aggression and closer to $G$. pennsylvanicus and G. rubens for the proportion of fights with a clear outcome and post conflict displays.

\section{Condition}

Male aggressive encounters with large size/mass differences have sometimes been shown to result in immediate dominance in other field cricket species (Robertson, 1986; Olsson, 1992; Brown et al., 2006). For example, Jang et al. (2008) found that larger G. pennsylvanicus males were more likely to win aggressive contests against smaller males. Further, male A. domesticus that were heavier (Hack, 1997) and in better condition (Brown et al., 2006) were typically more aggressive and likely to win a contest than light males in poor condition.

Because large size differences sometimes influence the outcome of aggressive interactions, I sized-matched each of the fighting males by ensuring there was no 
more than a $15 \%$ difference in each fighting pair's body mass. I did this to increase the odds that the males would engage in a fighting competition. It was not, therefore, surprising that aggression and/or fight outcome were not influenced by differences in male size and/or mass. Although Jang et al. (2008) did not size match their crickets, they showed that cricket mass and size differences did not affect the fight outcome in G. fultoni. G. vernalis, and G. rubens. Size effects may not, therefore, transcend across field cricket species as relationships were found in $A$. domesticus and $G$. pennylvanicus but not in studies performed on G. fultoni, G. vernalis, and G. rubens (Jang et al., 2008).

Male condition should theoretically be an indicator of how well he will be able to perform in a fighting contest (Shackleton et al.. 2005). Males of better condition should be able to allocate more energy to aggressive behaviours and therefore they should be able to last longer in a contest because they have a higher resource holding potential (Mortez, 2003). My results did not, however, support this hypothesis. Body condition did not differ between winners or losers and did not affect aggression. This finding is surprising, as residual mass has been found to be a good measure of condition in G. assimilis. Males with unlimited access to food were found to be in significantly better condition than males fed on a low food diet (Whattam 2009). This finding suggests that residual mass should accurately reflect condition.

Male G. assimilis that won the aggressive contests typically performed more aggressive behaviours and performed them for a longer period of time without any significant differences in male size, mass or condition. One model that may then be occurring in G. assimilis aggressive competitions is the 'war of attrition', as it does not require a component of male size or condition to determine fight outcome. In this 
model, two contestants of a fighting competition compete for a resource of value, and each contestant chooses (often randomly) when to concede the resource to the other opponent, while accumulating costs at a constant rate. This suggests that the outcome of the contest is decided only by the display duration (Maynard-Smith, 1974; Bishops and Cannings, 1978). In other words, strategically each competitor makes a 'bid' about how long they can last in the competition and whoever can last the longest (highest 'bid') in the aggressive contest wins the resource; however, both competitors must pay the loser's lowest lowest 'bid' on that resource (the energetic expenses, risk of injury) (Maynard-Smith, 1974; Bishops and Cannings, 1978). The 'war of attrition' model may be the reason as to why males still won and lost aggressive contests, even though there were not any phenotypic differences found between the males.

Collectively, my findings suggest that aggressive displays and fight outcomes do not accurately predict a male's condition to observers, such as females looking for a mate or potential male opponents searching for a calling territory.

\section{Future Research and Considerations}

Fight aggressiveness and outcome may be more dependent on hormone levels than on cricket condition, as males with high testosterone or octopamine levels are typically more aggressive than males with lower levels (Atkins \& Stout, 1994; Marler \& Moore, 1988). For example, higher testosterone levels in birds have been linked to increased territory size, more success in male-male fighting contests and therefore a higher position on the dominance hierarchy (Marler \& Moore, 1988; Watson \& Parr, 1981; Wingfield, 1984). In the field cricket G. bimaculatus, Adamo et al. (1995) found that octopamine (the 'fight or flight' hormone of insects) increased 
significantly from baseline levels during aggressive encounters. They hypothesized that octopamine may be a neurohormone that is released to prepare an animal for an extended period of activity or to help it recover after increased energy demand (Adamo et al., 2005). It may only take antennal contact for males to release this hormone. Supporting this contention is the finding that male crickets that are depleted of octopamine exhibit significantly depressed aggressiveness in contrast to males with normal amount of octopamine (Stevenson et al., 2005). Together, these findings suggest that future studies exploring the factors influencing aggression in G. assimilis should quantify octopamine and testosterone levels.

Aggressiveness in male G. assimilis and G. veletis is thought to increase the longer they are isolated from other individuals (Alexander, 1961). In my experiment, males were isolated from other individuals from day 1 of adulthood until day 14 when they were placed into a fighting contest. This two-week period of isolation may have increased the level of aggression reached in the contests, compared to males that regularly interact with other individuals in nature.

The use of a small fighting arena is another component that may affect aggressiveness in G. assimilis and that may differ between my fights and nature. When aggressive contests occur in nature, the loser and winner are unlikely to come into contact again after the fighting period has ended (at least in the near future) and the loser typically flees from the winner. Performing trials in a relatively small observation arena does not allow the loser to flee a far distance from the winner. When the loser retreats, he may immediately run back into the winner, resulting in the resumption of the fight (Bertram et al., in press). This creates aggressive contests that tend to occur in bursts, separated by periods of no contact. Performing the contests in 
a much larger, more natural setting may create outcomes more equivalent to aggressive contests in nature. 
Chapter 2: Attraction Displays: Age, Size, and Condition 


\section{Abstract}

Signalling can play an important role in sexual selection as competition between males to be selected by females as mates is often based on long range signalling. Condition, size and age of the signaler may influence the attractiveness of long range signalling displays, and thus may provide the female with information on male quality. To explore the factors influencing long range acoustic mate attraction signals in the Jamaican field cricket, Gryllus assimilis, I quantified the acoustic mate attraction signals of 53 males throughout much of their adult lives. Males exhibited extensive natural variation in all of their mate attraction signalling parameters. I used a Principle Component Analysis to reduce these parameters to a more manageable number. The first and second principle component was an overall measure of signal quality. The third principle component was an overall measure of signal quantity. Both signalling quality and quantity were significantly influenced by age, with older males signalling with higher effort and producing more attractive signals. Condition did not affect overall signal quality or quantity. Dominant frequency of a signal was the only parameter indicative of male mass and size. Further, as male mass and size increased, signalling effort decreased: smaller/lighter males signalled with higher effort. My findings suggest that females preferentially selecting males with high quality/quantity signals would locate older males, but the males might also be smaller. Females would not, necessarily, locate males in good condition. Together these findings do not support the prediction that acoustic songs signal body condition. 


\section{Introduction}

Acoustically signalling species have been the focus of many sexual selection and communication studies. Signalling can play an important role in sexual selection as competition between males to be selected by a mate is often based on variation in signalling behaviour (e.g. morphological, acoustic, olfactory, tactile, and/or behavioural; Maynard Smith, 1991; Tregenza et al., 2006). Long-range mate signalling by one individual (usually male) is used to attract choosy individuals (usually females) to mate. To enhance attractiveness, males can sometimes adjust their signal quality to produce more attractive signals; however, there are usually significant costs associated with doing so (Tregenza et al., 2006). Mate attraction signals may, therefore, be good examples of secondary sexually selected traits that are costly to produce (Tregenza et al., 2006). The amount of effort an individual allocates to mate attraction displays (e.g. how often and for how long it signals) likely depends on the associated costs (e.g. energetics, reduced foraging time, and increased risk of predation and/or parasitism due to the higher probability of signal detection; Holzer et al., 2002; Bertram \& Warren, 2005). There must be sufficient benefits to offset the potential decrease in survival caused by amplified signalling behaviour.

The amount of energy an individual allocates to mate attraction displays should be driven by present signalling effort and future reproductive output (Bertram et al., 2004; Holzer et al., 2002). Therefore, the allocation of resources to signalling may be disproportionate from one moment to the next. For instance, a signaller in good condition may invest most of its daily energy into sexual displays in an attempt to attract females to mate with him (Holzer et al., 2002). However, in the three-spined stickleback, Gasteroteus aculeatus, males in poor condition also often invest more 
into current signalling effort when their future reproductive prospects are limited than males in good condition (Candolin, 1999). This seems to have resulted in the tendency for males in poor condition to make the best of a bad situation, thereby increasing their chances of mating prior to death (Candolin, 1999). Body condition can, therefore, play a strong role in maintaining variation within and across individuals in their daily and lifetime mate attraction signals.

Body size may also influence the attractiveness of a display. For example, in G. texensis, large males produce louder songs than small males (Bertram et al., 2004), and in birds, large body size is correlated with the brightest colouration (Andersson, 1994). In American toads, Sullivan (1992) found that dominant frequency is negatively correlated with male size (snout-vent length and mass). Females tend to mate with males who are larger in size and call at a low dominant frequency. Variation in body size could thus create a mating advantage for larger males. Mate attraction signalling can also change with age, often increasing over time. Bertram (2000) found that age affected signalling behaviour in G. texensis. Young and very old males called significantly less often then middle-aged males, suggesting that signalling increases with age until it plateaus in G. texensis. Signalling seemed to drop when males reach the age at which they typically die in nature. Felton et al. (2006) also demonstrated that age could influence signalling characteristics and the importance of male age to female preference in the amphibian Cophixalus ornatus. They found dominant frequency to be negatively correlated with age. Furthermore, males that signalled with low dominant frequencies attracted more mates. As such, age not only affected signalling behaviour, it also affected mate choice. Since future mating opportunities typically decline with age, signalling may 
become more honest over time. Females may, therefore, prefer older males because they are more honest signallers (Proulx et al., 2002). Preference for older males may confer indirect benefits since older males have demonstrated their ability to survive and may have higher viability (Wedell \& Ritchie, 2004).

Here I investigated male signalling behaviour in the field cricket, G. assimilis. Acoustic signals play important roles in field cricket territoriality, aggression, and sexual selection (Nelson \& Nolen, 1997). Male crickets produce three types of acoustic signals: aggressive songs, long distance mate attraction songs, and courtship songs (Wagner \& Reiser, 2000; Gray \& Eckhardt, 2001). Males produce these acoustic signals by rubbing their raised forewings together. On the upper surface of the lower wing is a 'scraper' which contacts the 'file' on the lower surface of the upper wing, producing a pulse of sound at a characteristic frequency (Bertram, 2002). Pulses are concatenated into chirps. The three types of acoustic signals have distinct temporal structures and frequencies (Brown et. al., 2006). The dominant male following an aggressive conflict performs aggressive songs most often. They usually consist of a single chirp and may cause the opponent to retreat (see discussion of post-conflict displays in Chapter1). Long-distance mate attraction signals are produced once a male has obtained a signalling territory in which to attract females. Gryllus assimilis long-distance mate attraction songs consist of short chirps of approximately seven to 14 pulses (pers. obs.). Once a female has been attracted to the territory, males switch to courtship songs (Nelson \& Nolen, 1997; Wagner \& Reiser, 2000; Gray \& Eckhardt, 2001), which must be produced before the attracted female will mate with the male (Guerra \& Pollack, 2007). Courtship songs are produced with 
short intervals of high and low frequency ticks followed by a silent period (Gray \& Eckhardt, 2001).

Long-distance mate attraction signals play an important role in cricket mate choice (Wagner \& Reiser, 2000). Females use long-distance mate attraction signals to distinguish between different species and to orient to potential mates (Nelson \& Nolen, 1997). Females also use long-distance mate attraction signals to discriminate among potential mates. Female field crickets can distinguish between different song characteristics such as pulse duration, interpulse duration, number of pulses per chirp, pulse rate, chirp duration, chirp rate, call amplitude and call frequency. For example, G. assimilis, G. firmus, and G. fultoni prefer to mate with males that produce mate attraction signals that are that are long in duration (long chirp duration and high number of pulses per chirp), produced at a high chirp rate, a low frequency, and that are also produced most often (high time spent signalling) and loudly (high amplitude) (Wagner \& Hoback, 1999; Scheuber et al., 2003). These parameters tend to be energetically expensive to produce and may, therefore, be honest indicators of condition (Wagner \& Hoback, 1999). For example, in the species Anurogryllus arboreus (Prestwich and Walker, 1981) and Neoconocephalus robustus (Stevens and Josephson, 1977), signalling used up to 10-16 times more energy than that of resting. Thus, female preference may be linked to selecting mates that are in good condition (Nelson \& Nolen, 1997; Guerra \& Pollack, 2007).

Acoustic signalling parameters may also provide females with information about the male's size, age, and/or genetic quality (Wagner \& Hoback, 1999). For example, Gray (1997) found that female A. domesticus preferred the chirps of larger males to the chirps of smaller males, with the mean number of pulses per chirps being 
one of the better indicators of size. In G. texensis, large males call a little more often than small males (Bertram, 2000). Thus, some aspects of male signalling behaviour appear to signal body size.

Cricket long distance mate attraction signals may, therefore, be honest indicators of condition and may reflect the ability of the male to provide direct or indirect benefits to the female. Direct benefits might include access to high-quality territories, food, egg-laying sites, and/or protection from predators (Andersson \& Simmons, 2006; Wagner \& Reiser, 2000; Maynard Smith, 1991). If a female can use male signals to distinguish between good and poor providers, then being choosy should allow her or her offspring to directly benefit from her choice. But what about the more likely situation in which male crickets offer their mates nothing other than sperm? Why should females be choosy in this situation? Choosy females may still acquire a genetic benefit for their offspring. Females that mate with males of high genetic quality should derive indirect fitness benefits since offspring inherit both the genes influencing choice and the genes for quality (Hunt et al., 2004).

The idea that choosy females derive genetic benefits for their offspring requires that both the signalling traits and the choice traits be heritable. Empirical evidence suggests that some of the sexually selected traits in male field crickets are heritable. Hedrick (1988) concluded that signalling-bout length in male G. integer has a mean estimated heritability of $\mathrm{h}^{2}=0.74$. Female $G$. integer evaluates signalling-bout length when selecting potential mates (Cade, 1981). Male G. texensis are estimated to have a realized heritability of $\mathrm{h}^{2}=0.50-0.53$ for total nightly signalling time, suggesting that signalling time also has an important genetic component (Cade, 1981). However, Bertram et al. (2007) estimated that signalling time is not heritable 
$\left(h^{2}=0.006 \pm 0.045\right)$ for the same species. The heritability of signalling time thus remains in question.

Female preferences and male traits can become genetically correlated, leading to female preferences evolving as a correlated response to the selection acting on the male trait (Hedrick, 1988). Gray \& Cade (1999) performed one of the first studies on the heritability of female preference and choosiness using $G$. integer. They found that in $F_{2}$ full-siblings, the parent-offspring heritability of the female preference for certain traits of male acoustic song was $34 \pm 17 \%$ and when looking at $F_{2}$ full-siblings families the preference heritability was estimated to be $47 \pm 21 \%$ (Gray and Cade, 1999). Genetic correlation between this female preference and the male signalling traits in the field was estimated at $0.51 \pm 0.17$, but disappeared after only one generation of random mating (Gray \& Cade, 1999). Therefore, female preferences for certain male traits can be heritable.

Due to the potentially large influence that acoustic signalling could have on mate choice, mating success, and fitness, it is important to understand the factors that influence the production of long distance acoustic mate attraction signals. Here I used the Jamaican field cricket, Gryllus assimilis, to explore the factors that influenced long-distance acoustic mate attraction signalling. Because female crickets are typically attracted to long, loud signals that are produced often (Wagner \& Hoback, 1999; Scheuber et al., 2003), I explored whether these acoustic parameters were correlated with body size and condition. I also determined whether there were any age effects on signalling behaviour. Lastly, I explored the relationships between acoustic signalling parameters to ascertain whether males that produced the most attractive 
signals also signalled louder and more often. Alternatively, males that produce less attractive signals may make the best of a bad situation by signalling most often.

\section{Methods}

Acoustic Recordings

I captured male and female adult G. assimilis in Austin, Texas, U.S.A. in September 2008. Crickets were reared and housed in the same manner described in Chapter 1. Males were placed into the New Electronic Acoustic Recording System (NEARS) on day 7 of adulthood, for seven consecutive days (Day $7-14$ ). The NEARS equipment monitors up to 96 males simultaneously, each with their own microphone. Each cricket is acoustically isolated from the others by being placed in its container into a Styrofoam enclosure with $7 \mathrm{~cm}$ thick walls lined with $3.5 \mathrm{~cm}$ thick acoustic foam. Inside each cricket's Styrofoam enclosure (but outside the cricket's plastic container) there is a single LED light that provided each male with $12 \mathrm{~h}: 12 \mathrm{~h}$ L:D cycle. Above the plastic container, but within the Styrofoam enclosure is a microphone. Each microphone is continuously monitored by a computer program (CricketSong; developed for our laboratory by Cambridge Electronic Design Ltd., Unit 4, Science Park, Milton Road, Cambridge, UK). CricketSong analyzes cricket sound waves in real time, calculating the following signalling parameters: total time spent signalling, pulse duration, pulses per chirp, interpulse duration (time between pulses), interchirp duration (time between chirps), pulse rate (pulses per minute), chirp rate (chirps per minute), dominant frequency (carrier frequency of the call) and amplitude (Figure 2.1). 
Each individual's acoustic mate attraction signalling parameters are quantified 24 hours a day, seven days a week, for as long as they are in the NEARs unit. The recordings were stopped however, every other day to check on the male's food and water supply. On day 14 of adulthood, all males were removed from the NEARS. Males were placed into a small, sand covered Plexiglas arena $(15 \mathrm{~cm} \mathrm{~L} \mathrm{x} 15 \mathrm{~cm} \mathrm{~W} \mathrm{x}$ $21 \mathrm{~cm} \mathrm{H}$ ) where they roamed freely and explored for 10 minutes (control males for the fights in Chapter 1). The males were then placed back into the NEARS to analyze their long distance mate attraction signals for another seven consecutive days (Day 14 -21). On day 21 these males were mated to virgin females (described in Chapter 3).
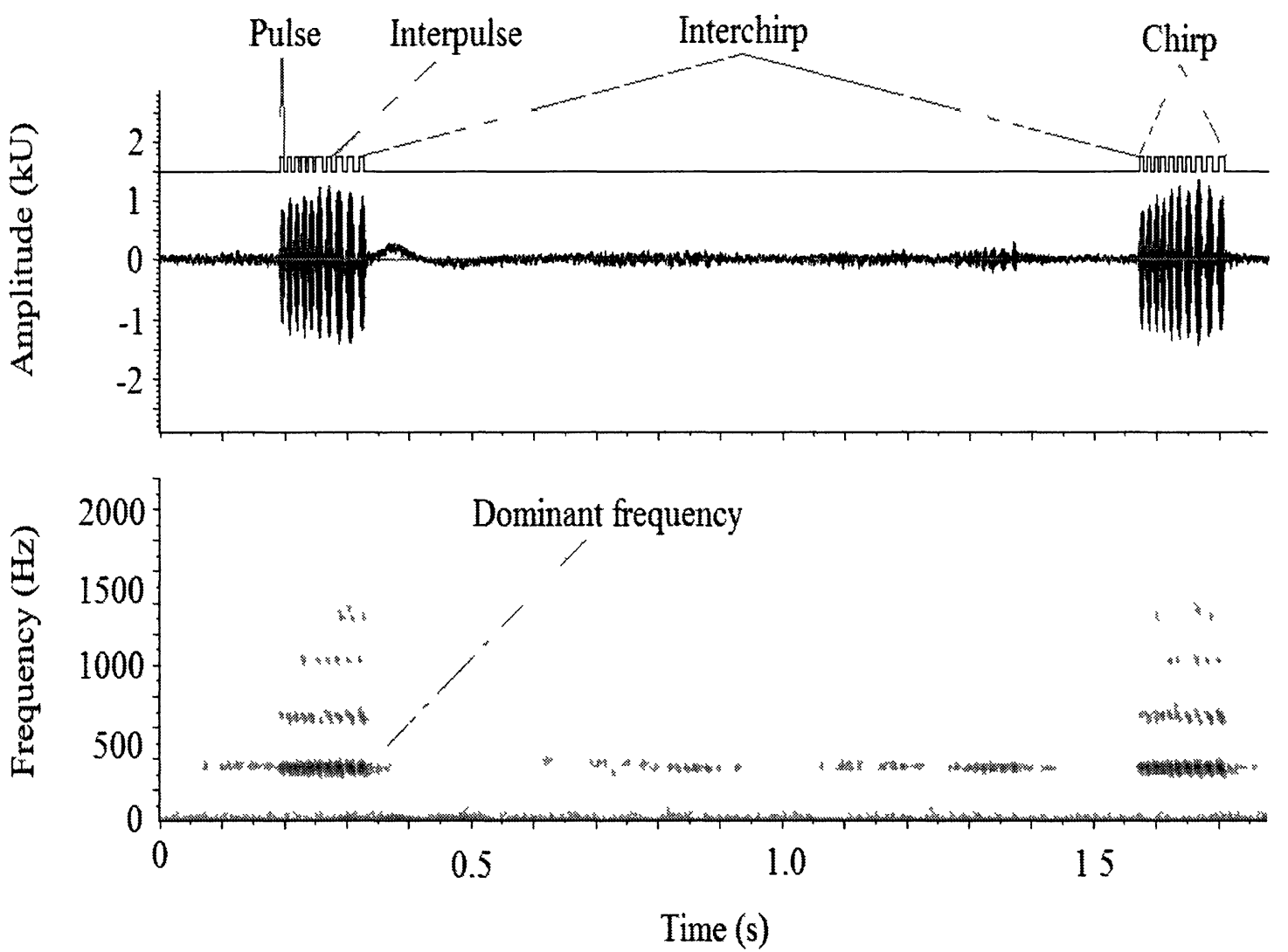

Figure 2.1: Acoustic signalling parameters of the long-distance mate attraction signals of $G$. assimilis (Created by E. Whattam). 
Size, Mass and Condition Measures

Upon conclusion of the experiment, males were euthanized (frozen) and their body size was quantified (see Chapter 1 for description). A Principle Component Analysis was performed to obtain an overall measure of body size. Condition was quantified using the residuals from an allometric regression of body mass onto body size. A complete description of the aforementioned measures is provided in Chapter 1. I used condition, pronotum area, and mass to assess their relationship with acoustic signalling because all of these variables are influenced by juvenile and/or adult diet (Whattam, 2009).

\section{Statistical Analyses}

Males that did not call for more than six seconds an hour on average $(<1 \%$ of the hour) were categorized as "satellite" males (Rowell and Cade, 1993), and were excluded from all signalling behaviour analyses. I used linear regressions to assess which signalling parameters were influenced by size, mass, and condition. I also used linear regressions to assess the relationships between signalling parameters. The influence of age on signalling behaviour was determined by conducting a multivariate repeatability model on the signalling parameters of two weeks' worth of signalling data. I used a Principle Component Analysis to decrease the number of signalling parameters to three, based on the signal quality and signalling effort of a male. I then regressed these principal components against age and condition to determine if there were any effects. I used a false discovery rate B-Y adjustment $(\alpha<0.0098)$ to account for the 92 regressions I performed. 


\section{Results}

Signalling Behaviour is Highly Variable

Males were highly variable in their long distance mate attraction signalling behaviour. On average they produced chirps that contained $7.99 \pm 1.20$ pulses, but ranged from 4 to 10 pulses (Table 2.1). Pulse duration averaged $9.70 \pm 3.42 \mathrm{~ms}$, but ranged from 5 to $13 \mathrm{~ms}$. Dominant frequency averaged $3.78 \pm 0.36 \mathrm{kHz}$, but ranged from 3.31 to $4.95 \mathrm{kHz}$. Time spent signalling per night averaged just over three hours, but ranged from males that never signalled to males that signalled for an average of ten hours a night (Table 2.1).

All acoustic signalling parameters were strongly correlated with each other (Table 2.2). For example, crickets that produced long pulses also produced more pulses per chirp, longer and louder chirps, and signalled at lower dominant frequencies, for longer amounts of time per night (Table 2.2). This finding suggests that individuals that produce the most attractive signals (high quality) also signal most often (high quantity).

Table 2.1: Natural variation of all signalling parameters for $G$. assimilis males aged 8 to 21 days of adulthood.

\begin{tabular}{lrrrr} 
Signalling parameter & Mean & Std Dev & Min & Max \\
\hline Mean pulse duration (ms) & 9.710 & 3.420 & 5.490 & 12.95 \\
Mean interpulse duration (ms) & 16.15 & 21.87 & 12.84 & 21.38 \\
Mean pulses per chirp & 7.990 & 1.170 & 3.830 & 9.56 \\
Mean chirp duration (ms) & 119.8 & 10.90 & 50.74 & 158.9 \\
Mean interchirp duration (ms) & 1520 & 562.8 & 570.0 & 3116 \\
Dominant frequency (Hz) & 3779 & 356.7 & 3308 & 4947 \\
Amplitude (dB) & 60.00 & 61.94 & 0.000 & 75.56 \\
Time spent signalling (min) & 211.3 & 176.6 & 0.000 & 608.7
\end{tabular}


Table 2.2: Correlations and probabilities between long distance mate attraction signalling parameters.

\begin{tabular}{|c|c|c|c|c|c|}
\hline Variables & $\begin{array}{c}\text { Time } \\
\text { Signalling }\end{array}$ & $\begin{array}{c}\text { Pulse } \\
\text { Duration }\end{array}$ & $\begin{array}{c}\text { Pulses per } \\
\text { Chirp }\end{array}$ & $\begin{array}{l}\text { Chirp } \\
\text { Duration }\end{array}$ & Amplitude \\
\hline $\begin{array}{c}\text { Pulse } \\
\text { Duration }\end{array}$ & $\begin{array}{r}0.4094 \\
\mathrm{P}=*<0.0001 \\
\end{array}$ & & & & \\
\hline $\begin{array}{l}\text { Pulses per } \\
\text { Chirp }\end{array}$ & $\begin{array}{r}0.2336 \\
\mathrm{P}=*<\mathbf{0 . 0 0 0 1} \\
\end{array}$ & $\begin{array}{r}0.4694 \\
\mathrm{P}=*<\mathbf{0 . 0 0 0 1} \\
\end{array}$ & & & \\
\hline $\begin{array}{c}\text { Chirp } \\
\text { Duration }\end{array}$ & $\begin{array}{r}0.1372 \\
\mathrm{P}=* \mathbf{0 . 0 0 0 4} \\
\end{array}$ & $\begin{array}{r}0.4852 \\
\mathrm{P}=*<0.0001 \\
\end{array}$ & $\begin{array}{r}0.8251 \\
\mathrm{P}=*<0.0001 \\
\end{array}$ & & \\
\hline Amplitude & $\begin{array}{r}0.2466 \\
\mathrm{P}=*<\mathbf{0 . 0 0 0 1} \\
\end{array}$ & $\begin{array}{r}0.2228 \\
\mathrm{P}=*<\mathbf{0 . 0 0 0 1} \\
\end{array}$ & $\begin{array}{r}0.1272 \\
\mathrm{P}=* \mathbf{0 . 0 0 1 1} \\
\end{array}$ & $\begin{array}{r}0.1295 \\
\mathrm{P}=* \mathbf{0 . 0 0 0 9} \\
\end{array}$ & \\
\hline Frequency & $\begin{array}{r}-0.2023 \\
\mathrm{P}=*<0.0001\end{array}$ & $\begin{array}{r}-0.5087 \\
P=*<0.0001\end{array}$ & $\begin{array}{r}-0.3989 \\
\mathrm{P}=*<\mathbf{0 . 0 0 0 1}\end{array}$ & $\begin{array}{r}-0.3675 \\
\mathrm{P}=*<\mathbf{0 . 0 0 0 1}\end{array}$ & $\begin{array}{r}-0.1800 \\
\mathrm{P}=*<0.0001\end{array}$ \\
\hline
\end{tabular}

Since all of the signalling parameters were strongly correlated, I performed a Principle Component Analysis to reduce the number of signalling parameters. The first principle component explained $49 \%$ of the variation. Pulse duration, pulses per chirp, chirp duration, and dominant frequency loaded most heavily on PC1 (Table 2.3). Pulse duration, pulses per chirp, and chirp duration all increased with one another. However, dominant frequency decreased as the other signalling parameters increased. These parameters are usually the ones that females select for (Wagner and Hoback, 1999), suggesting that males with high PC1 scores produce signals that are most attractive to females. Therefore, $\mathrm{PC} 1$ is most representative of an overall measure of signal quality. The second principle component explained $20 \%$ of the variation in signalling behaviour. Pulses per chirp, chirp duration, amplitude and time spent signalling loaded most heavily on PC2. These variables are also selected for by females (Wagner and Hoback, 1999), suggesting that PC2 is also representative of signal quality. The third principle component explained $13 \%$ of the variation and loaded most heavily on dominant frequency and time spent signalling. These 
parameters are indicative of signalling effort. Individuals with high PC3 scores called for a long time each night, likely attracting more females than males with low PC3 scores. This finding suggests that PC3 is an overall measure of signalling quantity.

Table 2.3: The eigenvectors from a multivariate Principle Component Analysis of signalling parameters.

Signalling Parameter PC1 Eigenvector PC2 Eigenvector PC3 Eigenvector

\begin{tabular}{lrrr}
\hline Pulse duration & 0.464 & 0.158 & -0.052 \\
Pulses per chirp & 0.460 & -0.429 & 0.216 \\
Chirp duration & 0.432 & -0.542 & 0.177 \\
Amplitude & 0.371 & 0.449 & -0.246 \\
Frequency & -0.415 & -0.105 & 0.612 \\
Time spent signalling & 0.277 & 0.534 & 0.696 \\
Eigenvalue & 2.942 & 1.198 & 0.758
\end{tabular}

Age Effects on Signalling Behaviours

To investigate whether there were any age affects on the signalling behaviour of male G. assimilis, I performed both univariate and multivariate analyses (univariate analyses and figures shown in Appendix 1). I used a general least squares model that explored how PC1 (signalling quality), PC2 (signalling quality) and PC3 (signalling quantity) were influenced by the individual, age, and individual by age interactions. These models were highly significant (Table 2.4, Figure 2.2). Overall, they suggest that both the quality and quantity of signalling increases with increasing age. However, there was a lot of variation in the way that age affected signalling quality and quantity across individuals (significant interaction effects); for many males signalling quality and quantity increased with age while in others, signalling 
quality and quantity decreased with age (significant interaction between individual and age).

Table 2.4: The effects of age on the Principle Components of signalling in male $G$. assimilis. Signalling was quantified from 8 to 21 days of adult age.

\begin{tabular}{lllll} 
Signalling Parameter & $\mathbf{R}^{\mathbf{2}}$ adj & Parameter & $\mathbf{F}$ & $\mathbf{P}$ \\
\hline PC1 & 0.626 & Whole model & 11.86 & $*<\mathbf{0 . 0 0 0 1}$ \\
& & Individual & 19.93 & $*<\mathbf{0 . 0 0 0 1}$ \\
& & Age of Cricket & 16.89 & $*<\mathbf{0 . 0 0 0 1}$ \\
& & Individual ${ }^{*}$ Age & 3.737 & $*<\mathbf{0 . 0 0 0 1}$ \\
\hline PC2 & 0.747 & Whole model & 20.14 & $*<\mathbf{0 . 0 0 0 1}$ \\
& & Individual & 36.30 & $*<\mathbf{0 . 0 0 0 1}$ \\
& & Age of Cricket & 0.602 & 0.4382 \\
& & Individual $*$ Age & 4.163 & $*<\mathbf{0 . 0 0 0 1}$ \\
\hline PC3 & 0.689 & Whole model & 15.36 & $*<\mathbf{0 . 0 0 0 1}$ \\
& & Individual & 28.18 & $*<\mathbf{0 . 0 0 0 1}$ \\
& & Age of Cricket & 8.144 & $* \mathbf{0 . 0 0 4 5}$ \\
& & Individual $*$ Age & 2.643 & $*<\mathbf{0 . 0 0 0 1}$
\end{tabular}



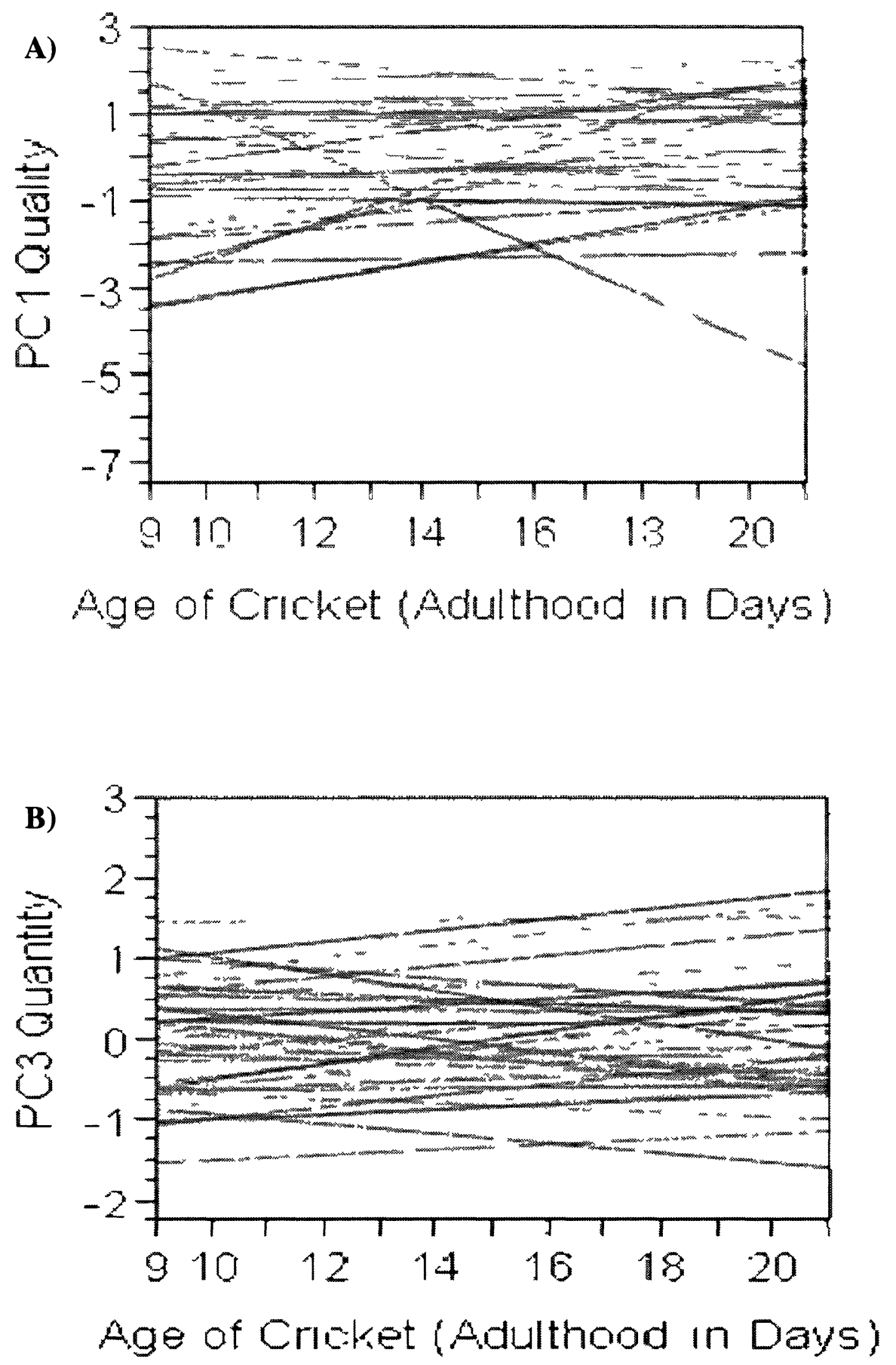

Figure 2.2: The influence of age (number of days past final moult) on the a) signalling quality (PC1), and b) signalling quantity (PC3) of male G. assimilis. 
Condition, Mass and Size Effects

Neither PC1 (signalling quality), PC2 (signalling quality), nor PC3 (signalling quantity) were correlated with body condition (Table 2.5; univariate statistics and figures shown in Appendix 1). Larger, heavier males had lower PC3 values than smaller, lighter males suggesting that smaller, lighter males may have signalled with higher effort. However, this finding was likely driven by the fact that larger males produced signals with lower dominant frequencies (Table 2.5; Figure 2.3; Appendix 1). None of the other principle components were influenced by variation in body mass or size (Table 2.5).

Table 2.5: Influence of body condition, mass, and size on the Principle Components of signalling in male $G$. assimilis. Male signalling behaviour was quantified from days 8 to 21 of adulthood, and then averaged to produce a mean value for each call parameter for each male.

\begin{tabular}{llrrrr} 
Body Parameter & Call Parameter & $\mathbf{R}_{\text {adj }}^{\mathbf{2}}$ & $\mathbf{F}$ & $\mathbf{T}$ & $\mathbf{P}$ \\
\hline Condition & PC1 & 0.021 & 0.033 & 0.18 & 0.8571 \\
& PC2 & 0.019 & 0.092 & -0.30 & 0.7627 \\
\multirow{3}{*}{ Mass } & PC3 & 0.010 & 0.502 & -0.71 & 0.4822 \\
& PC1 & 0.011 & 0.456 & 0.68 & 0.5028 \\
Size & PC2 & 0.002 & 1.112 & -1.05 & 0.2970 \\
& PC3 & 0.188 & 12.11 & -3.48 & $\boldsymbol{* 0 . 0 0 1 1}$ \\
& PC1 & 0.014 & 0.315 & 0.56 & 0.5776 \\
& PC2 & 0.031 & 2.535 & -1.59 & 0.1181 \\
& PC3 & 0.212 & 13.94 & -3.73 & $\boldsymbol{*} \mathbf{0 . 0 0 0 5}$
\end{tabular}



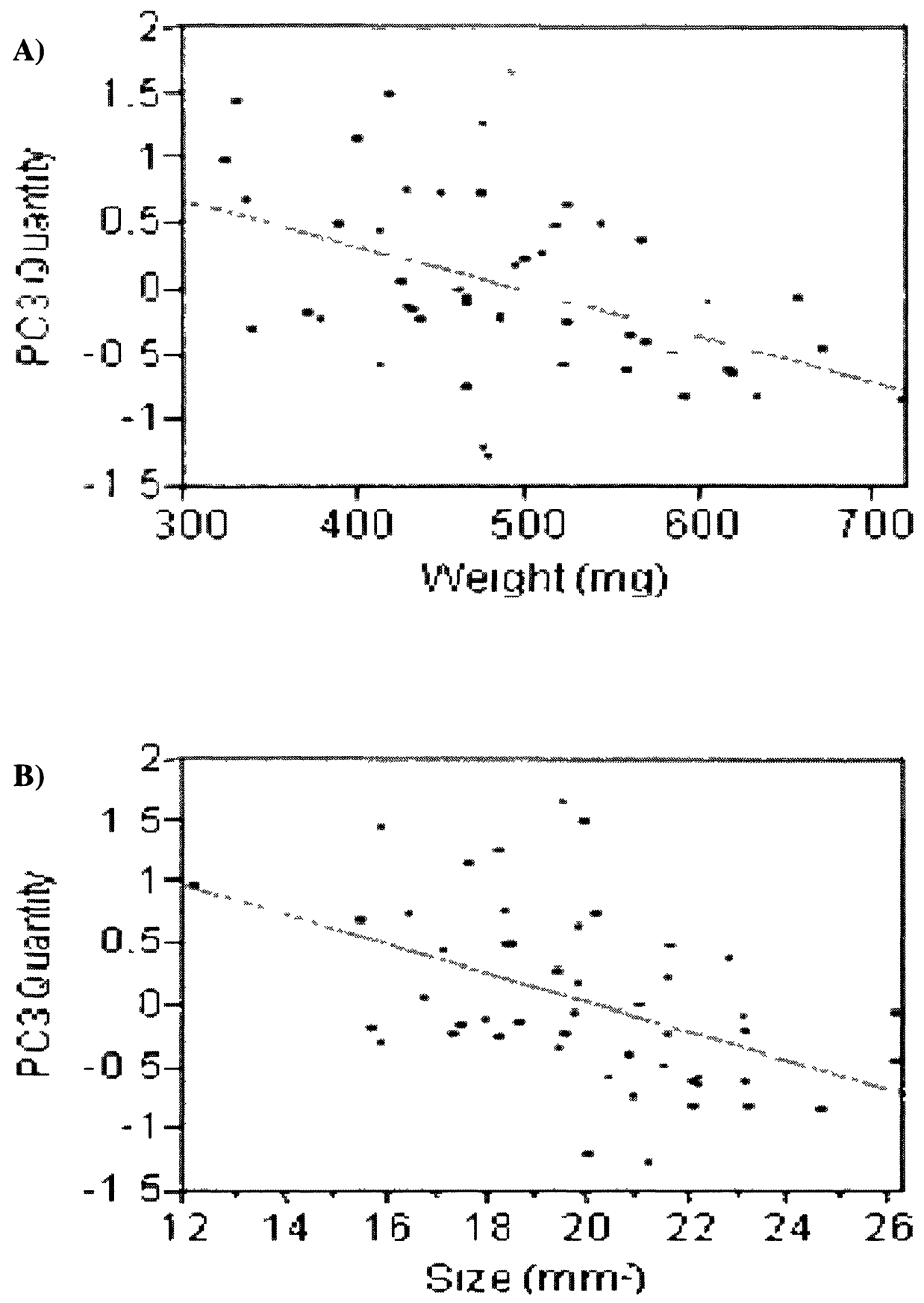

Figure 2.3: Influence of a) mass ( $\mathrm{mg}$ ) and b) s1ze (pronotum area $\mathrm{mm}^{2}$ ) on PC3 (Quantity) for control group G. assimilis males from age 8 to 21 days of adulthood. 


\section{Discussion}

\section{Correlations among Acoustic Signalling Parameters}

Bertram and Warren (2005) suggested that male crickets may be forced to make trade-offs between their different signalling parameters due to the risks associated with signalling such as predators or energetic demands, or because of biomechanical and/or physiological constraints. They suggested that if energy is allocated to one parameter in high amounts, then other parameters may not be able to be produced at the quality that females may prefer. For example, males with high effort signalling may not produce the highest quality call because much of their energy is allocated towards producing large amounts of signalling. In an experiment where all males were fed unlimited food and water, the variation in the acquisition of resources between males has been decreased or removed, allowing for the allocation of these resources to be looked at alone. My findings contradict Bertram and Warren's (2005) suggestions on the allocation of energy and resources. I found that all of the signalling parameters were significantly correlated to each other and thus energy and resources me be possibly allocated in equal amounts to the different signalling parameters. There were positive relationships between all signalling parameters, except for dominant frequency, which had a negative relationship with the other parameters. As such, individuals that produced the most attractive signals (long chirp duration, high pulses per chip and amplitude, and lower dominant frequency; Wagner \& hoback, 1999; Scheuber et al., 2003) also signalled most often throughout the evening. Because of the positive correlations between signalling effort and other signalling parameters, female $G$. assimilis who are trying to mate with a male that is of highest quality and who produces signals most often would be able to 
assess male quantity using signalling quality alone, without having to wait long periods of time to assess signalling quantity. Signalling parameters in birds may also have a similar effect as female may be able to use multiple signalling factors concurrently to determine whether they want to mate with the male or not. For example, Buchanan and Catchpole (1997) investigated the importance of potential cues from male songs on mate choice in the sedge warbler, Acrocephalus schoenobaenus. Repertoire size and song-flight (measures of quantity and quality) had a significant influence on mate choice and pairing of males and females, suggesting that females may be able to use multiple factors in choosing mates, instead of just one at a time.

\section{Age and Signalling Behaviours}

Age affected all of the signalling parameters measured. However, there were interaction effects between age and individuals. For many individuals, as age increased, so did the signalling quality and quantity, suggesting that male attractiveness may be influenced by age. There were, however, some individuals that decreased their signalling quality and quantity with increasing age. These individuals may have been making the best of a bad situation and signalling the best they could for as long as they could, before their signalling quality and quantity declined.

Females often discriminate between the signals of older and younger males, preferring the signals of older males (Robinson \& Hall, 2002). Models of sexual selection suggest that this may occur because old age is an indication of high viability, which could be heritable (Jacot et al., 2007). In the field cricket, $G$. campestris, dominant frequency decreases with increasing age. This results in an 
increase in male sexual attractiveness with increasing age, as female G. campestris prefer signals of low dominant frequency (Jacot et al., 2007). Dominant frequency may, therefore, be an indicator of a male's ability to survive to an old age, which should indirectly benefit the female if genetically determined, by providing her offspring with traits associated with survival to old age. Age effects on signalling have also been observed in the Texas field cricket, $G$ texensis. Middle-aged crickets call significantly more than young and very old crickets (Bertram, 2000).

Males may alter their signalling behaviour with increasing age due to the presence of predators or parasites that could shorten their life span. Older males may increase their signalling behaviour because they are more concerned with attracting a mate than being harmed from an attack. The parasitoid fly, Ormia ochracea, orients to the same signals that male field crickets produce to attract females. Ormia ochracea are most active from sunset to midnight and normally parasitize by laying larvae on or around signalling crickets (Bertram, 2000; Robinson \& Hall, 2002). The larvae then burrow into the cricket, where they can feed and grow until the host's death, which occurs within a week. Orimiine flies typically parasitize G. rubens and G. texensis; however, they are not host specific, and are attracted to various other cricket species that both chirp and trill such as G. assimilis, G. fultoni, G. integer, $G$. firmus, Orocharis luteolira and Scapteriscus borellii (Robinson \& Hall, 2002). Young males may signal less often than older males to reduce the risk of parasitism and probable death if the costs of being parasitized outweigh the benefits of mating with a female (Bertram, 2000). In contrast, older males may allocate more energy to signalling, to ensure mating will occur, as death may occur in the near future regardless of being parasitized. 
Once a male reaches a certain age, signalling quality can be influenced due to wear of the stridulatory apparatus. Degenerative changes to the file after long periods of signalling, such as abrasion or breaking of the teeth may cause the song structure to alter over time. This typically makes the songs less attractive (Robinson \& Hall, 2002). Males who call less often when they are young may be able to prolong their attractive signalling ability into older age than young males who call very often. These factors may also account for high variability in signalling parameters over increasing age of male G. assimilis.

\section{Influence of Condition, Mass and Size}

Dominant frequency decreased with both increasing mass and size. Body size, the size of a male's harp (resonant structure found on the male hind wings), and the speed of wing closure all have an effect on dominant frequency (Martin et al., 2000; Bailey et al., 2001; Whattam, 2009). Juvenile condition influences adult body size (which is stable following final moult) (Schuber et al., 2003). As such, it would be unlikely to observe any significant changes in the dominant frequency of an individual male's call, unless more effort and energy are allocated to this signalling parameter. In other field cricket species, insects, and anurans, larger males also produce signals at lower frequencies than smaller males. Females often prefer larger males that have a lower dominant frequency (Scheuber et al., 2004). My findings therefore suggest that female $G$. assimilis could use male dominant frequency as an indicator of male size. This idea agrees with the current literature for this species (Whattam, 2009). 
Female preference for certain signalling parameters and effort tends to increase with increasing energy expenditure (Wagner \& Hoback, 1999). Males that are in good condition and larger in size should, therefore, have more energy to allocate to signalling behaviour than males in poor condition, which should result in their being more attractive to females. I did not, however, find any relationship between male condition and acoustic mate attraction displays. Bertram (2000) similarly found that male condition did not explain any of the variation in either time spent signalling or signalling quality. It is somewhat surprising that I did not observe a relationship between condition and signalling quality or quantity, as signalling is thought to be an honest signal of male condition when attracting females (Nelson \& Nolen, 1997). The use of residual mass in calculating condition should be an accurate measure of condition in G. assimilis given that previous studies on G. assimilis found that adult males fed reduced diets were in significantly worse condition than males fed ad libitum (Whattam, 2009). Whattam's (2009) finding suggests that residual mass is an appropriate measure of condition. The indicator hypothesis predicts that sexually selected traits are positively correlated with condition. My lack of correlations suggests no strong support for the indicator hypothesis in this species.

\section{Future Research and Considerations}

All of my crickets were provided with unlimited access to food throughout my experiment to observe the allocation of resources equally between males. It is possible, therefore, that not only was the acquisition of resources low in variation but also the amount of variation in condition was quite low compared to what might occur in nature, especially given males don't usually have unlimited access to food. 
Thus, my finding that there is no relationship between condition and signalling may result from all the males being in relatively good condition. To really test this idea, it would be helpful to place males on one of two different diets (high and low) throughout development and then monitor their signals to test both the acquisition and allocation. Being in good or poor condition prior to analyzing signalling behaviour could have allowed me to more easily quantify the effects of condition on signalling behaviour.

Future studies should also assess whether onboard fuels such as whole body lipid stores or lipid within signalling muscles provide insights into understanding the variation in signalling behaviour. Further, it would be helpful to understand the relationship between hormone levels and signalling behaviour. Finally, it would be helpful if future studies quantified variation in the male stridulatory apparatus to determine whether degenerative changes to the file explain the relationship between age and signalling. 
Chapter 3: Interplay Between Aggression, Signalling, Courtship, Mating, and Condition 


\section{Abstract}

Males in good condition are often better at winning aggressive interactions and producing the sexiest mate attraction signals. However, most insect behavioural research has not explored the interplay between aggression and signalling behaviour and how the two combine to influence mating success and lifetime reproduction. I investigated whether male aggression and acoustic mate attraction signalling were indicators of condition and whether they influenced subsequent courtship, mating, and egg laying using the Jamaican field cricket, Gryllus assimilis. I quantified condition, aggression, and mate attraction signalling in 162 males. I then placed individual males with a virgin female and quantified their courtship behaviour, mating behaviour, and subsequent egg production. There were no significant results suggesting that highly aggressive males courted females more often than less aggressive males. Further, winners were no better courters than losers. Further, male attraction signals did not predict the probability of winning the aggressive contest. However, there were non-significant relationships between mate attraction signalling behaviour and subsequent courtship and mating behaviours. Male condition, mass, and/or size did not influence acoustic mate attraction displays, aggressive behaviours, courtship behaviours, or mating behaviours. Males did, however, court heavier females more vigorously than lighter females; and heavier females laid more eggs than lighter females. Overall, my findings suggest that cricket mass and male aggression both subtly influence courtship behaviours and subsequent mating behaviours. 


\section{Introduction}

When resources are allocated to sexually selected traits, they are depleted from other fitness enhancing traits. Because sexually selected traits are costly to express, they should continually drain the resources being allocated and, as such, should be representative of condition (Rowe \& Houle, 1996). When individuals are in good condition, they should have a large resource pool and be better able to allocate resources to their many competing demands. Therefore, higher condition individuals should be better able to pay the higher costs of further exaggerating their traits compared to individuals that are in poorer condition. Condition dependence is thus expected to arise in sexually selected traits that have evolved via the indicator mechanism (Rowe \& Houle, 1996).

Provided sexually selected traits have evolved via the indicator mechanism, traits used in both fighting (male-male competition) and mate attraction signalling (mate choice) should be honest indicators of one's condition. If aggressive displays and attractive displays are indicators of condition, then a male who is a better fighter should also be a good signaller, increasing his tendency to be chosen by a female and mate (Maynard Smith, 1991). Males who are in better condition should therefore have higher reproductive success than males in lower condition (Bateman et al, 2001). Brown (2008) demonstrated this in the black horned tree cricket (Oecanthus nigricornis). Larger males mated more often than smaller males, possibly due to the fact that they could out-compete their rivals.

By mating with a male that is successful in his fighting competitions, a female may be able to ensure that she is mating with a male that is of superior condition (Savage et al, 2004). Following aggressive contests involving male European house 
crickets, Acheta domesticus, Nelson and Nolen (1997) found that if a female cricket was immediately introduced to the winner and the loser, the winner would be more likely to court and mate than the loser (Nelson \& Nolen, 1997). Burk (1983) also found that males that recently lost aggressive contests in the field cricket, Teleogryllus oceanicus were less likely to produce courtship songs after encountering females than males that won aggressive contests. Given this, male size, condition, aggression and the outcome of prior fights may directly influence courtship behaviour and subsequent mating success (Wagner \& Hoback, 1999; but see Shackleton et al, 2005).

If mate choice has arisen through the indicator mechanism, then males in the best condition should also produce the most attractive signals and display most often. Female choice of high effort and/or high quality signallers would thus ensure that choosy females receive better genes that can then be passed on to ensure offspring also have a greater chance of being in good condition (Maynard Smith, 1976; 1991). For example, Kotiaho (2000) found that male wolf spiders, Hygrolycosa rubrofasciata, had a higher rate of signalling (drumming their abdomens) when fed ad libitum and were in better condition than males on food restricted diets. Further in the presence of a female, ad libitum fed males increased their signalling behaviour more than food restricted males. High signalling rates are preferred by females and should increase a male's attractiveness (Kotiaho 2000). Mate attraction signalling ability may thus be dependent upon body condition, which may in turn be able to affect male mating success.

It is also possible, however, that males in poor condition might be selected to make the best of a bad situation and invest most of their energy into current signal 
production to ensure reproduction instead of conserving resources for future reproduction (Wagner \& Hoback, 1999; Gray \& Eckhardt, 2001). Candolin (1999) found that male three-spined stickleback, Gasteroteus aculeatus, in poor condition often invest more into their current signalling effort when their future reproductive prospects are limited than males in good condition (Candolin, 1999). Thus, under certain circumstances, there may be no correlation between body condition and signal structure, even though males in better condition usually have the resources to produce attractive signals more frequently (Wagner \& Hoback, 1999).

Here I investigate how aggression, mate signalling, and condition interact to influence courtship, mating, and subsequent reproductive output using a field cricket. Male field crickets frequently engage in aggressive contests to gain access to food, territories, and/or to establish dominance in social interactions (Alexander 1961; described in detail in Chapter 1). In their territory, males produce long-range acoustic signals to attract potential mates (described in detail in Chapter 2). Males then switch to producing short-range courtship song once a female has entered the territory. When contact has been made between the female and male, he begins to stroke her with his antennae to excite her. This combination of singing and stroking often entices her to climb onto his back (mount; Shackleton et. al., 2005). The male then packages his semen into a spermatophore and passes it to the female. Females can store sperm for up to two weeks (Alexander, 1961). Female crickets lay their eggs by inserting their long, thin ovipositor into moist dirt (Alexander, 1961). The number of eggs laid by females typically range from 0-700 eggs (Gershman, 2010).

Because both aggressive behaviours and mate attraction signals should theoretically be honest indicators of condition, it is important to understand how 
condition, aggression and mate signalling interact to influence reproductive success. To date, however, most cricket studies have not explored the interplay between all of these factors. Instead they have focused either only on aggression (Parker, 1974; Adamo \& Hoy, 1995; Hofmann \& Schildberger 2001; Briffa, 2008; Jang et al, 2008), only on signalling (Wagner \& Hoback, 1999; Bertram, 2000; Robinson \& Hall, 2002; Bertram \& Warren, 2005), the interplay between aggression and mating (Bateman \& Toms, 1998; Kortet \& Hedrick, 2005; Shackleton et al, 2005; Brown et al, 2006), or the interplay between signalling and mating (Balakrishnan \& Pollack, 1996; Hack, 1997; Gray \& Eckhardt, 2001; Holzer et al, 2003; Simmons, 2004). Here I explore how all three components (condition, aggression, and mate attraction signalling) interact to influence courtship and subsequent mating and reproduction. Specifically my study addresses the following questions: Are high effort/sexy callers more aggressive and/or more likely to win fights than low effort/sexy callers? Are fight winners more likely to court/mate quickly and/or produce more offspring than losers? Are high effort/sexy callers more likely to court/mate quickly and/or produce more offspring than low effort/sexy callers? Finally, I explore whether body mass, size and/or condition influence courtship, mating, and offspring production. Addressing these questions should allow me to determine whether competitive ability and mate signalling are indicators of condition and influence reproductive success in crickets.

\section{Methods}

Acoustic Recordings and Aggressive Contests

Males and females were captured, reared, treated, and weighed in the same manner as described in Chapter 1. Males were placed into the NEARS containers on 
day seven of adulthood, for seven consecutive days (Day 7 - 14) to quantify signalling behaviour. On day 14 of adulthood, aggression was quantified by pairing 124 males into 62 dyadic fighting contests (2/3 of the males) and 53 males were places in to control trials ( $1 / 3$ of males; see Chapter 2 for description). Once fights and control trials were completed, all males were placed back into the NEARS to analyze signalling behaviour for another seven days (Day $14-21$ ). See Chapter 1 for a detailed description of quantifying fighting behaviour; see Chapter 2 for a detailed description of quantifying acoustic mate attraction signalling behaviour.

\section{Mating Trial}

On day 21 all males were removed from the NEARS, placed singly into a clear plastic container for two minutes to allow them to acclimatize, and then paired randomly with a lone virgin female. Females were of known age, mass, and all females were at least 10 days post final moult prior to mating. Mating trials were conducted between $900 \mathrm{~h}$ and $1200 \mathrm{~h}$. Their courtship and mating behaviours were observed and filmed in real time from above using a colour video camera (Canon HG10). Trials were later examined in slow motion (50\% to $75 \%$ slower than real time speed) to determine the latency to first contact, latency to initiate courtship song, latency to copulation, and whether a spermatophore was transferred. I also scored the number of courtship songs, duration of courtship songs, and duration the female was mounted. Trials were approximately $10 \mathrm{~min}$ in duration, but were terminated early if mating occurred and a spermatophore was passed from the male to the female. If the male cricket was still trying to court, or the male and female were mating at the 10 
min mark, the trial was continued until courtship had ceased or the spermatophore was transferred.

Males and females were left paired in their containers and placed back into the NEARS for 48 hours (Day 21-23). Females were removed from the NEARs on day 23. Males remained in the NEARS for 4 more days ( 7 days in the NEARS after the mating trial). Females were individually housed with an egg dish for two weeks (Day 23-36). After laying eggs for two weeks, females were removed and placed back into the adult colony. All eggs laid by each female were then sifted and counted.

\section{Size, Mass and Condition Measures}

Upon conclusion of the experiment males were euthanized (described in Chapter 1). Size and condition were then quantified (described in Chapter 1). I used condition, size, and mass and assessed their relationships with courtship behaviours. Female mass was taken at least one day prior to mating trial using a Pinnacle Series analytical balance (model PI-314).

\section{Statistical Analysis}

A Principle Component Analysis was performed on all aggressive behaviours for the experimental males who participated in the fighting trials. A second Principle Component Analysis was performed on all acoustic mate attraction signalling parameters for all experimental and control males signalling during the week prior to the fighting contest. Finally, a third Principle Component Analysis was performed on all courtship behaviours for the experimental and control males. Logistic regressions, ANOVA and pairwise analyses were used to quantify whether the winner or loser of a 
fighting contest influenced subsequent signalling or mating behaviours. I performed linear regressions to assess the relationship between different mating parameters, to explore which parameters were influenced by size and condition, and to identify which factors influenced mating success and lifetime reproduction. Also I used t-tests to ascertain whether males who mated during the 10 -min observation trials were heavier, bigger or in better condition than males who did not mate. I used a false discovery rate B-Y adjustment $(\alpha<0.0083)$ to account for the 230 statistical tests I performed.

\section{Results}

Does signalling ability predict aggression levels and fighting outcome?

No univariate or multivariate signalling parameters significantly predicted whether a male would win or lose the fighting contest. Males who produced sexy mate attraction signals were no more likely to win their aggressive contests than males who were poor signalers (Table 3.1). These findings suggest that signalling quantity and quality are not indicative of fighting outcome. Paired t-tests revealed that there was also no difference between winners and losers in their long-distance mate attraction signalling behaviours (Table 3.2). Further, there were no relationships between signalling behaviour and fight aggressiveness (Table 3.3). 
Table 3.1: The relationship between acoustic mate attraction displays and the probability of winning or losing a fight in G. assimilis (Logistic regression).

\begin{tabular}{lccc} 
Signalling Parameter & $\mathbf{R}^{\mathbf{2}}$ & $\mathbf{C h i}^{\mathbf{2}}$ & $\mathbf{P}>\mathbf{C h i}^{\mathbf{2}}$ \\
\hline Time spent signalling & 0.002 & 0.314 & 0.5754 \\
Pulse duration & 0.014 & 2.019 & 0.1554 \\
Interpulse duration & 0.001 & 0.074 & 0.7856 \\
Pulses per chirp & 0.002 & 0.220 & 0.6390 \\
Chirp duration & 0.003 & 0.440 & 0.5073 \\
Interchirp duration & 0.000 & 0.003 & 0.9537 \\
Amplitude & 0.006 & 0.832 & 0.3616 \\
Frequency (Hz) & 0.001 & 0.084 & 0.7716 \\
PC1 Signalling Before & 0.003 & 0.498 & 0.4803 \\
PC2 Signalling Before & 0.007 & 0.949 & 0.3299 \\
PC3 Signalling Before & 0.000 & 0.051 & 0.8209
\end{tabular}

Table 3.2: Do winners and losers differ in their acoustic long distance mate attraction signals? Paired t-tests suggest they do not.

\begin{tabular}{lrrrr} 
Matched Pairs & X Winner & X Loser & T-ratio & Prob $|\mathbf{t}|$ \\
\hline Pulse Duration & 9.623 & 9.174 & 1.40 & 0.1670 \\
Interpulse Duration & 16.58 & 16.37 & 0.62 & 0.5358 \\
Pulse per Chirp & 7.634 & 7.577 & 0.23 & 0.8209 \\
Chirp Duration & 116.6 & 114.8 & 0.49 & 0.6266 \\
Interchirp Duration & 1755 & 1780 & -0.23 & 0.8207 \\
Amplitude & 46.04 & 43.93 & 1.02 & 0.3116 \\
Frequency & 3806 & 3819 & -0.23 & 0.8231 \\
Time Spent Signalling & 203.1 & 230.2 & -0.92 & 0.3603 \\
PC1 Signalling Before & 0.149 & -0.052 & 0.59 & 0.5553 \\
PC2 Signalling Before & -0.054 & 0.135 & -1.02 & 0.3112 \\
PC3 Signalling Before & -0.005 & 0.048 & -0.41 & 0.6835
\end{tabular}


Table 3.3: Influence of signalling parameters and signalling quality and quantity on the number of observed aggressive behaviours and the duration of aggressive behaviours of the fighting contests.

\begin{tabular}{llrrrr}
$\begin{array}{l}\text { Aggression } \\
\text { Parameter }\end{array}$ & Parameter & $\mathbf{R}^{\mathbf{2}} \mathbf{a d j}$ & $\mathbf{F}$ & \multicolumn{1}{c}{$\mathbf{t}$} & $\mathbf{P}$ \\
\hline Number of & Pulse duration & 0.004 & 0.605 & 0.78 & 0.4386 \\
Observations & Interpulse duration & 0.006 & 0.411 & -0.64 & 0.5228 \\
& Pulses per chirp & 0.002 & 0.836 & 0.91 & 0.3625 \\
& Chirp duration & 0.006 & 0.394 & 0.63 & 0.5316 \\
& Interchirp duration & 0.009 & 0.019 & -0.14 & 0.8900 \\
& Amplitude & 0.004 & 1.442 & 1.20 & 0.2326 \\
& Frequency & 0.010 & 0.008 & -0.09 & 0.9272 \\
& Time spent signalling & 0.003 & 0.627 & -0.79 & 0.4303 \\
& PC1 Signalling & 0.005 & 0.483 & 0.70 & 0.4884 \\
& PC2 Signalling & 0.006 & 0.349 & -0.59 & 0.5562 \\
& PC3 Signalling & 0.009 & 0.020 & -0.14 & 0.8883 \\
\hline Duration of & Pulse duration & 0.004 & 0.620 & 0.79 & 0.4329 \\
Behaviours & Interpulse duration & 0.005 & 0.433 & -0.66 & 0.5118 \\
& Pulses per chirp & 0.005 & 1.502 & 1.23 & 0.2232 \\
& Chirp duration & 0.003 & 1.320 & 1.15 & 0.2533 \\
& Interchirp duration & 0.008 & 0.145 & -0.38 & 0.7041 \\
& Amplitude & 0.008 & 0.136 & 0.37 & 0.7134 \\
& Frequency & 0.009 & 0.080 & -0.28 & 0.7783 \\
& Time spent signalling & 0.007 & 0.228 & -0.48 & 0.6340 \\
& PC1 Signalling & 0.004 & 0.569 & 0.75 & 0.4523 \\
& PC2 Signalling & 0.001 & 1.093 & -1.05 & 0.2983 \\
& PC3 Signalling & 0.002 & 0.768 & 0.88 & 0.3828
\end{tabular}




\section{Courtship and Mating}

During the 10 -min mating trial, $53 \%$ of the males successfully mated and passed their spermatophore to the female (Table 3.4). Males took an average of $53 \pm 7 \mathrm{~s}$ to contact the female. Males took a further $87 \pm 9$ s to perform their first courtship song. Courtship songs were performed once for an average of $34 \pm 4 \mathrm{~s}$. Females mounted their mates an average of $36 \pm 6 \mathrm{~s}$ after the start of their mate's first courtship song (201 $\pm 17 \mathrm{~s}$ after first contact). Once a female had mounted a male, it took an average of $20 \pm 1 \mathrm{~s}$ for the male to pass his spermatophore to the female. Pairs were housed together for a further 48 hours following the conclusion of the 10-min mating trial. Almost all of the pairs (98\%) mated at some point during this study (either during the 10 min mating trial or during the 48 hours they were held together; assessed by the presence of cricket eggs). Females laid a mean of $316 \pm 13$ eggs in the following 2 weeks (Table 3.4).

Table 3.4: Descriptive statistics of all G. assimilis mating parameters.

\begin{tabular}{lcccr}
\multicolumn{1}{c}{ Mating Parameter } & Mean & Std Err & Min & Max \\
\hline Time to first contact (s) & 52.57 & 6.93 & 1 & 685 \\
Time from first contact to courtship call (s) & 86.50 & 9.46 & 2 & 652 \\
Total courtship call time (s) & 34.03 & 4.16 & 3 & 455 \\
Number of courtship signals & 1.020 & 1.10 & 1 & 6 \\
Time from contact to mount (s) & 200.9 & 16.8 & 8 & 718 \\
Number of mounting attempts & 0.820 & 0.09 & 1 & 9 \\
Total time mounted (s) & 20.16 & 1.20 & 2 & 191 \\
Egg Count & 316.0 & 12.8 & 5 & 690 \\
Number of judders & 4.500 & 0.36 & 1 & 25 \\
Length of aggression song & 1.820 & 0.91 & 1 & 132
\end{tabular}


Almost all courtship measures were strongly correlated with one another (Table 3.5). For example, some males took a long time to begin their courtship call after coming into contact with females. These males performed their courtship song for a long period of time and had to perform more courtship songs before females would mount them. Males also took a long time to pass their spermatophores. Because of these correlations, we term these individuals the slow-to-mate males (Table 3.5). Conversely, the fast-to-mate males took less time to begin their courtship call after coming into contact with a female. They also performed fewer courtship calls and the courtship calls were shorter in duration, likely because the female mated with them very quickly. These males also took less time to pass their spermatophores to the females (Table 3.5). Slow-to-mate males and fast-to-mate males form the two ends of a continuum.

Since courtship and mating parameters were highly correlated, I performed a Principle Component Analysis to reduce the number of variables. The first principle component explained 52\% of the variation and loaded most heavily on time from first contact to courtship call, total courtship call time, number of courtship signals, and time from first contact to mount (Table 3.6). These loadings suggest that the slow-tomate males have high PC1 scores (males need to invest a much higher effort into courtship before a female will mount them and copulation ensues) while the fast-tomate males have low PC1 scores (males only court females for a short period of time before the female mounts them and copulation ensues). The second principle component explained $18 \%$ of the variation and loaded most heavily on time from first contact to courtship song and time from first contact to mount (Table 3.6). Because both of these parameters have negative loadings, it suggests that high PC2 scores 
represent males with a high courtship effort and low PC2 scores represent males with low courtship effort. The third principle component explained $16 \%$ of the variation and loaded most heavily on total time mounted (Table 3.6). It is difficult from our study to ascertain whether being mounted for a long time is a good thing or not.

Table 3.5: Correlations and probabilities between courtship behaviour parameters.

\begin{tabular}{|c|c|c|c|c|}
\hline Variables & $\begin{array}{l}\text { First contact to } \\
\text { courtship call }\end{array}$ & $\begin{array}{l}\text { Number of } \\
\text { courtship } \\
\text { calls }\end{array}$ & $\begin{array}{l}\text { Total call } \\
\text { time }\end{array}$ & $\begin{array}{c}\text { First } \\
\text { contact to } \\
\text { mount }\end{array}$ \\
\hline $\begin{array}{c}\text { Number of } \\
\text { courtship calls }\end{array}$ & $\begin{array}{r}0.3578 \\
\mathrm{P}=*<0.0001\end{array}$ & & & \\
\hline Total call time & $\begin{array}{r}0.3766 \\
\mathrm{P}=*<\mathbf{0 . 0 0 0 1} \\
\end{array}$ & $\begin{array}{r}0.6116 \\
\mathrm{P}=*<0.0001 \\
\end{array}$ & & \\
\hline $\begin{array}{l}\text { First contact to } \\
\text { mount }\end{array}$ & $\begin{array}{r}0.6292 \\
\mathrm{P}=*<\mathbf{0 . 0 0 0 1}\end{array}$ & $\begin{array}{r}0.3437 \\
\mathrm{P}=*<\mathbf{0 . 0 0 0 1} \\
\end{array}$ & $\begin{array}{r}0.3561 \\
\mathrm{P}=*<0.0001 \\
\end{array}$ & \\
\hline $\begin{array}{c}\text { Total time } \\
\text { mounted }\end{array}$ & $\begin{array}{r}0.1932 \\
P=\mathbf{0 . 0 1 5 0}\end{array}$ & $\begin{array}{r}0.3307 \\
\mathrm{P}=*<0.0001\end{array}$ & $\begin{array}{r}0.3316 \\
\mathrm{P}=*<0.0001\end{array}$ & $\begin{array}{r}0.3884 \\
\mathrm{P}=*<0.0001\end{array}$ \\
\hline
\end{tabular}

Table 3.6: The eigenvectors from a multivariate Principle Component Analysis of the courtship parameters.

Courtship Parameter

First contact to courtship call

Total call time

Number of courtship signals

Total time mounted

First contact to mount

Eigenvalue

Percentage
PC1

Eigenvector

0.451

0.470

0.464

0.367

0.476

2.583

$52 \%$
PC2

Eigenvector

$-0.567$

0.409

0.440

0.263

$-0.499$

0.915

$18 \%$
PC3 Eigenvector $-0.238$ $-0.314$ $-0.310$

0.845

0.185

0.786

$16 \%$ 
Relationship between Mate Attraction, Aggression, and Courtship and Mating

Prior to launching into a multivariate exploration of the relationships between mate attraction, aggression, courtship, and mating, I first explored the univariate relationships (Tables and Figures in Appendix 2). I did this to ensure I had a complete understanding of what might be happening in this system. Below I describe my univariate findings and then describe my multivariate findings.

Most of the univariate correlations between mate attraction signalling, aggression, courtship, and subsequent mating were not significant. For example, there was no significant relationship between any of the aggressive behaviours and the subsequent courtship/mating behaviours (Appendix 2). Males that spent more time chasing their opponent appeared to be mounted for longer by females than males that did not chase as frequently, though this was not quite statistically significant (Appendix 2). Individuals that were highly aggressive did not differ in their courtship or mating behaviours from individuals who were not very aggressive. Further, there was no difference in courtship and mating between winners and losers. These findings suggest that there is no real relationship between male aggression and his subsequent courtship and mating behaviours.

While there were relationships between mate attraction signalling behaviour and subsequent courtship and mating behaviour, they were subtle (Appendix 2). There were non-significant trends that as time spent signalling increased so did the time from first contact until first courtship call, suggesting that high effort callers took longer to court females. Males who called with sexy signals (longer pulse durations) and longer signals (high time spent signalling) spent more time with females mounted on them, although this was also not quite significant (Appendix 2). Further, there 
were non-significant trends suggesting that males that called with higher amplitude and lower frequency (sexy signals) also spent more time with females mounted on them. Strangely though, females that mated with males that produced longer interpulse durations (less attractive mate attraction signals) also tended to lay more eggs, though this was also not quite significant (Appendix 2). Together, these findings suggest that the relationships between male mate attraction efforts and subsequent courtship and mating behaviours are subtle at best.

My multivariate results revealed no relationships between aggressive PCA's and courtship and mating PCA's (Table 3.7; PCA statistics in Appendix 2). Further, winners did not differ from losers in their courtship behaviours or egg counts (Table 3.8). There was also no relationship between male long distance mate attraction signalling behaviour PCA's (see Chapter 2 for PCA statistics) and male courtship or mating behaviour PCA's (Table 3.7). Together these results suggest that aggressive males and/or males that produce sexy mate attraction signals do not differ in their courtship or mating behaviours from males that are less aggressive and/or produce less attractive acoustic signals. 
Table 3.7: Influence of aggression and signalling behaviours on the courtship behaviours of males and the number of eggs laid by females.

\begin{tabular}{llrrrc} 
Courtship Parameter & PCA & $\mathbf{R}^{2} \mathbf{a d j}$ & $\mathbf{F}$ & \multicolumn{1}{c}{$\mathbf{t}$} & $\mathbf{P}$ \\
\hline PC1 Courtship & PC1 Aggression Rate & 0.005 & 0.500 & -0.71 & 0.4811 \\
& PC2 Aggression Rate & 0.010 & 0.000 & -0.00 & 0.9992 \\
& PC3 Aggression Rate & 0.009 & 0.010 & 0.10 & 0.9210 \\
& PC1 Call Quality & 0.006 & 0.037 & 0.19 & 0.8490 \\
& PC2 Call Quality & 0.006 & 0.148 & -0.38 & 0.7013 \\
& PC3 Call Quantity & 0.004 & 0.333 & 0.58 & 0.5650 \\
\hline PC2 Courtship & PC1 Aggression Rate & 0.009 & 0.097 & -0.31 & 0.7558 \\
& PC2 Aggression Rate & 0.003 & 0.715 & 0.85 & 0.3998 \\
& PC3 Aggression Rate & 0.009 & 0.029 & 0.17 & 0.8649 \\
& PC1 Call Quality & 0.007 & 0.012 & 0.11 & 0.9130 \\
& PC2 Call Quality & 0.007 & 0.018 & 0.13 & 0.8938 \\
& PC3 Call Quantity & 0.004 & 0.462 & -0.68 & 0.4975 \\
\hline PC3 Courtship & PC1 Aggression Rate & 0.001 & 0.957 & 0.98 & 0.3320 \\
& PC2 Aggression Rate & 0.013 & 2.363 & -1.54 & 0.1273 \\
& PC3 Aggression Rate & 0.013 & 2.419 & 1.56 & 0.1229 \\
& PC1 Call Quality & 0.005 & 1.730 & 1.32 & 0.1904 \\
& PC2 Call Quality & 0.007 & 2.136 & 1.46 & 0.1460 \\
& PC3 Call Quantity & 0.002 & 0.771 & 0.88 & 0.3814 \\
\hline Egg Count & PC1 Aggression Rate & 0.007 & 0.265 & 0.51 & 0.6079 \\
& PC2 Aggression Rate & 0.009 & 0.074 & 0.27 & 0.7855 \\
& PC3 Aggression Rate & 0.010 & 0.020 & -0.14 & 0.8872 \\
& PC1 Call Quality & 0.002 & 0.695 & 0.83 & 0.4059 \\
& PC2 Call Quality & 0.006 & 0.127 & -0.36 & 0.7216 \\
& PC3 Call Quantity & 0.006 & 0.097 & -0.31 & 0.7557
\end{tabular}

Table 3.8: Paired t-test on the courtship behaviours. Data is subdivided into the behaviour of the winner and loser.

\begin{tabular}{lrrrr} 
Matched Pairs & X Winner & X Loser & t-ratio & Prob $|\mathbf{t}|$ \\
\hline PC1 Courtship & 0.189 & -0.143 & 1.03 & 0.3086 \\
PC2 Courtship & 0.177 & -0.068 & 1.27 & 0.2108 \\
PC3 Courtship & -0.119 & 0.118 & -1.36 & 0.1788 \\
Egg Count & 332.6 & 322.6 & 0.32 & 0.7533
\end{tabular}


Condition, Mass, and Size Affects on Courtship and Reproductive Success

Heavier males tended to spend less total time producing courtship signals during the mating trials, but these results were not quite significant. Further, females tended to remain mounted on males for a longer period of time when the males were heavier relative to themselves, in comparison to the females who were mated to males that were quite light relative to themselves, though these trends are also not quite significant (Appendix 2). Males in good condition (residual mass) also tended to initiate their courtship signals faster following first contact with the female, however these were not quite significant (Appendix 2). These results suggest that females may be slightly quicker to mate with heavier males and males in better condition.

Female mass was correlated with none of the courtship principle components and only with the number of eggs they laid. This suggests that heavier females laid significantly more eggs than lighter females (Table 3.9; Figure 3.1).

The difference between male and female size was also correlated with most of the courtship principle components. As the ratio between male and female size decreases and males become equal in size or larger than females, PC1 courtship and the number of eggs laid by female's decreases (Table 3.9; Figure 3.2). This suggests that males may be performing higher quality courtship signals as the mass ratio decreases and that females may be choosier when the mass ratio is increased. When the difference in mass was large (meaning females were larger than males) females laid more eggs, which may have just been due to the fact that heavy females lay more eggs than lighter females. 
Table 3.9: Influence of body condition, mass, and size on courtship behaviour and number of eggs laid by females mated with $G$. assimilis males.

\begin{tabular}{llrrrr} 
Condition Parameter & PCA & $\mathbf{R}^{2} \mathbf{a d j}$ & $\mathbf{F}$ & \multicolumn{1}{l}{$\mathbf{T}$} & \multicolumn{1}{l}{$\mathbf{P}$} \\
\hline Male condition & PC1 Courtship & 0.003 & 1.489 & -1.22 & 0.2242 \\
& PC2 Courtship & 0.001 & 0.892 & -0.94 & 0.3465 \\
& PC3 Courtship & 0.006 & 0.123 & -0.35 & 0.7261 \\
& Egg Count & 0.002 & 0.692 & -0.83 & 0.4068 \\
\hline Male mass & PC1 Courtship & 0.019 & 3.985 & -2.00 & 0.0476 \\
& PC2 Courtship & 0.003 & 0.477 & -0.69 & 0.4907 \\
& PC3 Courtship & 0.006 & 0.015 & 0.12 & 0.9035 \\
& Egg Count & 0.006 & 0.091 & 0.30 & 0.7629 \\
\hline Male size & PC1 Courtship & 0.008 & 2.235 & -1.49 & 0.1370 \\
& PC2 Courtship & 0.005 & 0.163 & -0.40 & 0.6872 \\
& PC3 Courtship & 0.005 & 0.142 & 0.38 & 0.7064 \\
& Egg Count & 0.004 & 0.437 & 0.66 & 0.5098 \\
\hline Female mass & PC1 Courtship & 0.019 & 4.054 & 2.01 & 0.0458 \\
& PC2 Courtship & 0.010 & 2.623 & 0.63 & 0.1073 \\
& PC3 Courtship & 0.004 & 0.391 & 2.81 & 0.3910 \\
& Egg Count & 0.089 & 16.05 & 4.01 & $*<\mathbf{0 . 0 0 0 1}$ \\
\hline Difference between male & PC1 Courtship & 0.054 & 10.07 & -3.17 & $* \mathbf{0 . 0 0 1 8}$ \\
and female mass & PC2 Courtship & 0.002 & 1.251 & 1.12 & 0.2650 \\
& PC3 Courtship & 0.005 & 0.272 & -0.52 & 0.6026 \\
& Egg Count & 0.071 & 12.77 & -3.57 & $* \mathbf{0 . 0 0 0 5}$
\end{tabular}

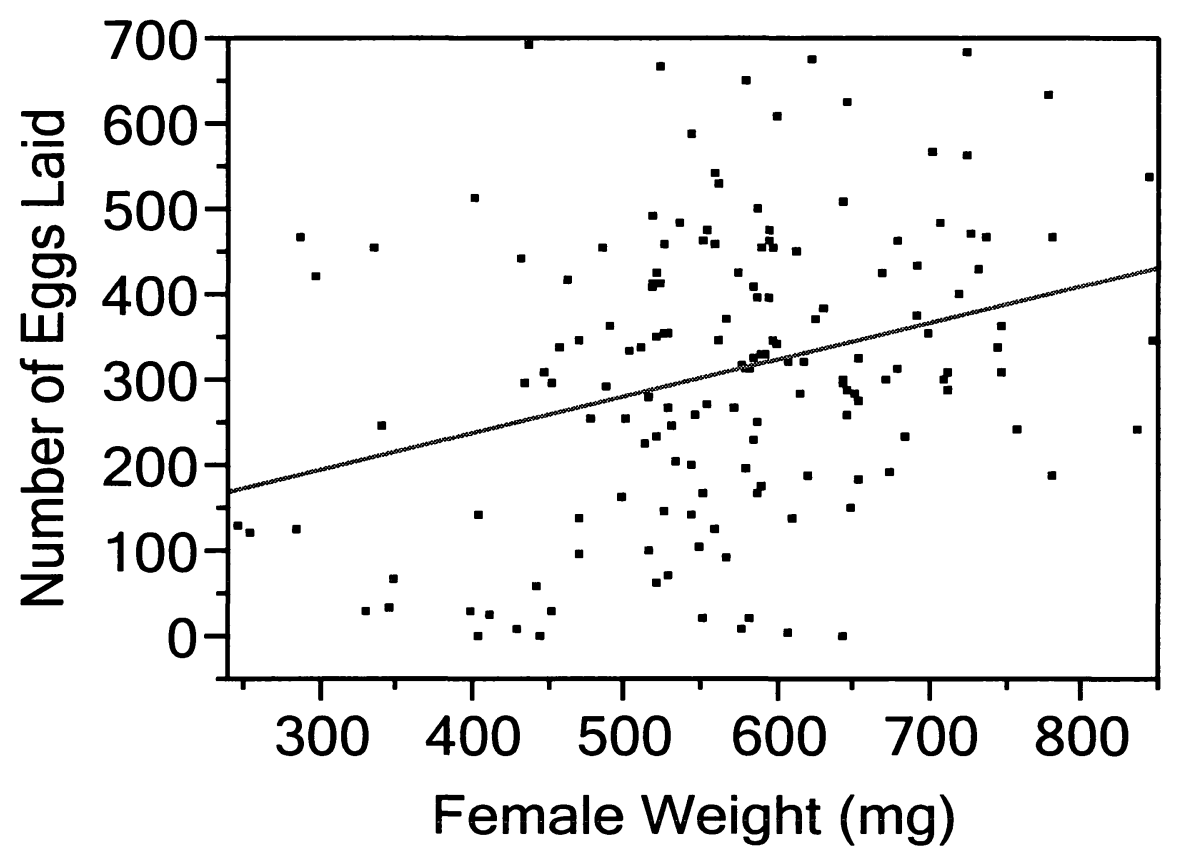

Figure 3.1: Influence of female mass (mg) onto the number of eggs laid by the female. 


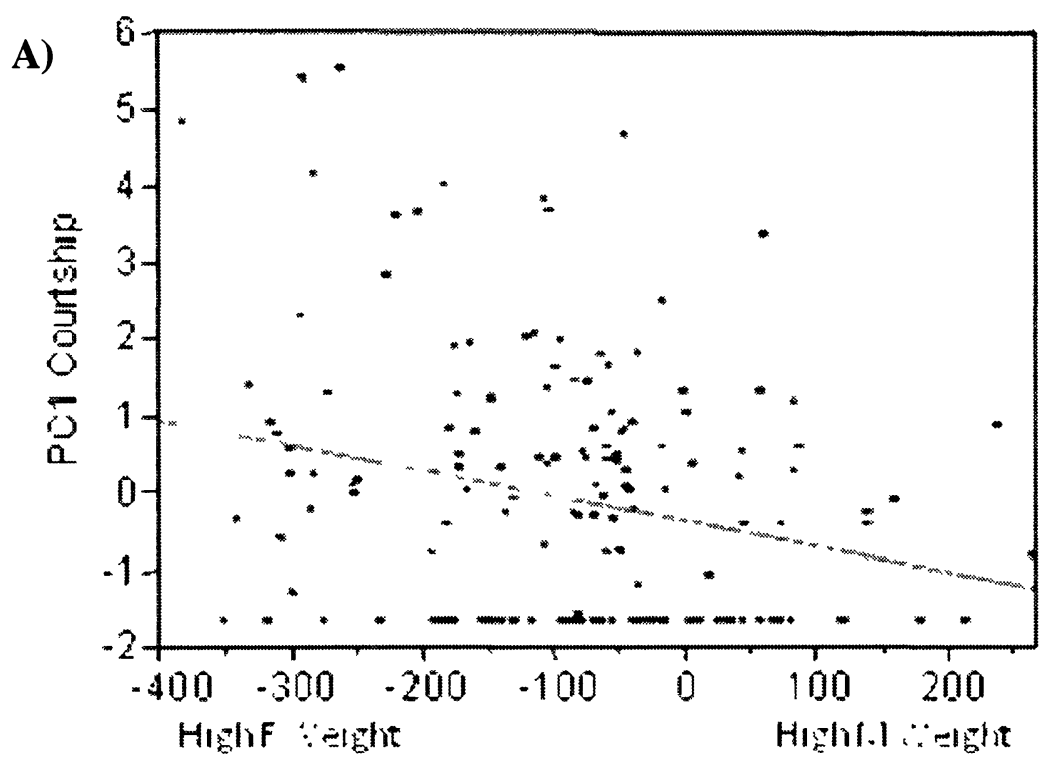

Difference Between M ale and Female Weight (mg)

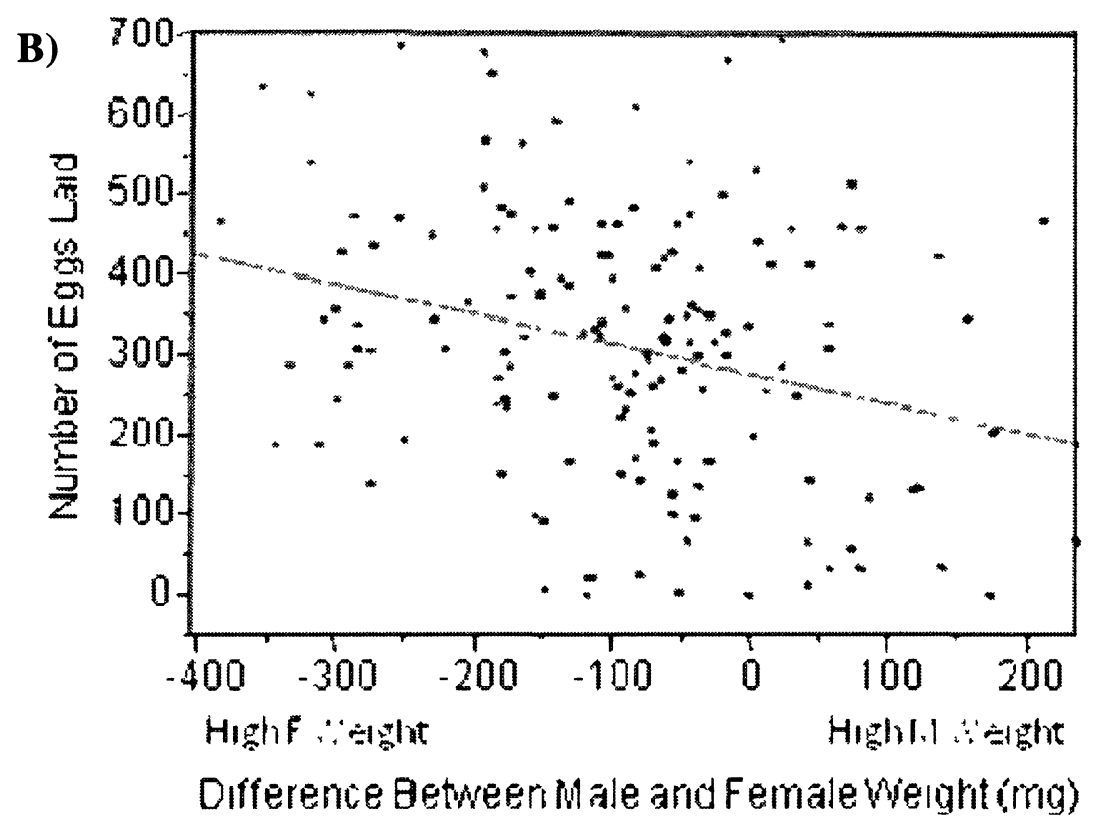

Figure 3.2: Influence of the difference in male and female mass onto A) PC1 courtship and B) the number of eggs laid by the female. 


\section{Discussion}

Does signalling ability predict aggression levels and fighting outcome?

Signalling ability did not appear to predict fighting outcome, as males with sexier signals were no more likely to win their aggressive contests than poor signalling males. These results suggest that higher quality and quantity signals are not indicative of fight performance, as males cannot signal their fighting ability to other individuals in the area. Shackleton et al (2005) found available energy allocated to both signalling and fighting may play a very important role in signalling ability and fight outcome (Shackleton et al, 2005). This, however, was not the case in $G$. assimilis as one behaviour did not appear to influence other behaviour.

There was also no relationship between signalling behaviour and the aggressiveness of the fight suggesting that males who reach a higher level of aggression in their contests are not necessarily sexier callers than males who reach a lower level. Being able to tease apart the differences in energetics and allocation of resources may allow more accurate determination of how signalling and fighting behaviour may influence female preference and subsequent reproduction in field crickets.

Relationship between Mate Attraction, Aggression, and Courtship and Mating

The typical mating strategy of male crickets is composed of: 1) defending a territory from other males, 2) producing mate attraction signals to attract females, and once a female has been attracted, 3) producing courtship songs to entice the females to mate. Because all three components can influence mating success, it is important to 
quantify the behavioural factors influencing courtship and subsequent mating behaviour.

Since most of the factors I investigated did not influence mating success as I predicted, I think it is important to look at hormone levels during fights and also during subsequent mating to see if there is any connection. Hormones such as testosterone may drive male aggression, courtship and mating behaviours (Atkins \& Stout, 1994; Marler \& Moore, 1988). Morler \& Moore (1988) implanted male lizards with testosterone and found they were much more aggressive than control males and were more successful in male-male competitions. Several studies have also shown that males with increased testosterone levels are typically more successful in reproductive competitions (Wittenberger, 1981). Examples of this can be seen in birds as males with high testosterone tend to have larger territory sizes, increased courtship behaviours, higher success in aggressive contests, and attracted more mates (Marler \& Moore, 1988). Though I did not test for hormonal levels in my study, future work should concentrate on incorporating this idea.

Another reason aggression may not have been correlated to courtship and/or the number of eggs laid by females is because the female was not able to observe the fighting contest. Females who are able to observe or listen to the aggressive interaction may be more likely to choose the winning male over the loser (Nelson \& Nolan, 1997). Further, Kortet and Hedrick (2005) examined the pheromones of dominant (winning) and subordinate (losing) male $G$. integer to determine which scent the female preferred. They found that females spent more time on the paper with the dominant male scent than the paper with the subordinate male scent. This 
suggests that females may be informed of male dominance and aggressiveness by the pheromones he releases during and after competitions (Kortet \& Hedrick, 2005).

Mate attraction signalling behaviour also did not correlate with courtship behaviours, mating behaviours, or with the number of eggs subsequently laid. There were, however, non-significant trends suggesting that high effort callers took longer to court females and males that called with more sexy (long pulse durations, higher amplitude and lower frequency) signals and longer signals spent longer times mounted with females. These findings suggest that there may be subtle relationships between the quality and quantity of male attraction signalling and their subsequent courtship and mating behaviour.

Theoretically, mate attraction signalling and aggression should be honest indicators of male quality as there are many costs associated with performing them. Costs include: energetics, reduced foraging time, increased risk of injury or death due to predation, and/or loss of territory (Tachon et al., 1999; Holzer et al., 2002). With many costs associated with producing attractive acoustic signals or being aggressive, it was thus somewhat surprising that no signalling or aggressive behaviours were significantly correlated with courting behaviours or reproduction. One explanation for this finding is a flaw in my experimental design. In retrospect, I should have given females a choice between the winners and losers from each fight. This would have allowed me to determine whether the males that produce the most attractive and energetically demanding signals also have the higher probability of winning the fight and mating with the female.

I should have also ensured females were able to listen to the mate attraction signals produced by males prior to the mating trials. If females are not able to hear the 
mate attraction songs and they are not allowed to select among different potential mates, they may have no indication of male quality if songs are in fact condition dependent. Females must then base their decision to mate on other factors such as courtship song or male size and mass. Of these variables, I assessed size, mass, and condition. I also assessed the quantity of courtship song produced. I did not, however, assess courtship song quality. In retrospect, courtship song quality may be extremely important and should have been assessed, given that courtship songs must be produced before a female will allow copulation to occur (Tregenza et al, 2006). Courtship song quality should, therefore, be looked at in a future study. An alternative explanation for my finding that mate attraction signalling and aggression were not correlated with courtship and mating behaviours is that these behaviours are not honest indicators of male quality. Both aggression and mate attraction behaviours should be honest indicators of male quality as they are energetically costly behaviours to perform. In fact, the indicator mechanism suggests that this is the main reason in which females are choosy when males offer them nothing more than their genes. My results do not support this theory, and may not, therefore, provide support for the indicator mechanism. However, it is important for this study to be repeated with females being allowed to choose between the winner and loser of the fight.

\section{Condition, Mass, and Size Effects on Courtship and Reproductive Success}

There were non-significant trends suggesting that heavier males spent less total time producing courtship signals during the mating trials and males in good condition (residual mass) appeared to initiate their courtship signals faster following 
first contact with the female. Many other studies have found larger effects of condition and/or size on mating behaviour. Larger males and/or males in good condition tend to have higher mating success than smaller males or males in poor condition (copperhead snakes, Schuett, 1997; European house cricket, Gray, 1997; African field cricket, Bateman et al, 2001; black-horned tree cricket, Brown, 2008). One difference between these studies and my own was that females were not given a choice between males, they either mated with the male they were placed with or they did not. When females are not given a choice, the only factor strongly influencing courtship behaviour and mating success is mass. Smith and Roberts (2003) study on male Crinia georgiana frogs investigated the relationship between mating success and male size in the field and found similar results to G. assimilis. Dominant frequency, which is strongly related to body size in many acoustically signalling species, was not significantly related to mating success, suggesting that male body size and condition may not influence mate choice in this species (Smith and Roberts 2003).

Male mass was the only factor that influenced the first principle component of courtship behaviours (quality). As male mass increased, PC1 decreased. In other words heavier males were the fast-to-mate males that invested more effort and produced better quality courtship displays (low PC1) than lighter males. Heavier males may have better courtship displays because they are able to put more energy into their courtship behaviour since they should have more available resources than lighter males.

Analysis of the courtship song quality may help ascertain whether courtship songs are honest indicators of male quality and used by females in mate choice. 
Courtship songs have been found to be more energetically costly to produce than pedestrian searching of females in A. domesticus and may, therefore, be a better indicator for females to use when deciding on whether they want to mate with the male or not (Hack, 1998). When compared to signalling song in A. domesticus, it was found that there was no correlation between the chirp rate of the long range signalling song and the courtship song, demonstrating that these two traits may provide different information to females about male quality (Nelson \& Nolen, 1997).

Female mass is also important in understanding variation in courtship, mating, and reproductive behaviours. Heavier females laid more eggs than lighter females, suggesting they are can allocate more energy to egg production than lighter females. Heavier females may have laid more eggs simply because they are larger and more able to support a larger quantity of eggs internally. I was not able to quantify female condition, as I could not afford to euthanize the females to perform size measurements (they had to be put back in the colony to ensure our lab population was sustained). Future studies should explore the relationship between female condition and courtship, mating, and subsequent egg lying.

Female hormonal state may also play an important role in understanding the factors influencing courtship, mating, and egg production (Bateman et. al., 2001; Mautz \& Sakaluk, 2008; Tachon et. al., 1999; Engelmann, 1968). Studying hormonal levels may reveal important information that cannot be seen at the behavioural level. Endocrine glands can be activated by various factors (ie. environment, food supply, reproductive state) that can vary in importance across species. This can make it to difficult to understand cross species analogies. 
Female age may also influence courtship, mating, and egg production If a female is young, she may be very choosey with who she mates with and may be willing to wait a long time to ensure that she mates with a high quality male (Tachon et. al., 1999). If the female is older, she may be less selective and mate with a less attractive male, so that she can ensure she copulates (Mautz \& Sakaluk, 2008; Tachon et. al., 1999). I avoided this issue by attempting to control for female age. 
General Discussion 
Signalling and Fighting

All of the signalling parameters I analyzed to determine the overall quality and effort of male signalling were significantly correlated with each other, suggesting that males that call most frequently are also producing the sexiest mate attraction signals. Further, all of the aggressive parameters I analyzed to quantify fighting behaviour were significantly correlated with each other, suggesting that some males are better fighters than others. Together these results suggest that signalling behaviour and fighting behaviour may be honest indicators of condition because they are costly behaviours to produce. Because fighting and signalling are costly behaviours, I also hypothesized that fighting ability and signalling behaviour would be correlated with each other.

My hypothesis that signalling would be correlated with fighting was not supported, suggesting that males who produced higher quality and/or quantity signals may not be signalling their subsequent aggressiveness and fighting ability.

\section{Fighting and Mating}

Theoretically, winning aggressive contests and having a better territory to call from should increase males' access and attractiveness to females (Simmons, 1986). However, I found no relationship between the aggressiveness of a contest and courtship/mating behaviour. Further, fight outcome did not influence mating success (winners were not more successful at courting or mating than losers). My results suggest that males who were involved in contests that reached a high level of aggression and intensity did not have a greater mating success, or number of female eggs laid. Many studies have found similar results where there was no correlation 
between fighting outcome and female preference (frogs: Morrison et al. 2001; lizards: Lopez et al. 2002; birds: Andersson et al. 2002; fish: Wong 2004; insects: Moore et al. 2001). This could be due to males providing no parental care (Savage et al., 2004), increased risk of female injury during mating, sperm depletion in males, or males may provide no genetic benefits to the offspring (Shackelton et al., 2005).

Future studies on male aggression in field crickets should concentrate on the physiology of why some males are more aggressive than others when in the presence of conspecifics. Looking at the hormonal state of males prior to, during and immediately after fighting contests to determine what role hormonal actively plays on aggressiveness and subsequent mating success would be beneficial to understanding inter-male variation in fighting behaviour. Using a larger, more natural setting or allowing an audience to watch the fighting contest may create outcomes more equivalent to aggressive contests in nature and also lead to potential insights about what motivates a male to engage in male-male competitions.

\section{Signalling and Mating}

Competition between males to be selected by females is typically based on male mate attraction signalling in G. assimilis (Maynard Smith, 1991). Male field crickets exhibit extensive variation in their signalling quality and quantity, suggesting that males may be producing honest signals. Because males that call most frequently also produce the sexiest mate attraction signals, females may be able to preferentially select mates based on any of the signalling parameters and locate a male that produces high quality and quantity signals. 
Male age influenced G. assimilis quality and quantity of acoustic mate attraction signals (older males produced pulse of higher duration, more pulses per chirp, longer chirp durations, had reduced dominant frequencies, and also signalled more often). These ontogenetic changes suggest that older males produce sounds that are typically favoured by females. Female preference for older males may result from an indication of high viability, which could be heritable (Jacot et al., 2007).

Mate attraction signalling ability did not influence the quality or quantity of courtship behaviours or the number of eggs laid by females. This contradicts my hypothesis that signalling quality and effort should heavily influence courtship and subsequent reproduction. Lack of choice mating tests may have caused my results to be very different from my predictions. Further, mate choice is dependent on the female being able to listen to the signals. Here I demonstrated that based on the signalling parameters females should be able to preferentially select mates based on any of the signalling parameters and locate a male that produces high quality and quantity signals. In the actual experiments, however, females did not have the opportunity to listen to these mate attraction signals. Not being able to listen to these signals would force the female to use other factors to decide whether or not she wanted to mate with the male placed in front of her. I quantified the number and duration of courtship displays, but I did not quantify the quality of the courtship songs. Courtship song quality may be a key factor influencing mating success and subsequent reproduction. Therefore, even though I found no relationship between mate signalling and subsequent courtship displays, we should not rule out its importance in influencing mating success and subsequent reproduction. 


\section{Condition Effects}

Condition did not explain the variation in male fighting, signalling, courtship, and reproductive behaviours. Winners were in no better condition than losers. Performing fighting trials in the future with randomly paired males instead of sized matched males may allow for more significant conclusions to be made about size. Size and mass explained some of the variation in dominant frequency, suggesting that larger males produced lower frequency mate attraction signals, which is typically more attractive to females. Females can use dominant frequency to locate males who are of larger size. Courtship behaviours were only somewhat influenced by male mass and condition; however, all results were not quite significant. These results suggest that females may be slightly more willing to mate with heavier males and males in better condition. Analyzing other forms of condition such as muscle density or quantifying hormonal differences may explain some of the factors influencing mating success and subsequent reproduction.

Female mass and difference between male and female mass (specifically females being larger than males), slightly influenced mating behaviour and reproductive output. This is not surprising given larger females should have more resources available to put off mating early and be choosy when deciding to mate with a male. Further, allocation of available resources should allow a larger female to produce more and support more eggs. It appears that in G. assimilis, female size is the factor most heavily influencing courtship, mating, and reproduction. This conclusion does not follow with my predictions, as male size and condition should be the most influential factor, suggesting that my assumption that the indicator mechanism was 
the theory that explained the evolution of mate choice in G. assimilis may not be correct.

The indicator mechanism suggests that females are more likely to mate with males that produce attractive signals, as male signals should reflect their broad genetic quality and overall fitness (Maynard Smith, 1976; 1991). For this mechanism to be supported, male secondary sexual traits should have been tightly tied to condition, allowing a female to base her choice of mates on honest indicators. I found no tight link between condition and aggression, signalling, or courtship behaviours, suggesting that the indicator mechanism may not be the theory best used to explain the evolution of mate choice without direct benefits. However, the indicator mechanism should not be dismissed quite yet as recent literature on this species has shown support for this theory (see Whattam, 2009). In her study she did show that there was a tight link between male acoustic signals and condition when manipulating male diets into high and low (Whattam, 2009). Therefore, future experimental designs should consider incorporating the suggestions listed throughout when trying to determine whether the indicator mechanism is in fact the hypothesis that explains the evolution of mate choice without direct benefits. 


\section{References}

Adamo, S.A. and Hoy, R.R. 1995. Agonistic behaviour in male and female field crickets, Gryllus bimaculatus, and how behavioural context influences its expression. Animal Behaviour, 49: 1491-1501.

Adamo, S.A., Linn, C.E., and Hoy, R.R. 1995. The role of neurohormonal octopamine during 'fight or flight' behaviour in the field cricket, Gryllus bimaculatus. The Journal of Experimental Biology, 198: 1691-1700.

Alexander, R.D. 1961. Aggressiveness, territoriality, and sexual behaviour in field crickets (Orthoptera: Gryllidae). Behaviour, 17: 130-223.

Andersson, M. B. 1994. Sexual Selection. Princeton New Jersey Press, Princeton, NJ.

Andersson, M. and Simmons, L.W. 2006. Sexual selection and mate choice. Trends in Ecology and Evolution, 21: 296-302.

Atkins, G. and Stout, J. 1994. Processing of song signals in the cricket and its hormonal control. American Zoologist, 34: 655-669.

Bailey, W.J., Bennet-Clark, H.C., and Fletcher, N.H. 2001. Acoustics of a small Australian burrowing cricket: the control of low-frequency pure-tone songs. Journal of Experimental Biology, 204: 2827-2841.

Balakrishnan, R. and Pollack, G.S. 1996. Recognition of courtship song in the field cricket, Teleogryllus oceanicus. Animal Behaviour, 51: 353-366.

Bateman, P.H. and Toms, R.B. 1998. Mating, mate guarding and male-male relative strength assessment in an African king cricket (Orthoptera: Mimnermidae). Transactions of the American Entomological Society, 124: 69-75. 
Bateman, P.H., Gibson, L.N., and Ferguson, J.W.H. 2001. Male size and sequential mate preference in the cricket, Gryllus bimaculatus. Animal Behaviour, 61: 631-637.

Benjamini, Y., Drai, D., Elmer, N., and Golani, I. 2001. Controlling the false discovery rate in behaviour genetics research. Behavioural Brain Research, 125: $279-284$.

Berglund, A. and Rosenqvist, G. 2000. Male pipefish prefer dominant over attractive females. Behavioural Ecology, 12: 402-406.

Bertram, S.M. 2000. The influence of age and size on temporal mate signalling behaviour. Animal Behaviour, 60: 1-7.

Bertram, S.M. 2002. Temporally fluctuating selection of sex-limited signalling traits in the Texas field cricket, Gryllus texensis. Evolution, 56: 1831-1839.

Bertram, S.M., Orozco, S.X., and Bellani, R.2004. Temporal shifts in conspicuousness: mate attraction displays of the Texas field cricket, Gryllus texensis. Ethology, 110: 963-975.

Bertram, S.M. and Warren, P. 2005. Tradeoffs in signalling components differ with signalling effort. Animal Behaviour, 70: 477-484.

Betram S.M., Kemp, D., Johnson, J.S., Orozco, S.X., and Gorelick, R. 2007. Heritability of acoustic signalling time in the Texas field cricket, Gryllus texensis. Evolutionary Ecology Research, 9: 1-12.

Bertram, S.M., Rook, V.L.M., and Fitzsimmons, L.P. In press. Strutting their stuff: Post-conflict displays in the spring field cricket, Gryllus veletis. Behaviour.

Bishop, D.T. and Cannings, C. 1978. A generalized war of attrition. Journal of Theoretical Biology, 70: 85-124. 
Briffa, M. 2008. Decisions during fights in the house cricket, Acheta domesticus: mutual or self assessment of energy, weapons and size? Animal Behaviour, 75: 1053-1062.

Brown, W.D., Smith, A.T., Moskalik, B., and Gabriel, J. 2006. Aggressive contests in house crickets: size, motivation and the information content of aggressive songs. Animal Behaviour, 72: 225-233.

Brown, W.D. 2008. Size-biased mating in both sexes of the black-horned tree cricket, Oecanthus nigricornis (Orthoptera: Gryllidae: Oecanthinae). Journal of Insect Behaviour, 21: 130-142.

Buchanan, K.L. and Catchpole, C.K. 1997. Female choice in the sedge warbler, Acrocephalus schoenobaenus: multiple cues from song and territory quality. Proceedings of the Royal Society: Biological Sciences, 264: 521-526.

Burk, T. 1983. Male aggression and female choice in a field cricket (Teleogryllus oceanicus): The importance of courtship song. In Gwynne, D. T., and Morris, G. K. (eds.), Orthopteran Mating Systems: Sexual Competition in a Diverse Group of Inisects, Westview Press, Boulder, CO, 97-119.

Byers, J.A., Wiseman, P.A., Jones, L., and Roffe, T.J. 2005. A large cost of female mate sampling in pronghorn. American Naturalist, 166: 661-668.

Cade, W.H. 1981. Alternative mate strategies: genetic differences in crickets. Science, 212: 563-564.

Candolin, U. 1999. Male-male competition facilitates female choice in sticklebacks. Proceedings of the Royal Society: Biological Sciences, 266: 785-789.

Carranza, J. 2010. Sexual selection and the evolution of evolutionary theories. Animal Behaviour, 79: 5-6. 
Cordero, C. and Eberhard, W.G. 2003. Female choice of sexually aggressive male adaptations: a critical review of some current research. Journal of Evolutionary Biology, 16: 1-6.

Cotton, S., Fowler, K., and Pomeiankowski, A. 2004. Do sexual ornaments demonstrate heightened condition-dependent expression as predicted by the handicap hypothesis? Proceedings of the Royal Society: Biological Sciences, 271: 771-783.

Darwin, C. 1871. The Descent of Man, and Selection in Relation to Sex. London: J. Murray.

Double, M.C. and Cockburn, A. 2003. Subordinate superb fairy-wrens (Malurus cyaneus) parasitize the reproductive success of attractive dominant males. Proceedings of the Royal Society: Biological Sciences, 270: 379-384.

Elwood, R.W., Wood, K.E., Gallagher, M.B., and Dick, J.T.A. 1998. Probing motivational state during agonistic encounters in animals. Nature, 393: 66-68.

Engelmann, F. 1968. Endocrine control of reproduction in insects. Annual Review of Entomology, 13: 1-16.

Felton, A., Alford, R.S., Felton, A.M., and Schwarzkopf, L. 2006. Multiple mate choice criteria and the importance of age for male mating success in the microhylid frog, Cophixalus ornatus. Behavioural Ecology and Sociobiology, 59: 786-795.

Fisher, R. A. 1930. The Genetical Theory of Natural Selection. Oxford, Clarendon, UK.

Gershman, S.N. 2010. Large number of matings give female field crickets a direct benefit but not a genetic benefit. Journal of Insect Behaviour, 23: 59-68. 
Gibson, R.M. and Bachman, G.C. 1992. The costs of female choice in a lekking bird. Behavioural Ecology, 3: 300-309.

Gray, D.A. 1997. Female house crickets, Acheta domesticus, prefer the chirps of large males. Animal Behaviour, 54: 1553-1562.

Gray, D.A. and Cade, W.H. 1999. Quantitative genetics of sexual selection in the field cricket, Gryllus integer. Evolution, 53: 848-854.

Gray, D.A. and Eckhardt, G. 2001. Is cricket courtship song condition dependent? Animal Behaviour, 62: 871-877.

Gray, S.M. and McKinnon, J.S. 2006. A comparative description of mating behaviour in the endemic telmatherinid fishes of Sulawesi's Malili Lakes. Environmental Biology of Fishes, 75: 471-482.

Guerra, P.A. and Pollack, G.S. 2007. A life history trade-off between flight ability and reproductive behaviour in male field crickets (Gryllus texensis). Journal of Insect Behaviour, 20: 377-387.

Hack, M.A. 1997. Assessment strategies in the contests of male crickets, Acheta domesticus (L.) Animal Behaviour, 53: 733-747.

Hack, M.A. 1998. The energetics of male mating strategies in field crickets (Orthoptera: Gryllinae: Gryllidae). Journal of Insect Behaviour, 11: 853-867.

Hagelin, J.C. 2002. The kinds of traits involved in male-male competition: a comparison of plumage, behaviour, and body size in quail. Behavioural Ecology, 13: 32-41.

Hedrick, A.V. 1988. Female choice and the heritability of attractive male traits: an empirical study. The American Naturalist, 132: 267-276. 
Hofmann, H.A. and Schildberger, K. 2001. Assessment of strength and willingness to fight during aggressive encounters in crickets. Animal Behaviour, 62: 337348.

Holzer, B., Jacot, A., and Brinkhof, M.W.G. 2002. Condition-dependent signalling affects male sexual attractiveness in field crickets, Gryllus campensis. Behavioural Ecology, 14: 353-359.

Hunt, J., Bussiere, L.F., Jennions, M.D., and Brooks, R. 2004. What is genetic quality? Trends in Ecology and Evolution, 19: 329-333.

Jacot, A., Scheuber, H., and Brinkhof, M.W.G. 2007. The effect of age on a sexually selected acoustic display. Ethology, 113: 615-620.

Jang, Y., Gerhardt, H.C., and Choe, J.C. 2008. A comparative study of aggressiveness in North American field cricket species (genus Gryllus). Behavioural Ecology and Sociobiology, 62: 1397-1407.

Kotiaho, J., Alatalo, R.V., Mappes, J., and Parri, S. 1997. Fighting success in relation to body mass and drumming activity in the male wolf spider, Hygrolycosa rubrofasciata. Canadian Journal of Zoology, 75: 1532-1535.

Kotiaho, J.S. 2000. Testing the assumptions of conditional handicap theory: costs and condition dependence of a sexually selected trait. Behavioural Ecology and Sociobiology, 48:188-194.

Kortet, R. and Hedrick, A. 2005. The scent of dominance: female field crickets use odour to predict the outcome of male competition. Behavioural Ecology and Sociobiology, 59: 77-83.

Kravitz, E.A. and Huber, R. 2003. Aggression in invertebrates. Current Opinion in Neurobiology, 13: 736-743. 
Lopez, P., Munoz, A., and Martin, J. 2002. Symmetry, male dominance, and female mate preferences in the Iberian rock lizard, Lacerta monticola. Behavioural Ecology and Sociobiology, 52: 342-347.

Marler, C.A. and Moore, C. 1988. Evolutionary costs of aggression revealed by testosterone manipulations in free-living male lizards. Behavioural Ecology and Sociobiology, 23: 21-26.

Martin, S.D., Gray, D.A., and Cade, W.H. 2000. Fine-scale temperature effects on cricket signalling song. Canadian Journal of Zoology, 78: 706-712.

Mautz, B.S. and Sakaluk, S.K. 2008. The effects of age and previous mating experience on pre- and post-copulatory mate choice in female house crickets (Acheta domesticus L.). Journal of Insect Behaviour, 21: 203-212.

Maynard Smith, J. 1974. Theory of games and the evolution of animal contests. Journal of Theoretical Biology, 47: 209-221.

Maynard Smith, J. 1976. Sexual selection and the handicap principle. Journal of Theoretical Biology, 57: 239-242.

Maynard Smith, J. 1991. Theories of sexual selection. TREE, 6: 146-151.

Mesterton-Gibbons, M. and Sherratt, T.N. 2006. Victory displays: a game-theoretic analysis. Behavioural Ecology, 17: 597-605.

Moretz, J.A. 2003. Aggression and RHP in the Northern swordtail fish, Xiphophoruscortezi: the relationship between size and contest dynamics in male-male competition. Ethology, 109: 995-1008.

Nakagawa, S. 2004. A farewell to Bonferroni: the problems of low statistical power and publication bias. Behavioural Ecology, 15: 1044-1045. 
Narum, S.R. 2006. Beyond Bonferroni: less conservative analyses for conservation genetics. Conservation Genetics, 7: 783-787.

Nelson, C.M. and Nolen, T.G. 1997. Courtship song, male agonistic encounters, and female mate choice in the house cricket, Acheta domesticus (Orthoptera: Gryllidae). Journal of Insect Behaviour, 10: 557-570.

Olsson, M. 1992. Contest success in relation to size and residency in male sand lizards, Lacerta agilis. Animal Behaviour, 44: 386-388.

Parker, G.A. 1974. Assessment strategy and the evolution of fighting behaviour. Journal of Theorectical Behaviour, 47: 223-243.

Prestwich, K. N. and Walker, T. J. 1981. Energetics of singing in crickets: effect of temperature in three trilling species (Orthoptera: Gryllidae). Journal of Comparative Physiology, 143: 199-212.

Proulx, S. R., Day, T., and Rowe, L. 2002. Older males signal more reliably. Proceedings of the Royal Society: Biological Sciences, 269: 2291-2299.

Radwan, J. 2008. Maintenance of genetic variation in sexual ornaments: a review of the mechanisms. Genetica, 134: 113-127.

Robertson, J.G.M. 1986. Male territoriality, fighting and assessment of fighting ability in the Australian frog, Uperoleia rugosa. Animal Behaviour, 34: 763772.

Robinson, D.J. and Hall, M.J. 2002. Sound signalling in Orthoptera. Advances in Insect Physiology, 29: 151-278.

Rowe, L., and Houle, D. 1996. The lex paradox and the capture of genetic variance by condition dependent traits. Proceedings of the Royal Society: Biological Sciences, 263: 1415-1421. 
Rowell, G.A. and Cade, W.H. 1993. Simulation of alternative male reproductive behaviour: calling and satellite behaviour in field crickets. Ecological Modeling, 65: 265-280.

Ryan, M. J., Fox, J. H., Wilczynski, W., and Rand, A. S. 1990. Sexual selection for sensory exploitation in the frog, Physalaemus pustlosus. Nature 343: 66-67.

Savage, K.E., Hunt, J., Jennions, M.D., and Brooks, R. 2004. Male attractiveness covaries with fighting ability but not with prior fight outcome in house crickets. Behavioural Ecology, 16: 196-200.

Scheuber, H., Jacot, A., and Brinkhof, M.W.G. 2003. Condition dependence of a mutlicomponent sexual signal in the field cricket, Gryllus campestris. Animal Behaviour, 65: 721-727.

Schuett, G.W. 1996. Body size and agonistic experience affect dominance and mating success in male copperheads. Animal Behaviour, 54: 213-224.

Shackleton, M.A., Jennions, M.D., and Hunt, J. 2005. Fighting success and attractiveness as predictors of male mating success in the black field cricket, Teleogryllus commodus: the effectiveness of no-choice tests. Behavioural Ecology and Sociobiology, 58: 1-8.

Simmons, L.W. 2004. Genotypic variation in signalling song and female preferences of the field cricket, Teleogryllus oceanicus. Animal Behaviour, 68: 313-322.

Smith, M.J. and Roberts, J.D. 2003. Call Structure may affect male mating success in the quaking frog, Crinia Georgiana (Anura: Myobatrachidae). Behavioural Ecology and Sociobiology, 53: 221-226.

Stevens, E. D. and Josephson, R. K. 1977. Metabolic rate and body temperature in singing katydids. Physiology and Zoology, 50: 31-42. 
Stevenson, P.A., Dyakonova, V., Rillich, J., and Schildberger, K. 2005. Octopamine and experience-dependent modulation of aggression in crickets. The Journal of Neuroscience, 25:1431-1441.

Sullivan, B.K. 1992. Sexual selection and signalling behaviour in the American toad. Copeia, 1: 1-7.

Tachon, G., Murray, A.M., Gray, D.A., and Cade, W.H. 1999. Agonistic displays and the benefits of fighting in the field cricket, Gryllus bimaculatus. Journal of Insect Behaviour, 12: 533-543.

Tregenza, T., Simmons, L.W., Wedell, N., and Zuk, M. 2006. Female preference for male courtship song and its role as a signal of immune function and condition. Animal Behaviour, 72: 809-818.

Vitousek, M.N, Mitchell, M.A., Woakes, A.J., Niemack, M.D., and Wikelski, M. 207. High costs of female choice in a lekking lizard. PLOS ONE, 2: e567.

Wagner, W.E. and Hoback, W.W. 1999. Nutritional effects on male signalling behaviour in the variable field cricket. Animal Behaviour, 57: 89-95.

Wagner, W.E. and Reiser, M.G. 2000. The importance of signalling song and courtship song in female mate choice in the variable field cricket. Animal Behaviour, 59: 1219-1226.

Walling, C. A., Royle, N.J., Linstrom, J., and Metcalfe, N.B. 2008. Experienceinduced preference for short-sworded males in the green swordtail, Xiphophorus helleri. Animal Behaviour, 76: 271-276.

Watson, A. and Parr, R. 1981. Hormone implants affecting territory size and aggressive and sexual behaviour in red grouse. Ornis Scandinivica, 12: 55-61. 
Wedell, N. and Ritchie, M.G. 2004. Male age, mating, and nuptial gift quality in a bushcricket. Animal Behaviour, 67: 1059-1065.

Wescott, W. 1992. Inter- and intra-sexual selection: the role of song in a lek mating system. Animal Behaviour, 44: 695-703.

Whattam, E.M. 2009. A test of the multiple messages and redundant signals hypotheses in two species of field crickets, Gryllus texensis and Gryllus assimilis. Msc. Graduate Thesis, Carleton Univerity, Ottawa, Canada.

Wingfield, J.C. 1984. Environmental and endocrine control of reproduction in the song sparrow, Melospiza melodia. II. Agonistic interactions as environmental information stimulating secretion of testosterone. General and Comparative Endocrinology, 56: 417-424.

Wittenberger, J. 1981. Animal Social Behaviour. Boston: Duxbury Press. 


\section{Appendix I: Univariate data on signalling parameters}

To investigate whether there were any age effects on the signalling parameters of male G. assimilis I used a general least squares model that explored how signalling parameters were influenced by the individual, age, and individual by age interactions. These univariate models were highly significant for all signalling parameters. (Table I.I, Figure I.I). Overall, there was a lot of variation across individuals. Most males increased most of their signalling parameters as they aged, but a handful decreased them. In fact, significant age affects occurred in all parameters except dominant frequency. Interactions between individual and age were strongly significant. 
Table I.I: Influence of age on the signalling parameters and first Principle Component Analysis of male G. assimilis aged 8 to 21 days.

\begin{tabular}{|c|c|c|c|c|}
\hline Signalling Parameter & $\mathbf{R}^{2} \mathbf{a d j}$ & Parameter & $\mathbf{F}$ & $\mathbf{P}$ \\
\hline \multirow[t]{4}{*}{ Pulse duration } & 0.635 & Whole model & 12.27 & $*<0.0001$ \\
\hline & & Individual & 21.02 & $*<0.0001$ \\
\hline & & Age of Cricket & 0.182 & 0.6699 \\
\hline & & Individual*Age & 3.821 & $*<0.0001$ \\
\hline \multirow[t]{4}{*}{ Interpulse duration (ms) } & 0.328 & Whole model & 4.169 & $*<0.0001$ \\
\hline & & Individual & 6.126 & $*<0.0001$ \\
\hline & & Age of Cricket & 9.184 & *0.0026 \\
\hline & & Individual*Age & 2.124 & $*<0.0001$ \\
\hline \multirow[t]{4}{*}{ Pulse per chirp } & 0.620 & Whole model & 11.57 & $*<0.0001$ \\
\hline & & Individual & 18.13 & $*<0.0001$ \\
\hline & & Age of Cricket & 42.16 & $*<0.0001$ \\
\hline & & Individual*Age & 4.608 & $*<0.0001$ \\
\hline \multirow[t]{4}{*}{ Chirp duration (ms) } & 0.615 & Whole model & 11.35 & $*<0.0001$ \\
\hline & & Individual & 18.77 & $*<0.0001$ \\
\hline & & Age of Cricket & 11.74 & *0.0007 \\
\hline & & Individual*Age & 4.048 & $*<0.0001$ \\
\hline \multirow[t]{4}{*}{ Interchirp duration (ms) } & 0.629 & Whole model & 12.01 & $*<0.0001$ \\
\hline & & Individual & 21.73 & $*<0.0001$ \\
\hline & & Age of Cricket & 16.21 & $*<0.0001$ \\
\hline & & Individual*Age & 2.401 & $*<0.0001$ \\
\hline \multirow[t]{4}{*}{ Amplitude } & 0.689 & Whole model & 15.34 & $*<0.0001$ \\
\hline & & Individual & 26.69 & $*<0.0001$ \\
\hline & & Age of Cricket & 74.73 & $*<0.0001$ \\
\hline & & Individual*Age & 2.604 & $*<0.0001$ \\
\hline \multirow[t]{4}{*}{ Dominant Frequency $(\mathrm{Hz})$} & 0.594 & Whole model & 10.48 & $*<0.0001$ \\
\hline & & Individual & 19.02 & $*<0.0001$ \\
\hline & & Age of Cricket & 3.090 & 0.0793 \\
\hline & & Individual*Age & 1.944 & $* 0.0003$ \\
\hline \multirow[t]{4}{*}{ Time spent signalling (min) } & 0.738 & Whole model & 19.45 & $*<0.0001$ \\
\hline & & Individual & 34.79 & $*<0.0001$ \\
\hline & & Age of Cricket & 4.366 & 0.0371 \\
\hline & & Individual*Age & 4.051 & $*<0.0001$ \\
\hline
\end{tabular}


A)
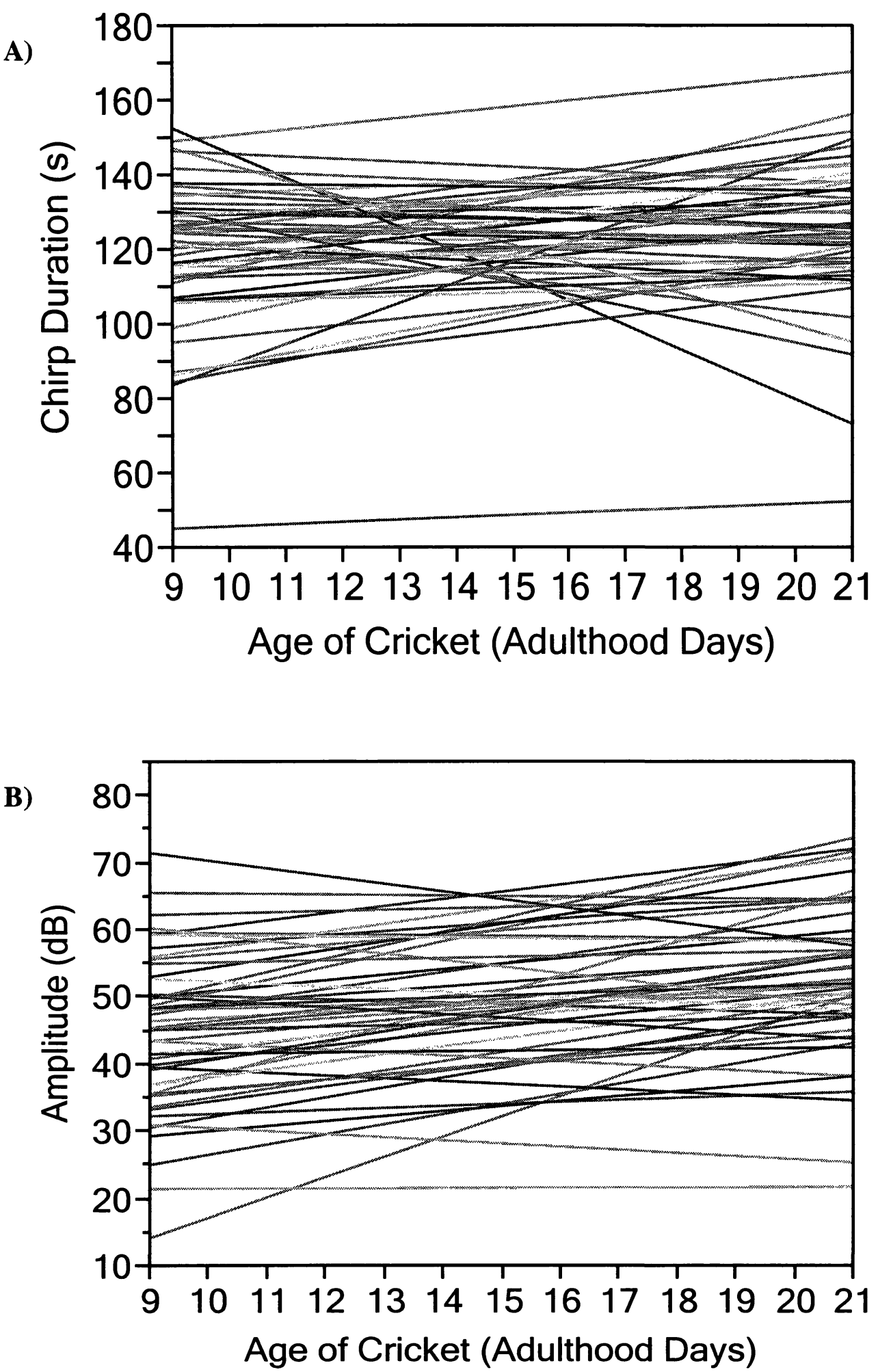

Figure I.I: Influence of age on A) chirp duration and B) amplitude of male $G$. assimilis aged 8 to 21 . 
Heavier and larger crickets produced acoustic mate attraction signals that were lower in frequency than lighter and smaller crickets (Table I.II; Figure I.II). Larger males also had higher interchirp durations and amplitudes.

Table I.II: Influence of body condition, mass, and size onto signalling parameters of G. assimilis males aged 8 to 21 days of adulthood (parameters averaged across days).

\begin{tabular}{|c|c|c|c|c|}
\hline \multirow[b]{2}{*}{ Signalling Parameter } & \multicolumn{4}{|c|}{ Body Condition } \\
\hline & $\mathbf{R}^{2} \mathbf{a d j}$ & $\mathbf{F}$ & $\mathbf{t}$ & $\mathbf{P}$ \\
\hline Mean pulse duration (ms) & 0.020 & 0.000 & 0.00 & 0.9966 \\
\hline Mean interpulse duration (ms) & 0.020 & 0.000 & 0.01 & 0.9918 \\
\hline Mean pulse per chirp & 0.019 & 0.026 & -0.16 & 0.8723 \\
\hline Mean chirp duration (ms) & 0.019 & 0.036 & -0.19 & 0.8510 \\
\hline Mean interchirp duration (ms) & 0.005 & 1.230 & -1.11 & 0.2727 \\
\hline Amplitude & 0.020 & 0.010 & -0.10 & 0.9223 \\
\hline Dominant Frequency (Hz) & 0.020 & 0.000 & 0.01 & 0.9907 \\
\hline \multirow[t]{2}{*}{ Time spent signalling (min) } & 0.007 & 0.662 & -0.81 & 0.4196 \\
\hline & \multicolumn{4}{|c|}{ Mass } \\
\hline Mea & 0.013 & 0.357 & 0.60 & 0.5526 \\
\hline Mea & 0.005 & 0.236 & -0.49 & 0.6295 \\
\hline per chirp & 0.012 & 1.655 & 1.29 & 0.2041 \\
\hline hirp duration & 0.015 & 1.812 & 1.35 & 0.1842 \\
\hline Mea & 0.020 & 2.056 & 1.43 & 0.1576 \\
\hline Amp & 0.050 & 3.765 & 1.94 & 0.0579 \\
\hline Dominant Frequency (Hz) & 0.132 & 8.895 & -2.98 & $* 0.0044$ \\
\hline \multirow[t]{2}{*}{ Time spent signalling (min) } & 0.011 & 1.600 & -1.26 & 0.2117 \\
\hline & \multicolumn{4}{|c|}{ Size } \\
\hline Mear & 0.015 & 0.254 & 0.50 & 0.6164 \\
\hline Mean interpulse dur & 0.012 & 0.392 & -0.63 & 0.5340 \\
\hline Mean pulse per chirp & 0.042 & 3.253 & 1.80 & 0.0773 \\
\hline Mean chirp duration (ms) & 0.048 & 3.596 & 1.90 & 0.0637 \\
\hline Mean interchirp duration (ms) & 0.105 & 7.010 & 2.65 & $* 0.0108$ \\
\hline Amplitude & 0.064 & 4.494 & 2.12 & $* 0.0390$ \\
\hline Dominant Frequency $(\mathrm{Hz})$ & 0.182 & 12.33 & -3.51 & $* 0.0010$ \\
\hline Time spent signalling (min) & 0.032 & 2.683 & -1.64 & 0.1077 \\
\hline
\end{tabular}



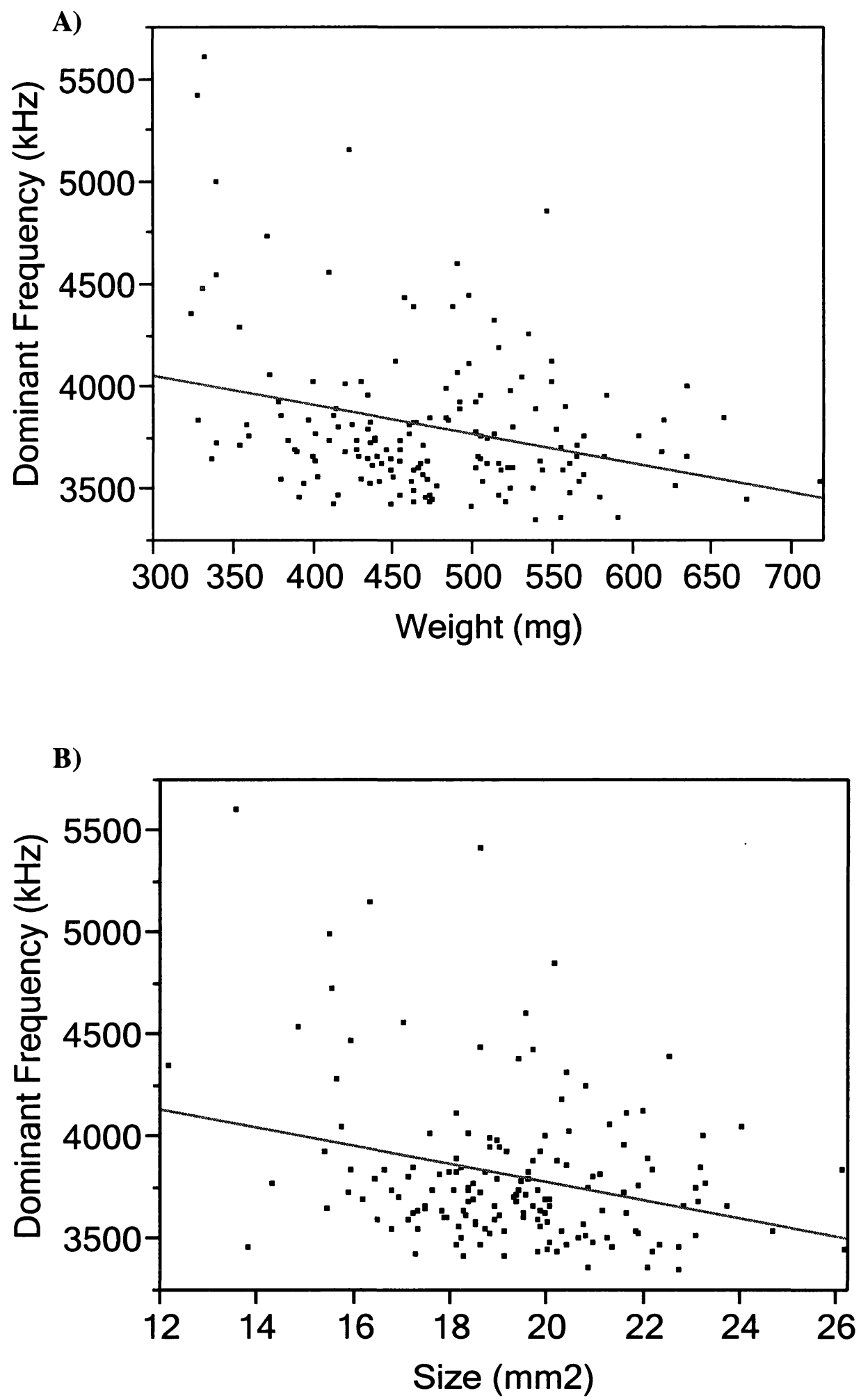

Figure I.II: Influence of A) mean mass (mg) and B) mean size (pronotum area $\mathrm{mm}^{2}$ ) on dominant frequency $(\mathrm{kHz})$ for $G$. assimilis males aged 8 to 21 days. 


\section{Appendix 2: Principle Component Analysis on Rate of Aggressive Behaviours}

\section{and Univariate data on Courtship}

More than half of the aggressive rate measures were strongly correlated with one another (Table II.I). For example, some males performed a high rate of aggressive songs. These males also had a higher rate of body jerks, chasing the opponent and antennation. Since the rate of aggression parameters were highly correlated, I performed a principle component analysis to reduce the number of variables. The first principle component explained $46 \%$ of the variation and rate of aggressive song and rate of body jerks loaded most heavily on PC1 (Table II.II). These loadings suggest PC1 scores may reflect post-conflict displays, with high PC1 males performing a lot of post-conflict displays and males with low PC1 displays performing few post-conflict displays. The second principle component explained $22 \%$ of the variation and rate of unilateral mandible spread and rate of antennation loaded most heavily on PC2 (Table II.II). These loading suggest that high PC2 scores represent males that have higher aggressive rates while engaged with the opponent than males with low PC2 scores. The third principle component explained $18 \%$ of the variation and rate of unilateral mandible spread loaded most heavily on PC3 (Table II.II). 
Table II.I: Correlations between rates of aggression parameters.

\begin{tabular}{llrr} 
Variable & By Variable & Correlation & $\mathbf{P}$ \\
\hline Rate Antennate & Rate Chase & -0.0290 & 0.7647 \\
Rate Rock Body & Rate Chase & 0.2976 & $* \mathbf{0 . 0 0 1 7}$ \\
Rate Rock Body & Rate Antennate & 0.4640 & $*<\mathbf{0 . 0 0 0 1}$ \\
Rate Agg Song & Rate Chase & 0.3633 & $* \mathbf{0 . 0 0 0 1}$ \\
Rate Agg Song & Rate Antennate & 0.4186 & $*<\mathbf{0 . 0 0 0 1}$ \\
Rate Agg Song & Rate Rock Body & 0.7578 & $*<\mathbf{0 . 0 0 0 1}$ \\
Rate Unilateral Spread Rate Chase & 0.0163 & 0.8662 \\
Rate Unilateral Spread Rate Antennate & 0.1814 & 0.0591 \\
Rate Unilateral Spread Rate Rock Body & 0.1297 & 0.1787 \\
Rate Unilateral Spread Rate Agg Song & 0.2344 & $\mathbf{0 . 0 1 4 1}$
\end{tabular}

Table II.II: Eigenvectors from a multivariate Principle Component Analysis on the rates of aggressive behaviours.

\begin{tabular}{lrrr} 
Aggression Parameter & $\begin{array}{c}\text { PC1 } \\
\text { Eigenvector }\end{array}$ & $\begin{array}{c}\text { PC2 } \\
\text { Eigenvector }\end{array}$ & $\begin{array}{c}\text { PC3 } \\
\text { Eigenvector }\end{array}$ \\
\hline Rate Chase & 0.290 & -0.725 & 0.340 \\
Rate Antennate & 0.421 & 0.464 & -0.390 \\
Rate Rock Body & 0.581 & -0.072 & -0.203 \\
Rate Agg Song & 0.592 & -0.092 & -0.007 \\
Rate Unilateral Spread & 0.223 & 0.496 & 0.831 \\
Eigenvalue & 2.308 & 1.083 & 0.888 \\
Percentage & $46 \%$ & $22 \%$ & $18 \%$
\end{tabular}

Univariate regression tables described in Chapter 3 for courtship behaviours and aggressive parameters (Table II.III), courtship behaviours and signalling parameters (Table II.IV), and courtship behaviours and condition parameters (Table II.V). 
Table II.III: Univariate correlations and probabilities of courtship parameters by aggressive parameters.

\begin{tabular}{c|r|r|r|r|r|r} 
Variables & $\begin{array}{r}\text { First contact to } \\
\text { courtship call }\end{array}$ & $\begin{array}{c}\text { Number of } \\
\text { courtship calls }\end{array}$ & $\begin{array}{c}\text { Total call } \\
\text { time }\end{array}$ & $\begin{array}{c}\text { First contact } \\
\text { to mount }\end{array}$ & $\begin{array}{c}\text { Total time } \\
\text { mounted }\end{array}$ & $\begin{array}{c}\text { Number of } \\
\text { Eggs }\end{array}$ \\
\hline Rate Antennate & 0.0235 & 0.0961 & -0.0348 & -0.0550 & -0.0620 & 0.1431 \\
& $\mathrm{P}=0.8597$ & $\mathrm{P}=0.4689$ & $\mathrm{P}=0.7936$ & $\mathrm{P}=0.6788$ & $\mathrm{P}=0.6407$ & $\mathrm{P}=0.2837$ \\
\hline Rate Bilateral & 0.0892 & 0.0510 & -0.0991 & 0.0171 & 0.0027 & 0.1181 \\
Spread & $\mathrm{P}=0.5017$ & $\mathrm{P}=0.7010$ & $\mathrm{P}=0.4552$ & $\mathrm{P}=0.8977$ & $\mathrm{P}=0.9840$ & $\mathrm{P}=0.3774$ \\
\hline Rate Chase & 0.1182 & -0.1617 & -0.0807 & 0.0849 & 0.2918 & 0.0240 \\
& $\mathrm{P}=0.3725$ & $\mathrm{P}=0.2213$ & $\mathrm{P}=0.5435$ & $\mathrm{P}=0.5227$ & $\mathrm{P}=\mathbf{0 . 0 2 4 9}$ & $\mathrm{P}=0.8581$ \\
\hline Rate Rock Body & -0.0560 & -0.1229 & -0.1139 & -0.1176 & -0.0040 & 0.1497 \\
& $\mathrm{P}=0.6735$ & $\mathrm{P}=0.3538$ & $\mathrm{P}=0.3904$ & $\mathrm{P}=0.3748$ & $\mathrm{P}=0.9761$ & $\mathrm{P}=0.2619$ \\
\hline Rate Grapple & 0.1480 & -0.0087 & -0.0100 & 0.0816 & 0.0257 & 0.0914 \\
\hline Rate Aggression & $\mathrm{P}=0.2634$ & $\mathrm{P}=0.9477$ & $\mathrm{P}=0.9401$ & $\mathrm{P}=0.5391$ & $\mathrm{P}=0.8465$ & $\mathrm{P}=0.4952$ \\
Song & -0.0868 & -0.0646 & -0.0999 & -0.1107 & 0.0860 & 0.1053 \\
\hline Rate Mandible & $\mathrm{P}=0.5131$ & $\mathrm{P}=0.6271$ & $\mathrm{P}=0.4517$ & $\mathrm{P}=0.4040$ & $\mathrm{P}=0.5170$ & $\mathrm{P}=0.4316$ \\
Engagement & 0.0437 & -0.0582 & -0.0903 & -0.0056 & 0.0862 & 0.0910 \\
\hline Rate Unilateral & $\mathrm{P}=0.7423$ & $\mathrm{P}=0.6615$ & $\mathrm{P}=0.4962$ & $\mathrm{P}=0.9666$ & $\mathrm{P}=0.5161$ & $\mathrm{P}=0.4971$ \\
Spread & -0.0931 & -0.0548 & -0.0504 & -0.0897 & 0.0365 & 0.0388 \\
\hline Maximum & $\mathrm{P}=0.4832$ & $\mathrm{P}=0.6804$ & $\mathrm{P}=0.7045$ & $\mathrm{P}=0.4992$ & $\mathrm{P}=0.7838$ & $\mathrm{P}=0.7723$ \\
Aggression Score & 0.1782 & 0.0077 & -0.0247 & 0.0147 & -0.0181 & 0.0502 \\
\hline Fight Intensity & $\mathrm{P}=0.1770$ & $\mathrm{P}=0.9536$ & $\mathrm{P}=0.8525$ & $\mathrm{P}=0.5203$ & $\mathrm{P}=0.8916$ & $\mathrm{P}=0.7080$ \\
\hline & 0.0672 & 0.1200 & -0.0397 & 0.0147 & -0.1634 & 0.0364 \\
$\mathrm{P}=0.6133$ & $\mathrm{P}=0.3653$ & $\mathrm{P}=0.7653$ & $\mathrm{P}=0.9121$ & $\mathrm{P}=0.2163$ & $\mathrm{P}=0.7863$
\end{tabular}

Table II.IV: Univariate correlations and probabilities of courtship parameters by signalling parameters.

\begin{tabular}{c|r|r|r|r|r|r} 
Variables & $\begin{array}{c}\text { First contact } \\
\text { to courtship } \\
\text { call }\end{array}$ & $\begin{array}{c}\text { Number of } \\
\text { courtship } \\
\text { calls }\end{array}$ & $\begin{array}{c}\text { Total call } \\
\text { time }\end{array}$ & $\begin{array}{c}\text { First } \\
\text { contact to } \\
\text { mount }\end{array}$ & $\begin{array}{r}\text { Total time } \\
\text { mounted }\end{array}$ & $\begin{array}{r}\text { Number } \\
\text { of Eggs }\end{array}$ \\
\hline Pulse & 0.1779 & 0.0431 & 0.0917 & 0.1111 & 0.2392 & -0.0313 \\
Duration & $\mathrm{P}=0.1055$ & $\mathrm{P}=0.6973$ & $\mathrm{P}=0.4068$ & $\mathrm{P}=0.3145$ & $\mathrm{P}=0.0284$ & $\mathrm{P}=0.7816$ \\
\hline Interpulse & -0.0582 & -0.0453 & -0.1676 & -0.0121 & -0.1026 & 0.2407 \\
Duration & $\mathrm{P}=0.5991$ & $\mathrm{P}=0.6822$ & $\mathrm{P}=0.1275$ & $\mathrm{P}=0.9133$ & $\mathrm{P}=0.3531$ & $\mathrm{P}=0.0304$ \\
\hline Pulses per & 0.0850 & 0.0069 & 0.0627 & 0.0645 & 0.1585 & -0.0857 \\
Chirp & $\mathrm{P}=0.4423$ & $\mathrm{P}=0.9506$ & $\mathrm{P}=0.5709$ & $\mathrm{P}=0.5597$ & $\mathrm{P}=0.1498$ & $\mathrm{P}=0.4466$ \\
\hline Chirp & 0.0794 & 0.0167 & -0.0325 & 0.0700 & 0.1560 & -0.0239 \\
Duration & $\mathrm{P}=0.4728$ & $\mathrm{P}=0.8800$ & $\mathrm{P}=0.7692$ & $\mathrm{P}=0.5266$ & $\mathrm{P}=0.1565$ & $\mathrm{P}=0.8321$ \\
\hline Interchirp & -0.1430 & 0.0295 & -0.1437 & -0.1255 & -0.1675 & 0.1448 \\
Duration & $\mathrm{P}=0.1945$ & $\mathrm{P}=0.7902$ & $\mathrm{P}=0.1923$ & $\mathrm{P}=0.2554$ & $\mathrm{P}=0.1277$ & $\mathrm{P}=0.1970$ \\
\hline Amplitude & 0.0976 & -0.0098 & 0.0509 & -0.0296 & 0.1847 & 0.0108 \\
& $\mathrm{P}=0.3773$ & $\mathrm{P}=0.9293$ & $\mathrm{P}=0.6458$ & $\mathrm{P}=0.7889$ & $\mathrm{P}=0.0925$ & $\mathrm{P}=0.9234$ \\
\hline Frequency & -0.0393 & 0.1322 & 0.0448 & 0.0008 & -0.1963 & 0.0337 \\
\hline Time Spent & $\mathrm{P}=0.7227$ & $\mathrm{P}=0.2305$ & $\mathrm{P}=0.6855$ & $\mathrm{P}=0.9941$ & $\mathrm{P}=0.0735$ & $\mathrm{P}=0.7653$ \\
Signalling & 0.2709 & -0.0414 & 0.0638 & 0.1241 & 0.2456 & 0.0619 \\
& $\mathrm{P}=0.0116$ & $\mathrm{P}=0.7049$ & $\mathrm{P}=0.5595$ & $\mathrm{P}=0.2550$ & $\mathrm{P}=0.0226$ & $\mathrm{P}=0.5786$
\end{tabular}


Table II.V: Univariate correlations and probabilities of courtship parameters by condition parameters.

\begin{tabular}{c|r|r|r|r|r|r} 
Variables & $\begin{array}{c}\text { First contact } \\
\text { to courtship } \\
\text { call }\end{array}$ & $\begin{array}{c}\text { Number of } \\
\text { courtship calls }\end{array}$ & $\begin{array}{c}\text { Total call } \\
\text { time }\end{array}$ & $\begin{array}{c}\text { First } \\
\text { contact to } \\
\text { mount }\end{array}$ & $\begin{array}{c}\text { Total time } \\
\text { mounted }\end{array}$ & $\begin{array}{c}\text { Number of } \\
\text { Eggs }\end{array}$ \\
\hline Male & -0.1969 & -0.1687 & -0.2441 & -0.1368 & -0.1339 & -0.0097 \\
Weight & $\mathrm{P}=0.0692$ & $\mathrm{P}=0.1206$ & $\mathrm{P}=\mathbf{0 . 0 2 3 5}$ & $\mathrm{P}=0.2091$ & $\mathrm{P}=0.2190$ & $\mathrm{P}=0.9306$ \\
\hline Male Size & -0.1516 & -0.0373 & -0.1607 & -0.1063 & -0.1421 & 0.0270 \\
& $\mathrm{P}=0.1636$ & $\mathrm{P}=0.7331$ & $\mathrm{P}=0.1395$ & $\mathrm{P}=0.3298$ & $\mathrm{P}=0.1919$ & $\mathrm{P}=0.8086$ \\
\hline Male & -0.2592 & -0.1421 & -0.1008 & -0.1560 & 0.0026 & -0.0677 \\
condition & $\mathrm{P}=\mathbf{0 . 0 1 5 9}$ & $\mathrm{P}=0.1917$ & $\mathrm{P}=0.3560$ & $\mathrm{P}=0.1516$ & $\mathrm{P}=0.9812$ & $\mathrm{P}=0.5432$ \\
\hline Female & -0.0166 & 0.0337 & -0.0124 & -0.0117 & 0.1414 & 0.2080 \\
Weight & $\mathrm{P}=0.8794$ & $\mathrm{P}=0.7582$ & $\mathrm{P}=0.9098$ & $\mathrm{P}=0.9150$ & $\mathrm{P}=0.1940$ & $\mathrm{P}=0.0592$ \\
\hline Difference & -0.1039 & -0.1349 & -0.1366 & -0.2170 & -0.0720 & -0.2073 \\
in Weight & $\mathrm{P}=0.3413$ & $\mathrm{P}=0.2157$ & $\mathrm{P}=0.2098$ & $\mathrm{P}=\mathbf{0 . 0 4 4 8}$ & $\mathrm{P}=0.5098$ & $\mathrm{P}=0.0600$
\end{tabular}

